\title{
MODELAGEM DE SISTEMAS DE MANUFATURA ORIENTADA PELO CUSTEIO DAS ATIVIDADES E PROCESSOS
}

Marcelo Silveira Colmanetti

Dissertação apresentada à Escola de Engenharia de São Carlos da Universidade de São Paulo, como parte dos requisitos para obtenção do título de Mestre em Engenharia Mecânica.

ORIENTADOR: Prof. Dr. Arthur José Vieira Porto

São Carlos

2001 

Dedicatória

A Deus, Aos meus pais, Waldir e Maria Conceição, A minha noiva, Kátia, Aos irmãos Patrícia, Rafael e Sabrina. 


\section{Agradecimentos}

Ao meu orientador, Professor Dr. Arthur José Vieira Porto, pelo incentivo, amizade e apoio profissional.

Em especial a Sayuri e Mamoru pela contribuição e enriquecimento deste trabalho.

Aos amigos do grupo de Simulação de Eventos Discretos, Anna Cristina, Andrea, Beth, Carlos Ravelli, Elídio, Jandira, José Luiz, Mariella, Patrícia, Paulo Marcos, Rafael, Silvia, Simone e alunos de iniciação científica, pelo constante apoio e compreensão.

Aos professores do departamento de Mecânica Eduardo Vila Gonçalves Filho, Ricardo Yassushi Inamasu, Ernesto Massaropi Jr pela ajuda técnica.

Aos amigos da USP, Giovani, André, Cláudio, Roberto e Luiz pelo companheirismo.

Aos amigos de república Pérson, Rogério, Anderson e Lauro.

A todos os funcionários do departamento que contribuíram com o trabalho, com ajuda e amizade, em especial ao Sr. Antônio e Sra. Beth e Ana Paula.

Ao CNPq, pela bolsa concedida.

Meus sinceros agradecimentos 


\section{SUMÁRIO}

LISTA DE FIGURAS ..................................................................................................VII

LISTA DE TABELAS................................................................................................. IX

LISTA DE ABREVIATURAS E SIGLAS.................................................................. X

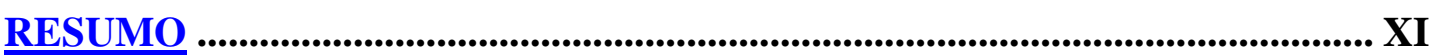

ABSTRACT ......................................................................................................................XII

CAPÍTULO 1 - INTRODUCÃO

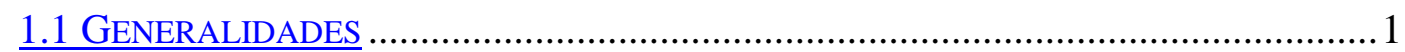

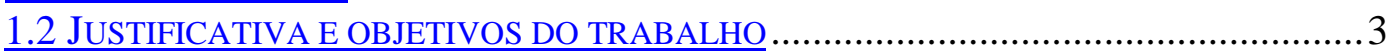

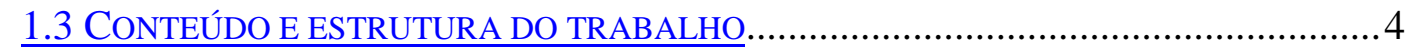

CAPÍTULO 2 - REVISÃO BIBLIOGRÁFICA...........................................................6

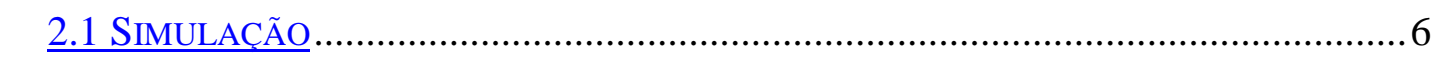

2.1.1 Introdução e conceituação ........................................................................ 7

2.1.2 Conceitos gerais de simulação.................................................. 8

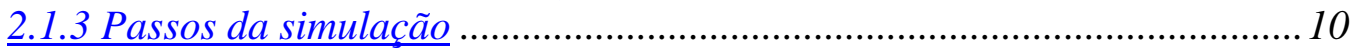

2.1.4 Areas de atuação da simulação..................................................... 14

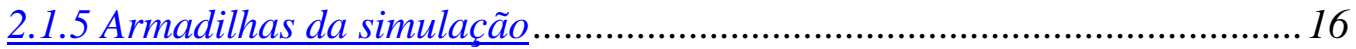

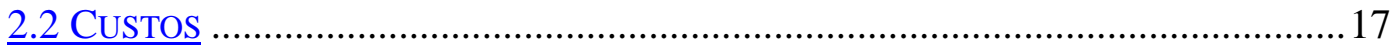

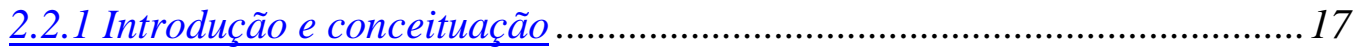

2.2.2 Classificacão e nomenclatura dos custos.............................................. 17

2.2 .3 Custeio tradicional ...............................................................................

2.2.4 Formas de custeamento........................................................... 24

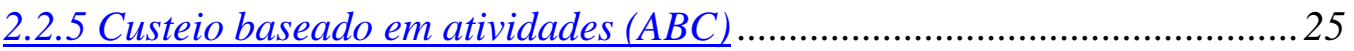

2.2 .6 Custo ABC x custo tradicional .......................................................... 30

2.3 ARRANJO FÍSICO ....................................................................................... 32

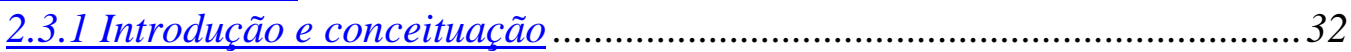

2.3.2 Sistemas de manufatura .................................................................... 33

2.3.3 Classificação dos tipos de arranjo físico ................................................ 34

CAPÍTULO 3 - O MODELO DE CUSTO ..............................................................41

3.1 GENERALIDADES ................................................................................. 41

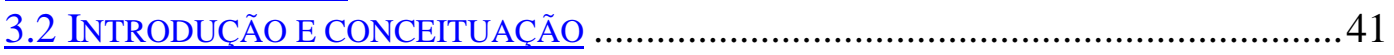

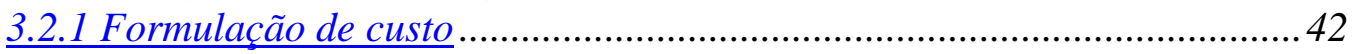

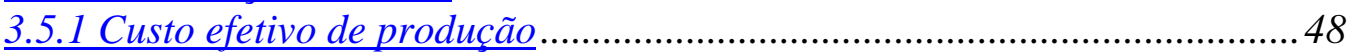

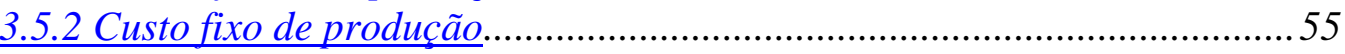

3.5 .3 Custo de inventário de produção ....................................................57

CAPÍTULO 4 - PROCEDIMENTOS DE MODELAGEM DE SISTEMAS DE

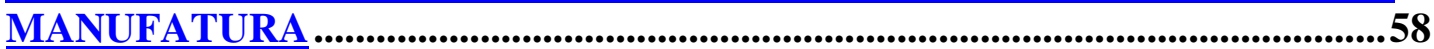

4.1 GENERALIDADES ......................................................................................... 58

4.2 ESCOPO DE APLICAČ̃̃O DO MODELO DE CUSTO.......................................59 
4.3 SISTEMAS DE MANUFATURA A SEREM ESTUDADOS ......................................6

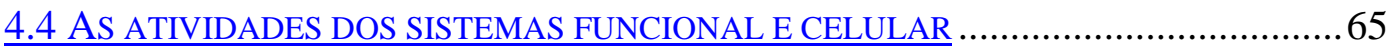

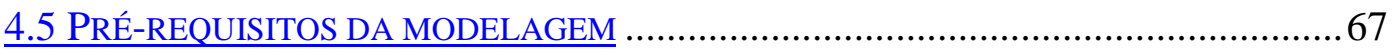

4.6 PROPOSTA DE APLICAC̃̃̃ EM MODELOS DE SIMULAC̃̃OO..................................6 68

4.6.1 Variáveis do sistema ......................................................................... 69

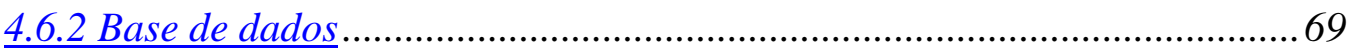

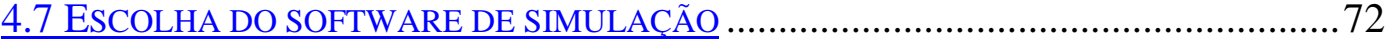

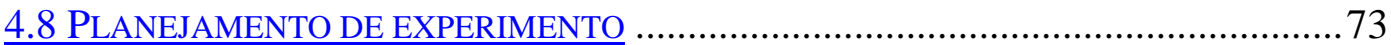

CAPÍTULO 5 - MODELAGEM DE SISTEMAS DE MANUFATURA

ORIENTADA PELO CUSTEIO DAS ATIVIDADES.....................................76

5.1 GENERALIDADES ...................................................................................... 76

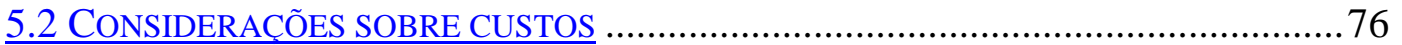

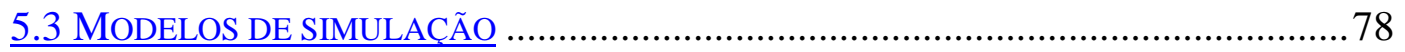

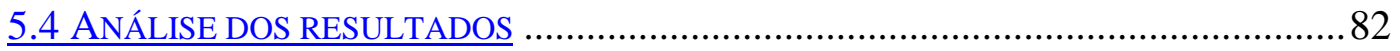

CAPÍTULO 6 - CONCLUSÖES …................................................................................86

REFERÊNCIAS BIBLIOGRÁFICAS ...................................................................89

APÊNDICE - RESULTADOS DE EXPERIMENTOS 


\section{LISTA DE FIGURAS}

FIGURA 01 - SISTEMATIZAC̄ÃO DA SIMULAC ÃO..........................................12

FIGURA 02 - ARMADILHAS DA SIMULACCÁO...................................................16

FIGURA 03 - ILUSTRACÃO DE GASTO/CUSTO/DESPESA............................19

FIGURA 04 - EXEMPLO DE CUSTO

DIRETO/INDIRETO/FIXO/VARIAVEL. ...................................................21

FIGURA 05 - PONTO DE EQUILÍBRIO. ...................................................................24

FIGURA 06 - IMPLEMENTAC̄̃̃O DO ABC...............................................................29

FIGURA 07 - MÉTODO DO CUSTEIO TRADICIONAL.....................................30

FIGURA 08 - METODO DO CUSTEIO ABC. ..................................................30

FIGURA 09 - EXEMPLO DE APURAÇ̃̃O DE CUSTO ABC TRADICIONAL.

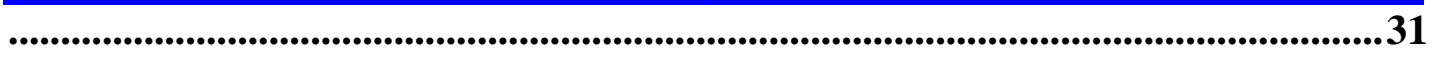

FIGURA 10 - DEFINIĈ̃O DE SISTEMA DE MANUFATURA.........................34

FIGURA 11 - ARRANJO FÍSICO FUNCIONAL..............................................36

FIGURA 12 - ARRANJO FİSICO EM LINHA..................................................37

FIGURA 13 - TIPO DE INDÚSTRIA /VOLUME PRODUTOS/ARRANJO

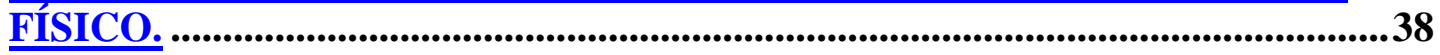

FIGURA 14 - ARRANJO FÍSICO CELULAR.........................................................40

FIGURA 15 - CUSTOS A SEREM CONSIDERADOS......................................64

FIGURA 16 - VISTA SUPERIOR DO MODELO CELULAR...........................80

FIGURA 17 - VISTA LATERAL DO MODELO CELULAR...........................81

FIGURA 18 - VISTA SUPERIOR DO MODELO FUNCIONAL .......................81

FIGURA 19 - RESULTADOS DE CUSTO DO MODELO FUNCIONAL

(EXPERIMENTO 1) .......................................................................................................882

FIGURA 20- RESULTADOS DE CUSTO DO MODELO FUNCIONAL

(EXPERIMENTO 2) .........................................................................................................83

FIGURA 21- RESULTADOS DE CUSTO DO MODELO CELULAR

(EXPERIMENTO 1) 
FIGURA 22- RESULTADOS DE CUSTO DO MODELO CELULAR

(EXPERIMENTO 2) .................................................................................................................84 
TABELA 01 - ATIVIDADES/DIRECIONADORES DO ARRANJO FISICO

FUNCIONAL ........................................................................................................................66

TABELA 02 - ATIVIDADES/DIRECIONADORES DO ARRANJO FISICO

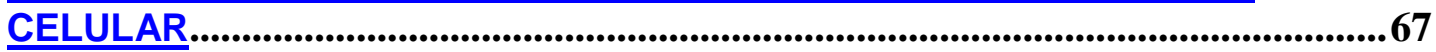

TABELA 03 - VARIÁVEIS DOS MODELOS....................................................69

TABELA 04 - DADOS DE LOTE/PROCESSO DE FABRICACÃO. .........................70

TABELA 05 - DADOS DE DISPONIBILIDADE/QUANTIDADE/NOME DE

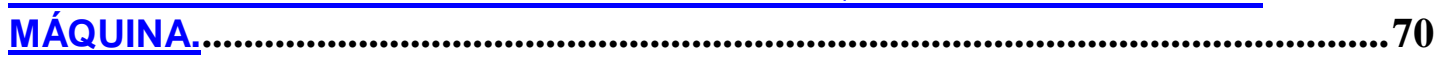

TABELA 06 - DADOS DE PROCESSAMENTO E SETUP........................................71

TABELA 07 - DADOS PARA O EXPERIMENTO 1 DO SISTEMA FUNCIONAL .. 73

TABELA 08 - DADOS PARA O EXPERIMENTO 2 DO SISTEMA FUNCIONAL .. 74

TABELA 09 - DADOS PARA O EXPERIMENTO 1 DO SISTEMA CELULAR ......75

TABELA 10 - DADOS PARA O EXPERIMENTO 2 DO SISTEMA CELULAR ......75

TABELA 11 - TEMPOS DE TRANSPORTE/SISTEMA

FUNCIONAL/EXPERIMENTO1.

TABELA 12 - TEMPOS DE TRANSPORTE/SISTEMA

FUNCIONAL/EXPERIMENTO 2. 


\section{LISTA DE ABREVIATURAS E SIGLAS}

ABC - Activity Based Cost

CIF - Custo Indireto de Fabricação

PE - Ponto de Equilíbrio

PLR - Participação nos Lucros e Resultados

SME - Society of Manufacturing Engineers 


\section{RESUMO}

COLMANETTI, M. S. Modelagem de sistemas de manufatura orientada pelo custeio das atividades e processos. São Carlos, 2001. 94p. Dissertação (Mestrado) Escola de Engenharia de São Carlos, Universidade de São Paulo.

Com o aumento da competitividade do mundo globalizado se faz necessário o uso do estudo de ferramentas e teorias que proporcionem aumento de produtividade. Muitas são as tentativas de se criar métodos e meios de se ganhar produtividade. Dentro deste enfoque a simulação aparece como uma destas teorias. Este trabalho tem o objetivo de propor procedimentos de modelagem, usando-se como parâmetro principal o estudo das atividades custeáveis envolvidas nos sistemas de manufatura existentes. A formulação proposta é resultante do conceito de custo, sugerido pela SOCIETY OF MANUFACTURING ENGINEERS, estruturada na forma de custo por atividades. A utilização da simulação nesta análise possibilita, durante 0 processo de modelagem, o detalhamento das variáveis que geram custos. O resultado esperado deste estudo irá facilitar uma análise de custo mais adequada e apropriada dentro do processo de manufatura.

Palavras-chave: custo, simulação, modelagem, arranjo físico 


\section{ABSTRACT}

COLMANETTI, M. S. Modelagem de sistemas de manufatura orientada pelo custeio das atividades e processos. São Carlos, 2001. 94p. Dissertação (Mestrado) Escola de Engenharia de São Carlos, Universidade de São Paulo.

With the increase of the competitiveness in a globalization world it is necessary to develop tools and theories that provide increase in productivity. Many are the attempts to create methods and approaches in order to get migher productivity. With this focus the theory of simulation appears as one of these tools. The objective of this research work is to propose a modeling procedure using as main parameter the relationship of the cost activity involved in the scenarios that it's analyzed. The proposed formula is the result of the cost concept, suggested by the SOCIETY OF MANUFACTURING ENGINEERS, structured in the ABC (activity based cost). The use of simulation in the analysis allows, during the modeling process, an extensive detailing of the variables that generate costs. The expected result of this study will facilitate a cost analysis more appropriated and adapted to the manufacturing process.

Keywords: cost, simulation, modeling, layout 


\section{CAPÍTULO 1 - INTRODUÇÃO}

\subsection{Generalidades}

Nos dias atuais o controle de custos na manufatura tornou-se sinônimo de diferencial de produtividade, competitividade e crescimento patrimonial. Toda empresa, por mais que se empenhe no controle de seus custos, sempre incorrerá em capital para seu funcionamento (BLACK, 1998).

NOVASKI (1991) alerta que, para a empresa produzir bens e serviços é necessário o uso de vários recursos como pessoas, máquinas, equipamentos e materiais. Assim, a empresa assume na consecução de suas atividades inúmeros compromissos, onde na atividade de compra e venda incorre em custos, que podem ser dimensionados, avaliados e melhorados. Isto se faz necessário, pois a eficácia do sistema de custo auxilia no aumento da produtividade da empresa.

GONÇALVES FILHO (2001) relata em seu trabalho que a manufatura é uma das funções que possui influência determinante no desempenho da empresa, pois para que ela venha a ter sucesso no mercado, deve possuir um sistema de manufatura enxuto e eficiente. Portanto, o conhecimento e a medição dos custos de manufatura devem ser práticas que as empresas devam tomar. 
Com a chegada da globalização, e conseqüentemente de mercados cada vez mais competitivos, surgem tentativas de criar métodos e meios de se ganhar produtividade. As novas filosofias de produção e novas tecnologias surgidas nos últimos anos podem auxiliar as empresas na busca de uma melhor produtividade. Dentro deste enfoque a simulação aparece como uma destas ferramentas de auxilio.

BANKS (1999) já comentava que a simulação é uma ferramenta indispensável na solução de muitos problemas, sendo usada para descrever e analisar o comportamento de um sistema real, além de responder a perguntas sobre este sistema. A simulação é uma ferramenta importante nessa análise de custos, porque durante o processo de modelagem são detalhadas as variáveis e as atividades que geram custos.

RIBEIRO et al. (2001), observam que várias empresas se engajam neste objetivo de procura de melhoria de seu sistema de custo, principalmente aquelas que concorrem diretamente em preço, pois quanto menor o custo, menor poderá ser o preço oferecido aos consumidores, mantendo-se a mesma margem de lucro.

BLACK (1998), classifica materiais, pessoas e equipamentos como alguns dos fatores complementares na fabricação, que devem ser combinados corretamente para atingir baixo custo, qualidade superior e entrega dentro do prazo. Segundo ele o preço de venda de um produto é determinado pelo mercado, e assim a manutenção do lucro depende de esforços para redução dos custos em todos os setores da empresa e, portanto, do sistema de fabricação.

BLACK (1998) relata ainda que dentro deste aspecto temos várias despesas para formação do preço de venda: são despesas com pesquisa e desenvolvimento, engenharia, vendas e pessoal administrativo, marketing, além de uma porcentagem de lucro e os custos de fabricação. Dentro dos custos de fabricação existem os custos com energia, depreciação da planta, máquinas, peças e materiais, mão-deobra direta e a mão-de-obra indireta.

Para ressaltar a importância de se ter uma manufatura enxuta estudos feitos por HERAGU (1997), mostram que mais de $50 \%$ do custo de um produto pode ser 
atribuído à movimentação de materiais. Tudo isto é reflexo do uso inadequado do arranjo físico que, como conseqüência, pode aumentar os custos da instituição tornando o sistema de manufatura menos produtivo e menos eficiente.

\subsection{Justificativa e objetivos do trabalho}

Como foi mostrado anteriormente conhecer e dimensionar os custos de um sistema fabril e saber aplicar ferramentas adequadas é de fundamental importância. Uma das motivações que levaram ao desenvolvimento desta dissertação é que os sistemas de manufatura precisam ser custeados e avaliados. Vários autores engajaram-se em custear sistemas de manufatura, porém sem o auxílio da técnica da simulação. A idéia de dimensionar custos por meio de softwares de simulação vem sendo aplicada nos últimos anos, porém sem detalhar informações sobre a base de dados formulada para o cálculo destes custos. Assim o trabalho agora proposto visa estudar a Modelagem de Sistemas de Manufatura Discreta, orientada pelo Custeio das Atividades e Processos como objetivo principal. Assim é necessário o estudo de todas as variáveis (atividades produtivas e de suporte) que geram custos dentro de alguns tradicionais sistemas de manufatura.

Para desenvolvimento do trabalho será necessário o conhecimento e o estudo das diversas áreas que fazem parte do objetivo principal. Assim o conhecimento dos vários modelos de custo existentes na literatura se faz necessário. Posteriormente um modelo de custo deve ser adotado e aplicado na modelagem dos sistemas de manufatura.

Em seguida deve-se também, estudar os softwares de simulação de sistemas de manufatura existentes no mercado adotando-se um deles, bem como estudar as características específicas dos sistemas de manufatura discreta, identificando se a ferramenta envolvida os representa bem.

Como objetivo secundário, o trabalho proposto deve auxiliar na geração de procedimentos de modelagem que caracterizem o funcionamento dos sistemas de fabricação e permitam gerar análises orientadas ao custeio das peças. Além disso, as atividades geradoras de custo devem ser possíveis de serem representadas e de serem medidas. 
Tais procedimentos de modelagem devem atender alguns pré-requisitos quanto à peça, quanto ao arranjo físico que se quer estudar, quanto ao sistema de custo a ser adotado e quanto à programação da produção.

Os pré-requisitos de modelagem quanto ao processo de fabricação da peça (máquina, operação, tempo de setup, tempo de usinagem) e programação da produção são: o modelo final deve possuir flexibilidade quanto à quantidade de peças que se quer produzir aos processos de fabricação que ela seguirá, e a programação deve possuir um caráter de flexibilidade quanto à quantidade de processos e quanto à ordem destes processos.

Os pré-requisitos de modelagem quanto ao arranjo físico são: a modelagem deve ser capaz de representar as atividades típicas ou específicas de cada arranjo, que devem ser possíveis de serem bem representadas independentemente do tipo de arranjo a ser adotado.

Três áreas distintas do conhecimento serão abrangidas pelo trabalho proposto para a dissertação de mestrado: a área de custo como parâmetro de medida, a área de simulação como ferramenta de aplicação e ainda a área de arranjo físico como ambiente do estudo e aplicação. Como escopo do trabalho serão analisados dois tipos de arranjo físico: sistema funcional e sistema celular.

O resultado esperado deste estudo deverá apontar as modelagens mais adequadas para a análise de custo dentro do processo de manufatura, justificando-se, portanto, os procedimentos de modelagem orientada pelo custeio das atividades.

\subsection{Conteúdo e estrutura do trabalho}

Esta dissertação está estruturada em seis capítulos que seguem:

O capítulo 1 define os objetivos que motivaram este trabalho, a justificativa e o conteúdo da dissertação.

No capítulo 2 é feita uma revisão bibliográfica dos assuntos pertinentes ao trabalho. São eles: Simulação, Custos e Arranjo Físico. 
No capítulo 3 é detalhado o modelo de custo sugerido pela SOCIETY OF MANUFACTURING ENGINEERS (1965).

No capítulo 4 são apresentados os procedimentos de modelagem para sistemas de manufatura.

No capítulo 5 é apresentada a modelagem de sistemas de manufatura orientada pelo custeio das atividades.

No capítulo 6 são apresentadas, as conclusões do trabalho sugerido e propostas dos trabalhos futuros.

O apêndice apresenta em detalhes os resultados da simulação dos experimentos propostos. 


\section{CAPÍTULO 2 - REVISÃO BIBLIOGRÁFICA}

Esta revisão como comentado no capítulo 1 será dividida em três partes. A primeira parte para o assunto simulação, a segunda parte para o assunto custo e a última parte para arranjo físico.

\subsection{Simulação}

Com o crescente aumento da competitividade entre os sistemas produtivos devido à globalização, faz-se necessário o estudo de técnicas e teorias que proporcionem aumento de produtividade. No processo de desenvolvimento de novos produtos, equipamentos e sistemas, muitos profissionais deparam-se com a dificuldade de obtenção de informações que possam servir-lhes de embasamento para a tomada de decisão.

Dentro deste enfoque, a simulação aparece como uma poderosa técnica de análise na solução de diversos problemas, relacionados à manufatura, processos, etc. Um estudo de simulação permite, entre outras possibilidades que se façam análises de um sistema ainda não existente, obtendo-se informações importantes para o objetivo do estudo realizado. Isto se faz através da construção de um modelo lógico matemático, que represente de forma satisfatória o sistema real. 


\subsubsection{Introdução e conceituação}

Definições de simulação são ilustradas a seguir:

"Simulação é uma técnica de resolução de problemas pela observação do comportamento sobre o tempo, de um modelo dinâmico de um sistema" (GORDON, 1978).

"Simulação é um método de modelar a essência de uma atividade ou sistema, de modo que possam ser feitas experiências para avaliar o comportamento do sistema ou o seu efeito ao longo tempo" (MONKS, 1987).

"Simulação é uma técnica usada por computadores para imitar, ou simular as operações ou processos de várias espécies do mundo real" (LAW \& KELTON, 1991).

"Simulação é um método de experimentação que faz uso de um modelo detalhado do sistema real para determinar como este sistema irá responder a mudanças em sua estrutura, no ambiente ou em considerações colocadas a respeito do mesmo" (HARREL et al. 1992).

"Simulação é a imitação de operações de um processo ou sistema real" (BANKS, 1996).

A simulação permite observar do comportamento de modelos de um ou mais sistemas existentes com a finalidade de tirar conclusões relativas às suas características operacionais.

BANKS (1999) comenta que ela é uma técnica (ferramenta) indispensável na solução de muitos problemas sendo usada para descrever e analisar 0 comportamento de um sistema real, além de responder perguntas sobre este sistema. Tanto sistemas conceituais como sistemas existentes podem ser modelados com a simulação. 
Ela pode ser executada através de sistemas computacionais ou não. A simulação pode estudar sistemas sem que seja necessário construir ou modificar o sistema real através da construção de um modelo (CARVALHO, 1998).

PRITSKER (1986) define simulação como sendo um processo que consiste em se criar um modelo de forma lógica e matemática de um sistema real e de experimentá-lo com o auxílio de um computador, o que permite obter conclusões sobre sistemas sem construí-los, se forem novos, e sem perturbá-los, se existentes.

Ela ainda permite que o projeto do produto e/ou o projeto do processo de produção sejam estudados a um nível bastante detalhado, pois na execução da simulação o ritmo do tempo pode ser alterado, acelerado ou desacelerado (AKBAY, 1996).

Segundo LOBÃO \& PORTO (1997) a simulação permite que se possa fazer:

- Identificação de problemas;

- Comparação com o desempenho de outros sistemas;

- Estudos sobre a utilização da capacidade instalada, níveis de inventário, lógica de controle, refinamento de projeto, integração, seqüenciamento, gargalos do sistema, melhor arranjo físico e melhor índice de produtividade dos funcionários.

- Treinamento de operadores, testes de inicialização de equipamentos, etc.

\subsubsection{Conceitos gerais de simulação}

Existe uma série de conceitos importantes ligados à simulação. Dentre estes conceitos destacam-se segundo BANKS et al. (1996), LAW \& KELTON (1998) os seguintes: sistema, componentes de um sistema (entidade, atributo, evento, estado, variável), modelo de um sistema, tipos de modelos, simulação de eventos discretos e simulação de eventos contínuos. Os tópicos são detalhados a seguir:

- Sistema - É definido como sendo um grupo de objetos que são agrupados com a finalidade de interação e interdependência voltadas para a realização de um propósito. Um exemplo é o sistema produtivo para manufatura de automóveis.

- Componentes de um Sistema - Vários elementos compõem o sistema. Tem-se: Entidade é um objeto que possui interesse no sistema, como por exemplo, pessoa, 
máquina, etc. Atributo é uma propriedade de uma entidade. Atividade representa um período de tempo de uma parte específica, como por exemplo, usinar a peça, etc. Estado é o conjunto de variáveis necessárias do sistema para descrever o sistema em um tempo particular relativo aos objetivos de estudo. Evento é uma ocorrência instantânea que pode mudar o estado do sistema.

- Modelo de um Sistema - Um modelo é definido como sendo a representação de um sistema real, com o propósito de estudo deste sistema. Existe um interesse sobre os limites ou fronteiras de um modelo que supostamente represente 0 sistema. Aspectos que envolvem um determinado sistema são representados em um modelo e o modelo, por definição, é a simplificação do sistema. O modelo deve ser suficientemente detalhado para que se permita obter conclusões sobre o sistema real. BANKS (1996) ainda comenta: "Diferentes modelos de um mesmo sistema podem ser necessários com o propósito de se investigar mudanças".

- Tipos de Modelo - Modelos podem ser classificados como sendo matemáticos ou físicos, estáticos ou dinâmicos, determinísticos ou estocásticos, e discretos ou contínuos e híbridos. As definições são dadas a seguir:

Modelo matemático - Usa notações simbólicas em termos de lógica e equações matemáticas para representar um sistema.

Modelo físico - Reproduz o sistema real cujas características construtivas devem reproduzir em menor, igual ou maior escala geométrica as do modelo real, observando-se as mesmas características físicas e estruturais dos mesmos. Ex: réplica de um carro em menor escala.

Modelo estático - É a representação de um sistema em um ponto particular no tempo. Ex: Olhar uma foto tirada em um determinado instante.

Modelo dinâmico - Representa sistemas que mudam com a influência do tempo. Ex: Simulação da movimentação num determinado período de tempo.

Modelo determinístico - Se os componentes do modelo de simulação não contêm uma probabilidade associada a eles, então ele é determinístico. Nos modelos 
determinísticos, a saída é determinada, uma vez que o conjunto de entrada de dados no modelo é estabelecido (determinado). Um exemplo é determinar que o tempo entre chegadas de uma peça em uma esteira transportadora é de 20 segundos.

Modelo estocástico - Modelo de simulação que possui probabilidade, ou seja, possui comportamento aleatório. Um exemplo é estabelecer que, o tempo entre chegadas de uma peça obedece a uma distribuição de probabilidade de um certo tipo, em que a média entre chegadas é 20 segundos e o desvio padrão é de \pm 2 segundos.

- Simulação de Eventos Discretos - Sistema discreto é aquele no qual o estado do sistema muda de acordo com um número finito de mudanças no tempo. Mudanças no status do sistema ocorrem somente em pontos isolados no tempo. Por exemplo, se um centro de usinagem produz uma peça acabada a cada 3 minutos, o número de peças acabadas produzidas pelo sistema (isto é, o estado do sistema), muda somente em instâncias discretas. A simulação de eventos discretos começa a partir de uma definição matemática e lógica de como o estado do sistema irá mudar no tempo. As variáveis de estado são estabelecidas para coletar as estatísticas sobre o desempenho do sistema. Um relógio simula o tempo decorrido, no qual com o decorrer do tempo de simulação, ocorrem processamentos de acordo com um calendário de eventos que contém uma listagem de quando cada tipo de evento irá ocorrer no sistema. Tais eventos podem ser as chegadas de material, início das operações, fim das operações, quebras de máquinas, entre outros. Um gerador de números aleatórios gera os valores de tempo de acordo com uma distribuição de probabilidades previamente especificada.

- Simulação de Eventos Contínuos - Sistema contínuo é aquele no qual o estado do sistema muda continuamente no tempo. Um exemplo de um sistema contínuo é a concentração de um reagente dentro de um processo químico.

\subsubsection{Passos da simulação}

Vários autores como INGELS (1985), PEDGEN et al. (1990), SCRIBER (1991), HARREL et al. (1992), PRITSKER (1992), BANKS et al. (1996) ilustram a 
sistematização da simulação como forma de melhoria e otimização para um bom desenvolvimento do processo. Para PORTO (1998) a aplicação da simulação em vários tipos de sistemas com diferentes tipos de estudos, resulta em variações na maneira de se realizar simulação. Alguns passos básicos são:

- Identificação do problema;

- Planejamento do estudo;

- Formulação do modelo matemático;

- Construção de um programa de computador para o modelo;

- Especificação dos valores das variáveis;

- Corridas de simulação;

- Avaliação dos resultados;

- Proposição de novo experimento.

BANKS et al. (1996) ilustram sua sistematização na figura 1 que segue: 


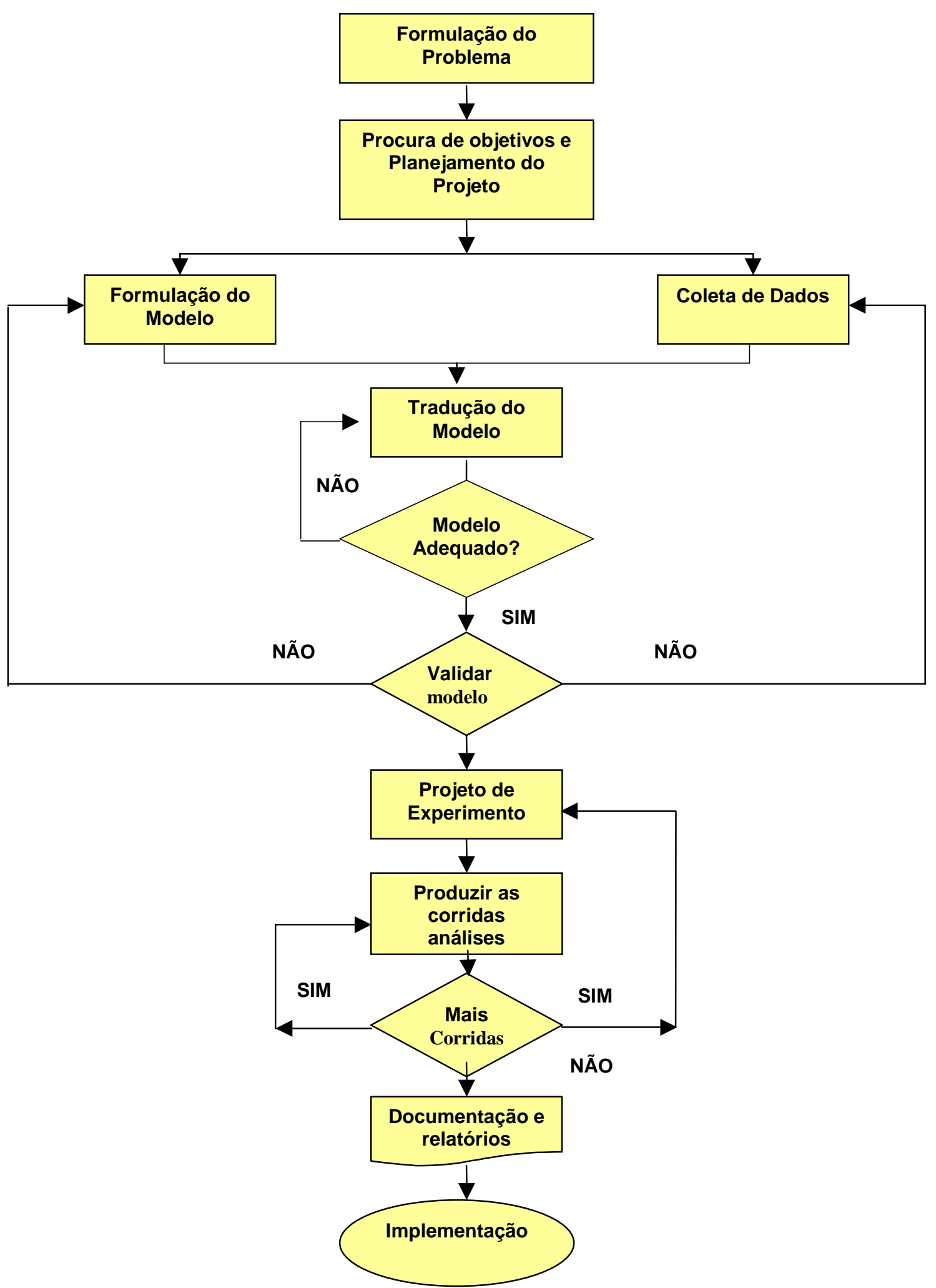

FIGURA 01- SISTEMATIZAÇÃO DA SIMULAÇÃO.

Fonte: BANKS et al. (1996). 
A seguir estão os passos de uma sistematização ilustrada por LOBÃO (2000) de forma a condicionar o desenvolvimento do processo de simulação. São eles:

Passo 1 - Definição do problema e dos objetivos do estudo. É de fundamental importância conhecer os reais motivos que levaram à construção do modelo, bem como estabelecer seus objetivos de forma clara e consistente. Sem este conhecimento todo o esforço dispensado terá sido em vão e tudo terá que ser refeito.

Passo 2 - Elaboração de um primeiro modelo para estudo do fluxo de dados e da hierarquia entre seus módulos. Um estudo do que virá a ser o modelo é realizado. Estudos sobre arranjo físico de componentes, fluxo de informações dentro do sistema e hierarquia de seus módulos é considerado nesta etapa. Na verdade é feito um esboço do modelo.

Passo 3 - Aquisição de dados. Os dados a serem colhidos dependem da situação que se tem do modelo criado no passo anterior. Para sistemas existentes, dados históricos são recomendados. Para sistemas inexistentes os dados são obtidos de catálogos de fabricantes, sistemas similares, entrevistas com pessoas pertinentes à área a qual o estudo é focado.

Passo 4 - Validação e verificação dos dados. Para validar os dados, testes podem ser aplicados no modelo formulado anteriormente. Pode-se projetar os testes a serem realizados. É essencial a qualidade dos dados colhidos, pois dados ruins traduzem em queda de confiabilidade no que se quer projetar.

Passo 5 - Construção de um modelo para realização do estudo de simulação. modelo propriamente dito será construído nesta etapa. O software de simulação será escolhido nesta etapa também.

Passo 6 - Verificação e validação do modelo. Aqui se faz a relação de fidelidade dos resultados obtidos com o modelo construído e o sistema real. 
Passo 7 - Projetar o experimento. Fase composta da realização dos testes para analisar e comparar as diversas alternativas possíveis na solução do problema levantado.

Passo 8 - Executar o experimento e analisar os resultados. Aqui se faz a execução da simulação. É importante que se faça uma documentação dos resultados obtidos, para cada alternativa testada.

Passo 9 - Refinar o projeto do experimento. Se os resultados não forem satisfatórios deve-se repetir o procedimento a partir da etapa 7.

Passo 10 - Análise final dos resultados e documentação do processo. Por fim, com uma confiabilidade adequada dos dados e uma consistência dos resultados, faz-se a documentação final. Nesta etapa de análise dos resultados adiciona-se valor ao estudo realizado, sendo possível dimensionar os ganhos do trabalho.

\subsection{4 Áreas de atuação da simulação}

As áreas de aplicação da simulação são numerosas e diversas. Elas são destacadas por LAW \& KELTON (1991), BANKS (1996), PORTO (1998) e LOBÃO (2000) como sendo as seguintes:

- Sistemas computacionais;

- Sistemas de telecomunicações;

- Fabricação;

- Negócios;

- Logística;

- Assuntos governamentais;

- Sistemas de saúde;

- Ensino e treinamento;

- Militar;

- Sistemas de restaurantes e alimentos;

- Sistemas de análise financeira e econômica;

- Etc. 
A seguir apresenta-se uma série de trabalhos referentes à simulação em sistemas de manufatura. São eles:

- MORRIS \& TERSINE (1990) examinaram a influência de determinados fatores em ambiente operacional, sobre o desempenho de um arranjo físico celular. Foi utilizado um modelo de simulação, com os dados de fábrica para comparar-se arranjo físico de processo e arranjo físico celular. Os parâmetros considerados para a comparação foram: nível de tempo em processamento da peça, tempo do fluxo de saída de peças. Os fatores examinados foram: (1) a relação de setup com o tempo de processo; (2) tempo de deslocamento de material entre as estações de trabalho e (3) estabilidade de demanda (pedidos). Os resultados deste experimento foram usados para se postular um ambiente ideal de arranjo físico celular.

- WAY \& CARR (1997) relatam um estudo de simulação na área de logística, sobre o desenvolvimento de um modelo flexível de simulação para operações ferroviárias, onde uma análise de problemas de layout é feita em Bradenton, na Flórida, USA. Tal modelo de simulação serviu como ferramenta de análise no conhecimento de despesas futuras que viessem a ocorrer, caso houvesse um aumento na entrega de produtos (aumento de demanda). O modelo foi inicialmente validado somente com o centro de distribuição do nordeste, e permitiu avaliar muitas formas de carregamento e entrega do produto. Como resultado determinou-se que não era necessária a aquisição de mais um carro ferroviário, caso a demanda fosse inferior a um determinado valor de pedidos.

- GARCIA et al. (1999) descreveram um estudo de simulação para uma companhia de jornal, cuja, a finalidade foi melhorar o tempo de entrega para o produto. Os resultados mostraram uma melhoria de $13 \%$ no tempo de entrega para impressão de jornal e tarefas de armazenagem. 
- ANDERSON \& MORRICE (1999) investigaram o comportamento dinâmico de um sistema da cadeia de suprimentos. Isto foi feito na presença de uma demanda variável usando simulação. O modelo de simulação usado comparou várias estratégias de administração da capacidade. Medidas de desempenho foram incluídas, entre elas: níveis de pedido e custos totais acumulativos.

\subsubsection{Armadilhas da simulação}

A simulação apesar de mostrar-se uma técnica muito poderosa para o projeto e análise de diversos estudos, pode tornar-se ineficiente, cara e inútil, se realizada sem uma abordagem sistêmica. ULGEN et al. (1996) definem simulação como sendo uma técnica de construção e experimentação de um modelo de um sistema real por meio de sistemas computacionais. Sendo assim várias armadilhas podem ser encontradas na execução de um projeto de simulação (figura 02):

\begin{tabular}{|c|}
\hline Armadilhas da Simulação \\
\hline $\begin{array}{l}\text { Relacionadas ao processo } \\
\text { - Não definir claramente o projeto e manter o cliente sem informação } \\
\text { - Não estabelecer uma base para comparações e criar expectativas não realistas } \\
\text { - Não avaliar criteriosamente os dados de entrada } \\
\text { - Não fornecer relatórios freqüentes e não documentar o projeto } \\
\text { - Não "venteragir com o cliente } \\
\text { - Mudar freqüentemente de escopo } \\
\text { - Acreditar demais nos resultados da simulação } \\
\text { - Não revisar adequadamente o projeto durante a sua execução } \\
\text { - Gastar mais tempo nos modelos do que nos problemas e não saber quando parar }\end{array}$ \\
\hline $\begin{array}{l}\text { Relacionadas aos modelos } \\
\text { - Não validar as hipóteses do modelo } \\
\text { - Iniciar com um modelo demasiadamente complexo } \\
\text { - Perder de vista os aspectos de implementação } \\
\text { - Utilizar o modelo de forma econômica } \\
\text { - Não compreender os limites do modelo }\end{array}$ \\
\hline $\begin{array}{l}\text { Relacionadas às pessoas } \\
\text { - } \quad \text { Falta de espírito de equipe } \\
\text { - Falta de envolvimento de pessoas chaves no processo de tomada de decisão } \\
\text { - } \quad \text { Prover uma pequena lista de alternativas ao cliente e ter medo de defender as } \\
\text { mudanças }\end{array}$ \\
\hline
\end{tabular}

FIGURA 02 - ARMADILHAS DA SIMULAÇÃO.

Fonte: ULGEN et al (1996). 


\subsection{Custos}

A existência e sobrevivência do ser humano são dependentes da satisfação de suas necessidades. Tais necessidades, por sua vez, são satisfeitas através de bens, previamente produzidos e distribuídos. A natureza é responsável por fornecer a matéria-prima e o homem é responsável por transformar esta matéria-prima em bens para uso próprio. Surgem assim os dois elementos diretos de custo de produção: Mão-de-obra e matéria-prima. Em seguida serão detalhados os conceitos, as classificações e os tipos de custos existentes nos sistemas produtivos.

\subsubsection{Introdução e conceituação}

Definições de custo são ilustradas a seguir:

"Custo é toda e qualquer aplicação de recursos, sob diferentes formas e expressa em seu valor monetário, para a produção e distribuição de mercadorias (ou prestação de serviços) até ao ponto em que se possa receber o preço convencional" (LIMA, 1970).

"Custos são todos os fatores aplicados direta e indiretamente no processo de produção, ou na geração de serviços prestados" (VIVEROS, 2000).

\subsubsection{Classificação e nomenclatura dos custos}

Para uma melhor compreensão do termo custo, faz-se necessário o uso de conceitos e classificações. A seguir apresenta-se uma nomenclatura formal para nomes segundo alguns autores.

SANTOS (1974), FRANCO (1983) e MARTINS (1985) sugerem a seguinte nomenclatura:

- Gasto - Sacrifício financeiro que a entidade ou a instituição arca para obtenção de um produto ou serviço qualquer, sendo este sacrifício representado por uma 
entrega ou promessa de entrega de ativos (geralmente dinheiro). É um compromisso que é assumido com a intenção de obtenção de produto ou serviço.

- Investimento - É um gasto ocorrido em função de sua vida útil, ou benefício futuro. É um bem e direito registrado no ativo de uma empresa para baixa em função da venda, consumo, desaparecimento, desvalorização e perecimento.

- Custo - Gasto relativo ao bem ou serviço utilizado na produção de outros bens ou serviços. São todos os gastos incorridos na instituição, ou que venham a incorrerem com o intuito de obtenção de lucros.

- Despesa - Todo pagamento feito pela entidade, toda saída de dinheiro, com qualquer destinação, seja para aplicação em bens patrimoniais (investimento), necessários à obtenção de seus fins, seja para pagamento de serviços e bens de consumo necessários àquele objetivo. Define-se também como um gasto não identificável diretamente com o processo de transformação ou geração de serviços. Ex despesas comerciais (propaganda, viagens, etc).

- Desembolso - Pagamento resultante da aquisição do bem ou serviço.

- Perda - Bem ou serviço consumidos de forma anormal e involuntária.

SANTOS (1974) sugere um exemplo para diferenciar "Custos" e "Despesas". Percebe-se que quando os gastos não referem-se a um sistema produtivo, estes gastos não podem ser considerados "custos", como no de uma mercadoria que não tem necessidade de ser processada.

Neste caso a mercadoria é comprada, gerando gasto, e depois ao ser vendida, o mesmo gasto recebe o nome de despesas com vendas. Não existem os custos para fabricá-la, pois ela já está pronta para ser vendida.

Quando a matéria-prima é comprada, o sistema de produção fabrica o produto, gerando custos, e em seguida, o produto é vendido, gerando despesas com vendas. A figura 03 seguinte ilustra a diferença. 


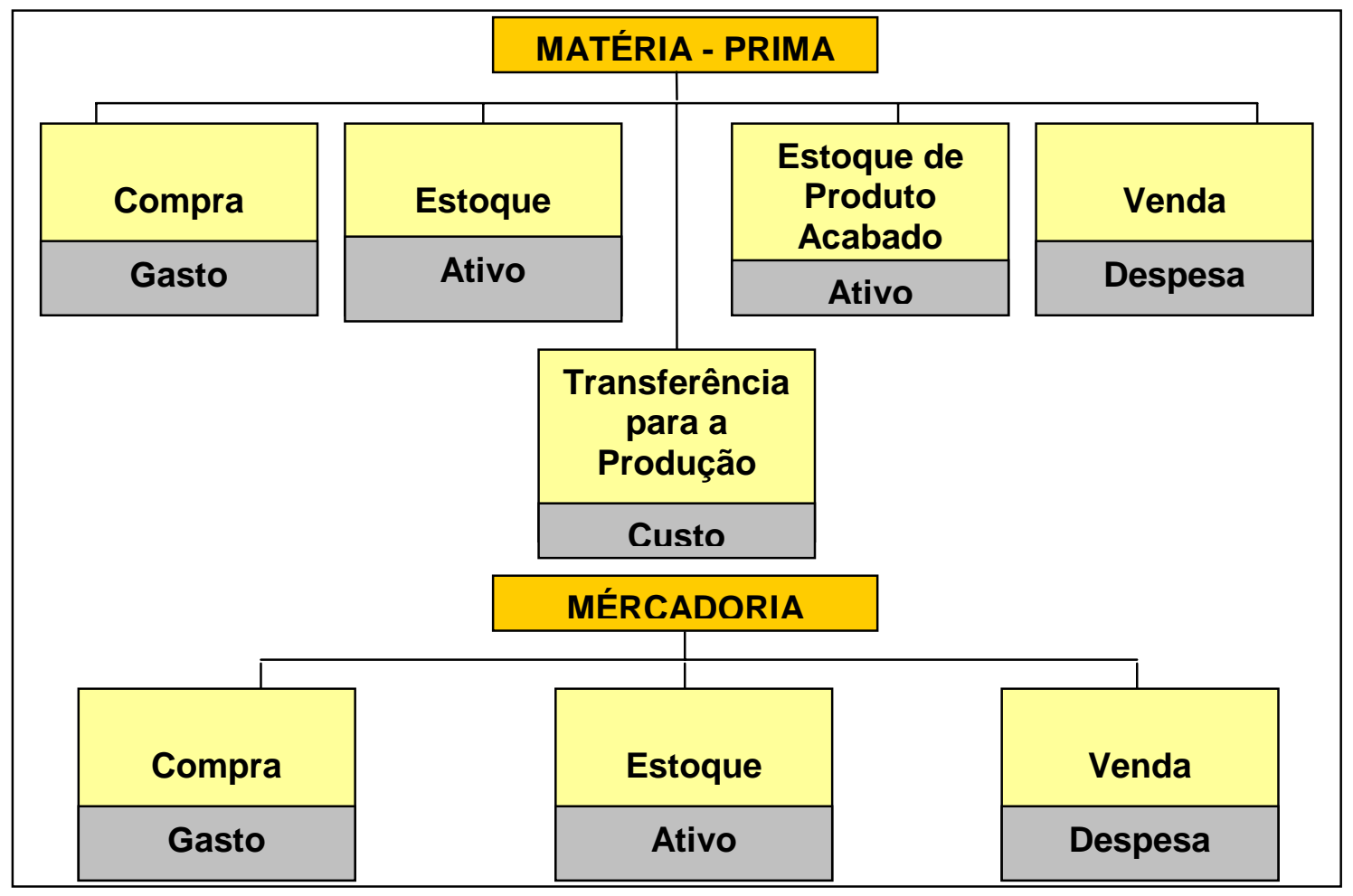

FIGURA 03 - ILUSTRAÇÃO DE GASTO/CUSTO/DESPESA.

Fonte: SANTOS (1974).

Vários são os tipos de custos de manufatura (fabricação) existentes dentro de uma instituição. Segundo BARRETO (1974) e NOVASKI (1991) os custos de fabricação dividem-se em custos variáveis e custos fixos. JÁ MANDARINO (1971), SANTOS (1974) e TOMMASI (2000), os custos de fabricação dividem-se em: custos variáveis, fixos e também semivariáveis. DUTRA (1995) sugere custos variáveis, fixos e mistos.

HERRMANN (1981) sugere custos proporcionais e fixos. Para VIVEROS (2000), LIMA (2000) e GALLORO \& GALLORO (2000), outro tipo de custo pode ainda ser classificado: os custos semifixos. Assim, por estes autores, tem-se as seguintes definições:

- Custos variáveis (ou proporcionais): representam os gastos incorridos diretamente com o produto fabricado, ou seja, são gastos dependentes do volume de produção sendo proporcionais ao aumento ou diminuição deste volume. Tais custos sofrem alterações com o processo de produção, tais como matéria-prima, energia, entre outros. 
- Custos fixos: representam gastos que independem do volume de produção da instituição, ou seja, permanecem constantes com o aumento ou diminuição deste volume. São os custos incorridos com materiais indiretos, salários indiretos, água, seguros, depreciação, impostos e conservação, entre outros.

- Custos semivariáveis (ou mistos): são os custos que possuem uma parcela de custo variável e uma parcela de custo fixo.

- Custos semifixos: são os custos que permanecem constantes dentro de certos intervalos de tempo, alterando-se em degraus até atingir um novo patamar de atividade. Exemplo: Propaganda, aluguel de máquina para aumento de produção, etc.

SANTOS (1974), HERRMANN (1981), VIVEROS (2000) e GALLORO \& GALLORO (2000) ainda classificam mais dois outros tipos de custos: custos diretos e custos indiretos.

- Custos diretos: são os custos apropriados diretamente aos produtos, bem como aos serviços. De forma geral, destaca-se como custo direto: mão-de-obra e matéria-prima.

Custos indiretos: são os gastos que não se identificam com os produtos de forma direta, sendo necessário fazer-se uso de critérios como o rateio para apropriar os custos aos produtos/serviços. O custo indireto é a soma de todos os custos ocorridos na produção que não são classificáveis como matéria-prima ou mão-deobra direta.

Sendo assim NOVASKI (1991) e DUTRA (1995) definem custo total como sendo a soma de duas parcelas. Uma parcela correspondente aos custos fixos e outra parcela correspondente aos custos variáveis unitários multiplicados pelo número de unidades produzidas no tempo. Assim, tem-se:

$$
C_{T}=\left(C_{V} \times Z\right)+C_{F} \text {, em que: }
$$

$C_{T}=$ Custo Total; 
$C_{V}=$ Custo Variável por unidade;

$Z=$ Unidades produzidas;

$C_{F}=$ Custo Fixo.

Para melhor compreensão destes conceitos VIVEROS (2000) elabora um exemplo do que é custo direto, indireto, fixo e variável, como ilustrado na figura 04 abaixo:

\begin{tabular}{|l|c|c|c|c|}
\hline \multicolumn{1}{|c|}{ Item } & Direto & Indireto & Variável & Fixo \\
\hline Matéria-prima & $\mathrm{X}$ & & $\mathrm{X}$ & \\
Serviços de terceiros & $\mathrm{X}$ & & $\mathrm{X}$ & \\
Mão-de-obra direta & $\mathrm{X}$ & & $\mathrm{X}$ & \\
Mão-de-obra indireta & & $\mathrm{X}$ & & $\mathrm{X}$ \\
Propaganda & & $\mathrm{X}$ & & $\mathrm{X}$ \\
Engenharia & & $\mathrm{X}$ & & $\mathrm{X}$ \\
Energia elétrica & $\mathrm{X}$ & & $\mathrm{X}$ & \\
Aluguel & & $\mathrm{X}$ & & $\mathrm{X}$ \\
\hline
\end{tabular}

FIGURA 04 - EXEMPLO DE CUSTO DIRETO/INDIRETO/FIXO/VARIÁVEL.

Fonte: VIVEROS (2000).

\subsubsection{Custeio tradicional}

O conceito de custeio tradicional está no fato de que os custos diretos constituem a base para a alocação de custos indiretos. Normalmente, o custo indireto é calculado multiplicando-se o custo direto por uma constante. O valor desta constante baseia-se na experiência de quem está confeccionando o sistema de custos. Anteriormente ao advento das modernas tecnologias de manufatura e às mudanças nos sistemas de produção (conduzido para o mercado e o ambiente econômico), o método de custeio tradicional era adequado devido a duas razões: a primeira delas é que a fração do custo total devido ao custo direto era maior do que à parte do custo indireto; a segunda razão se deve ao fato de que o custo indireto é, mais custoso para se determinar do que o custo direto. Por estas razões, o custeio tradicional foi, então, considerado satisfatório como forma de se determinar o custo de produtos manufaturados (ANDRADE et al. 1999). 
SANTOS (1974) e MARTINS (1985) enumeram uma série de conceitos e definições que envolvem o custeio tradicional. Dentre estes conceitos tem-se: critério de rateio, margem de contribuição, ponto de equilíbrio (PE) e formas existentes de custeamento tradicional (custeio por absorção, custeio direto ou variável e custeio padrão).

\section{- Critério do rateio}

O custeio tradicional usa o critério do rateio para determinar os custos indiretos. DUTRA (1995), define rateio como sendo: "a divisão proporcional por uma base que tenha valores conhecidos em cada função e que se julga que o custo ocorre nas mesmas proporções da base".

DUTRA (1995) ainda mostra que uma das formas de se conseguir o rateio é seguindo as seguintes etapas:

- conseguir a melhor base de rateio, entre as disponíveis para o custo;

- dividir o total a ser rateado pelo total da base escolhida, para obter um coeficiente de rateio;

- multiplicar o coeficiente de rateio por todos valores componentes da base, obtendo a parcela de custo indireto que será atribuído a cada função.

NAKAGAWA (1997), define rateio como sendo a alocação de custos indiretos de fabricação (CIF) aos produtos. Segundo TOMMASI (2000), os custos rateados referem-se aos custos indiretos atribuídos aos produtos/serviços em função de uma taxa de rateio. Narra ainda que apesar do rateio propiciar resultados satisfatórios, restrições podem ser encontradas. CHING (1995) enumera uma destas restrições comentando que o critério do rateio causa distorções e por sua vez erros na avaliação das decisões, e ainda impedem a transparência dos custos no sistema.

\section{- Margem de contribuição}

É o valor com que cada unidade de um produto fabricado e comercializado contribui para cobrir os custos de operação (fixos) na instituição. De forma geral obtém-se a margem de contribuição pela dedução dos custos diretos (ou variáveis) do valor de 
vendas. SANTOS (1974), MARTINS (1995), VIVEROS (2000) e TOMMASI (2000), definem margem de contribuição usando a fórmula:

$$
M C=V-C V, \text { em que; }
$$

$M C=$ Margem de Contribuição;

$V=$ Vendas;

$C V=$ Total do Custo Variável.

VIVEROS (2000) apresenta um exemplo para margem de contribuição que segue:

$\mathrm{R} \$$

Venda 300.000

Custos diretos (variáveis) $\underline{240.000}$

Margem de Contribuição 60.000

Logo, cada item contribui com $R \$ 60.000$ na absorção dos custos fixos, podendo verificar-se, então, que esse produto possui margem de contribuição da ordem de $20 \%$ do preço de venda.

\section{Ponto de equilíbrio}

SANTOS (1974), TOMMASI (2000) e VIVEROS (2000), definem ponto de equilíbrio como sendo o ponto em que a receita é suficiente para cobrir os custos variáveis e fixos, e tendo, como conseqüência, um lucro nulo. Ainda segundo estes autores, o ponto de equilíbrio equilibra as receitas e os gastos de uma empresa (figura 05), não ocorrendo lucro e nem prejuízo. Segundo TOMMASI (2000), a fórmula do ponto de equilíbrio é:

$$
P E=\left(\frac{C F}{M C \%}\right), \text { em que; }
$$

$C F=$ Custos Fixos

$M C \%=$ Margem de contribuição em porcentagem sobre as vendas;

$P E=$ Ponto de Equilíbrio. 


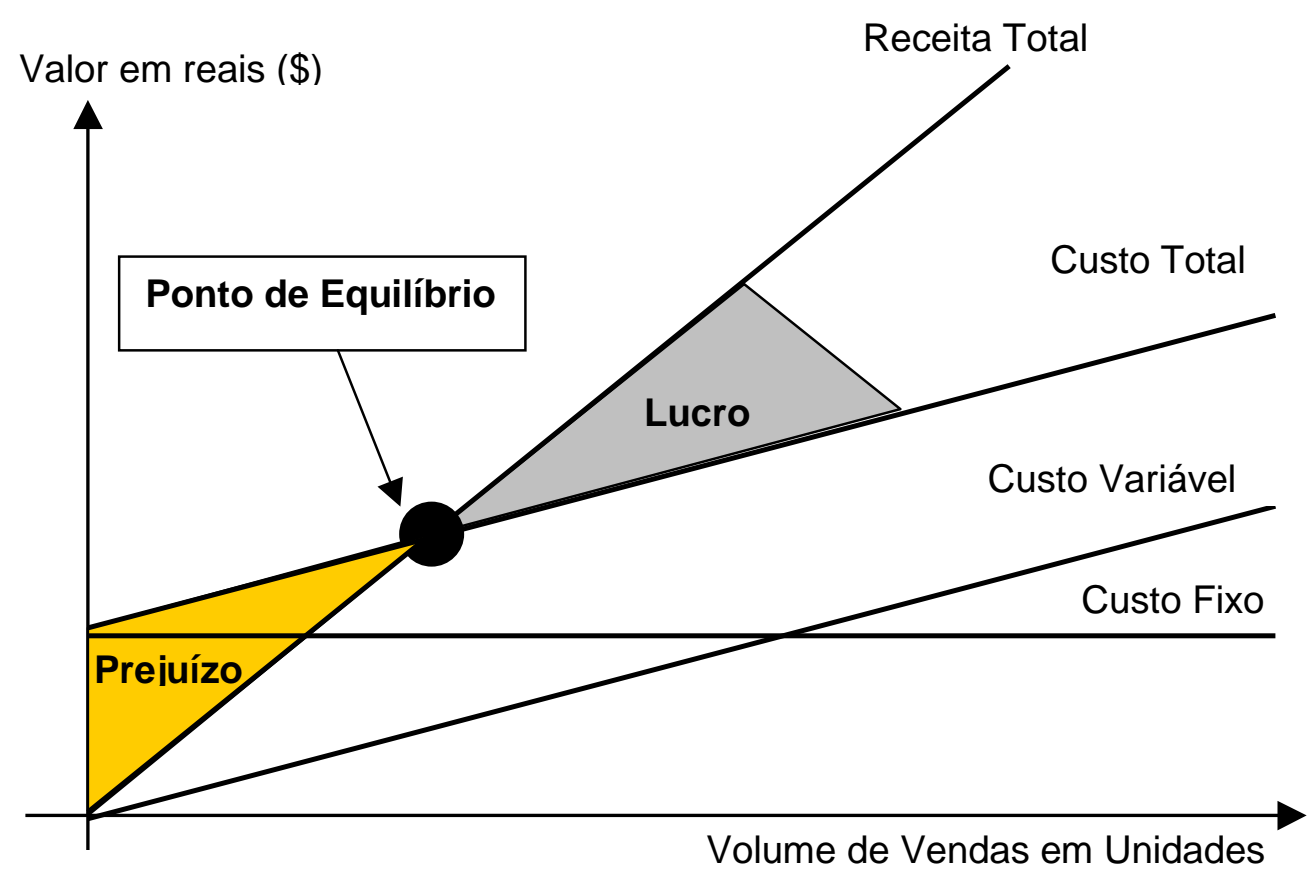

FIGURA 05 - PONTO DE EQUILÍBRIO.

Fonte: VIVEROS (2000), TOMMASI (2000).

\subsubsection{Formas de custeamento}

Em SANTOS (1974), MARTINS (1995), TOMMASI (2000) e VIVEROS (2000), encontram-se quatro formas de custeamento para produtos e serviços. Para o custeio tradicional enumeram-se três tipos de custo: custeio por absorção, custeio variável ou direto e custeio padrão. $O$ custo $A B C$ é a quarta forma de custeamento que será mais detalhada. Apresenta-se a seguir a definição de cada forma de custeio existente:

- Custeio por Absorção - Método de custeio no qual todos os custos diretos e indiretos de fabricação são apropriados ao produto, sejam eles variáveis ou fixos. Assim procura-se custear o produto atribuindo-lhe também a parte referente ao custo fixo. Em outras palavras, este método baseia-se na identificação dos custos diretos e na alocação dos custos indiretos aos produtos, independentemente dos produtos serem acabados no período. Usa-se o critério do rateio, que leva a conclusões distorcidas dos custos apurados. Tem a vantagem de apresentar 0 custo real para efeitos contábeis e fiscais, atendendo à legislação fiscal. O critério 
de rateio, usado para distribuir os gastos entre os departamentos nem sempre é objetivo e pode distorcer os resultados, penalizando alguns produtos em benefício de outros. Tem como desvantagem, a impossibilidade da identificação plena da relação custo/volume/lucro, tendo pouca validade para finalidades gerenciais.

- Custeio Variável ou Direto - Método de custeio de produtos e serviços que utiliza margem de contribuição, que é obtida pela diferença entre as receitas (vendas) e seus respectivos custos marginais (variáveis). Somente os custos diretos ou variáveis devem ser apropriados aos produtos, enquanto que os fixos (necessários para manter a capacidade instalada) afetam diretamente o resultado. A vantagem deste tipo de custeio é possibilitar o gerenciamento da margem real de rentabilidade de cada produto, sem a interferência manipuladora do critério de rateio. Enfoca, principalmente, o custo unitário de produção, visto que, com isso, isola a influência do volume sobre o custo. Sua desvantagem é que não é aceito para efeitos contábeis e fiscais, sendo que o valor de estoque não mantém relação com o custo total.

- Custeio Padrão - Método de custeio que representa um custo pré-determinado, que objetiva o controle e análise entre o que deveria acontecer (padrão) e o que realmente ocorreu (real). Sua vantagem é a possibilidade do custeamento por meio dos padrões de tempo de mão-de-obra e quantidade de material. $\mathrm{A}$ análise das variações pode indicar áreas de dificuldade ou erros de projeção do custo-padrão. A desvantagem é a complexidade do sistema e a dependência do critério de rateio.

- Custeio por Atividades ABC - Este método identifica as atividades que adicionam valor aos produtos finais. Existe um rastreamento das atividades que utilizam recursos, que, por sua vez, são consumidas pelos produtos finais. O critério do rateio não se aplica para esta forma de custeamento. $O$ método $A B C$ será explicado com maiores detalhes a seguir, pois corresponde a um dos focos do presente trabalho.

\subsubsection{Custeio baseado em atividades (ABC)}

O mercado globalizado exige das empresas características como competitividade, flexibilidade e criatividade. Tais características necessitam de ferramentas de 
gerenciamento eficientes, que proporcionem informações importantes para tomadas de decisões. Dentre as novas tecnologias que estão sendo utilizadas pelas empresas, tem-se o Activity Based Cost. Um dos aspectos do ABC é sustentar as vantagens competitivas que permitam às empresas enfrentarem a concorrência.

O ABC auxilia a tomada de decisão e proporciona a transparência dos custos, buscando identificar as atividades que agregam e não agregam valor aos produtos e serviços. Por esta identificação das atividades, a empresa pode atuar mais efetivamente na redução de custos, rastreando as atividades que não agregam valor, disponibilizando assim, mais recursos para outros investimentos e conseqüentemente, gerando mais receitas. $\mathrm{O} A B C$ é um facilitador de mudanças dentro da organização, pois, com a sua utilização, as pessoas conseguem perceber o que é essencial a ser realizado, aprendendo o conceito de agregação de valor, facilitando a fiscalização constante de atividades que possam aumentar os custos dentro do processo (CHING, 1995). Várias definições podem ser dadas para o ABC:

"ABC é um método baseado no consumo de recursos pelas atividades envolvidas na produção de um dado produto. Atividades não incluem somente processamento, mas também transporte de materiais, inspeção, e todos os outros estágios de produção que possam afetar os custos" (ANDRADE et al., 1999).

"O princípio básico do sistema $A B C$ é identificar as atividades de uma organização e calcular o custo de cada atividade e então custear o produto baseado no consumo das atividades" (GUNASEKARAN \& SINGH, 1999).

GUNASEKARAN \& SINGH (1999) relatam a importância do custeio $A B C$ na melhoria do desempenho operacional e seu sucesso em larga escala nas indústrias. Tal desempenho é obtido por meio da apropriação das informações sobre o consumo de recursos.

SPEDDING \& SUN (1999) também reforçam a idéia da importância do custo $A B C$, em seu artigo, relatando que este método de custeio, pode resolver muitas das limitações de sistemas tradicionais de custo. 
COGAN (1998) narra alguns benefícios do ABC. Um deles é que o $A B C$ permite que se tomem ações para o melhoramento contínuo de atividades, com redução dos custos indiretos posteriormente. Outro benefício é permitir uma melhoria nas decisões gerenciais, uma vez que se pode abandonar a idéia de produtos "supercusteados", conseguindo-se, assim, uma transparência de custos que posteriormente será usada para a tomada de decisão da empresa.

GUNASEKARAN \& SARHADI (1998) comentam sobre as distorções de informações que o sistema de custeio tradicional traz e promovem a adoção do $A B C$ na procura da precisão de informações sobre custos. Seguem a filosofia de que o $A B C$ procura identificar as atividades do sistema e verifica aquelas que não adicionam valor para a instituição. Identificam, ainda, a presença do $A B C$ em vários sistemas avançados de manufatura, sobretudo no projeto do sistema produtivo, no projeto para a qualidade e no projeto para distribuição de produtos.

\section{Vantagens e desvantagens do ABC}

CHING (1995) enumera algumas vantagens do $A B C$ que são:

- Apropriação precisa dos custos fixos, que são os custos que ocorrem todos os meses independentemente da produção. Ex: Aluguel.

- $O A B C$ não fornece as respostas (respostas diretas que são procuradas) e sim identifica as questões corretas, ou seja, as abordagens que devem ser feitas sobre os resultados gerados do uso do $A B C$;

- Possibilidade de uma mudança de comportamento e de atitudes das pessoas envolvidas no processo;

- Identificação das verdadeiras causas das atividades, verificando se elas agregam ou não valor aos produtos e aos clientes;

- Promove maior transparência e melhoria de custos, por meio da eliminação, redução e/ou racionalização das atividades.

TOMMASI (2000), VIVEROS (2000), MARTINS (1995), SANTOS (1974), enumeram algumas das desvantagens do sistema de custo $A B C$ :

- Analisa somente o aspecto custo e não analisa o lado benéfico da receita; 
- Sua implementação demanda um esforço organizacional e financeiro muito elevado, principalmente em relação à estruturação do sistema de informações, pois o detalhamento necessário para este sistema de custeio é maior.

- A implementação do custo $A B C$ tende a curto e médio prazo, restringir-se às empresas de grande porte, como multinacionais, por exemplo.

\section{- Passos para implementação do ABC}

GUNASEKARAN \& SARHADI (1998) sugerem alguns passos para a implementação do processo $A B C$, que são:

Identificar os objetos de custo - Vários esforços têm sido realizados para a seleção de componentes e produtos que serão custeados. Traçar os custos destes produtos com melhor precisão é um dos objetivos do ABC. Tais produtos e componentes selecionados para serem custeados são chamados de objetos de custo. Esta etapa tem a finalidade de escolher tais objetos de custo para o sistema ABC.

Analisar as atividades - Esta etapa, primeiramente, define e identifica as atividades do sistema, e busca custear estas atividades posteriormente. Procura seus respectivos direcionadores de custo como parâmetros de medida e, por fim, identifica o custo total do produto. Identifica as atividades que realmente adicionam valor aos produtos.

Identificar métodos de alocação de custos - Nesta etapa identifica-se métodos para alocação de custos, baseando-se nos recursos consumidos pelos produtos e nos direcionadores de custo que medem as atividades. Um produto consome recursos como horas de máquina, mão-de-obra e energia, entre outros. A alocação de custo baseia-se nestes parâmetros.

Monitoramento da implementação - A implementação deve ser monitorada com um plano de desenvolvimento, na qual pessoas envolvidas no sistema $A B C$ estão encarregadas de verificar (estudar) os resultados obtidos. Responsabilidades sobre os resultados do $A B C$ são delegadas a este grupo de pessoas.

Porém, para o sucesso da implementação do ABC, alguns aspectos devem ser considerados. São eles: 
Comprometimento da alta administração - Pessoas da alta administração devem encorajar a implementação do ABC, promovendo mudanças no sistema de custos da organização. Para tais mudanças, faz-se necessária uma orientação adequada da alta administração, bem como uma monitoração do sistema e suporte técnico e financeiro.

Educação e treinamento dos empregados - A instituição deve preocupar-se em dar suporte de conhecimento aos funcionários sobre o $\mathrm{ABC}$ e treiná-los posteriormente.

Incentivo e motivação dos empregados - Um esquema adequado de incentivo e motivação deve ser formulado para todos os empregados das diversas áreas da organização. O objetivo principal é conseguir a cooperação de todos os envolvidos.

Baseados nestas etapas, GUNASEKARAN \& SARHADI (1998), sugerem uma implementação do $A B C$ como representado na figura 06 , que sintetiza todas as etapas e os aspectos importantes a serem considerados na implementação do ABC.

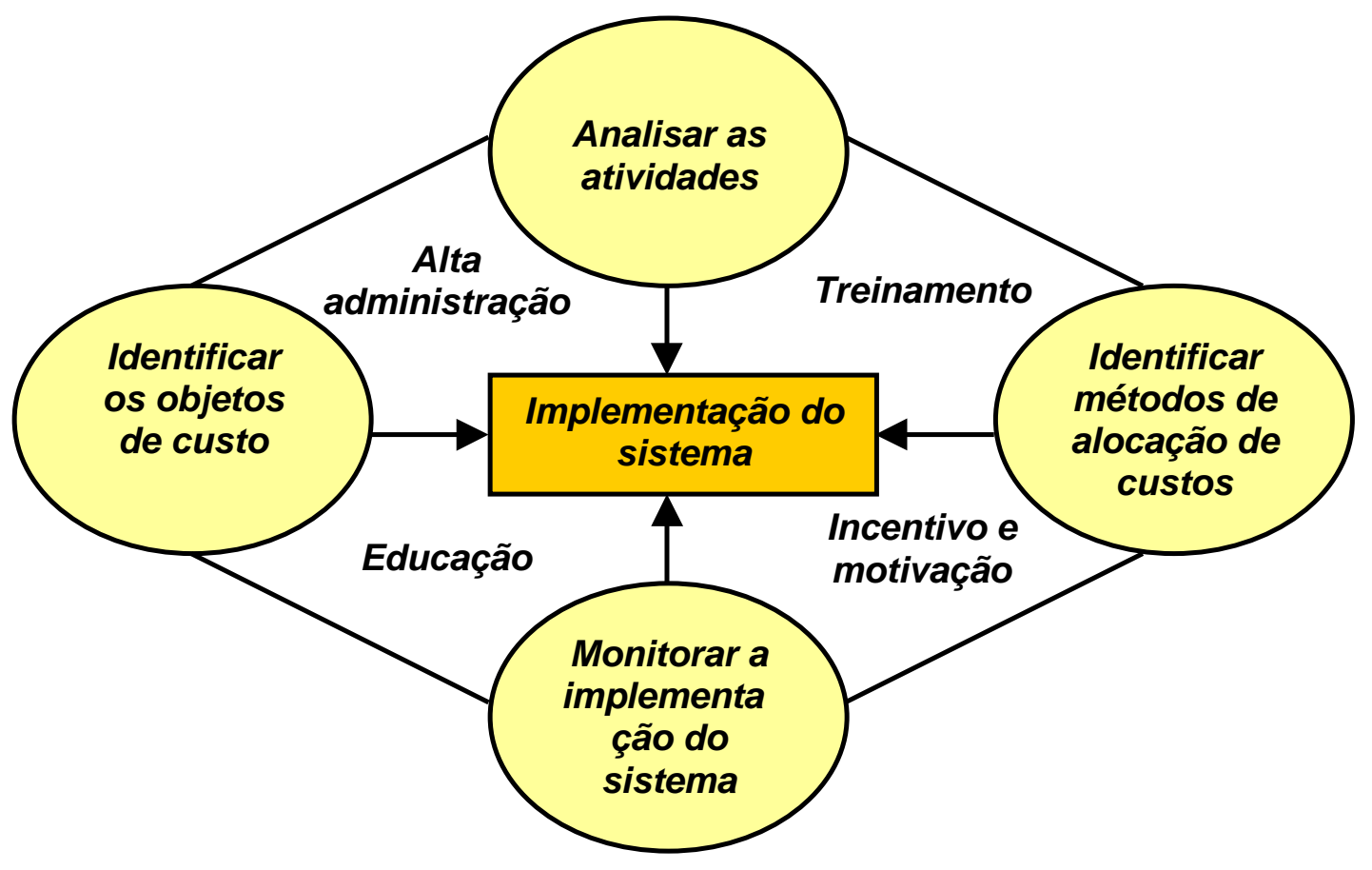

FIGURA 06 - IMPLEMENTAÇÃO DO ABC.

Fonte: GUNASEKARAN \& SARHADI (1998) 


\subsubsection{Custo $A B C \times$ custo tradicional}

Alguns fatores diferenciam o sistema de custeio tradicional e o custeio ABC (Activity Based Cost). COGAN (1998) CHING (1995) comentam resumidamente que, para o sistema de custeio tradicional, os produtos e serviços finais são os consumidores dos recursos da organização.

A figura 07 ilustra o consumo de recursos pelos produtos e serviços.

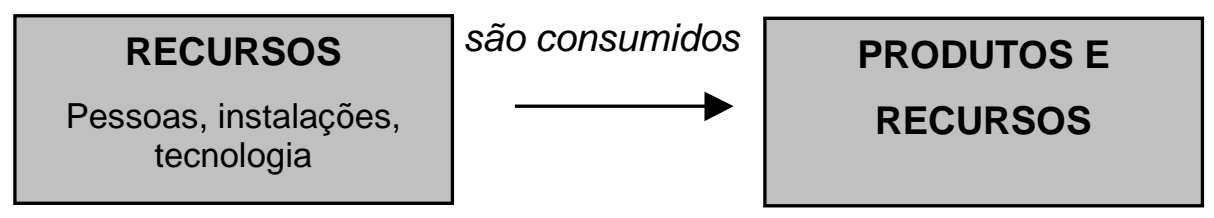

FIGURA 07 - MÉTODO DO CUSTEIO TRADICIONAL.

Fonte: CHING (1995).

Para o ABC, CHING (1995) comenta que as atividades consomem recursos e não os produtos, como no custeio tradicional. Os produtos surgem como conseqüência das atividades. Busca-se verificar as atividades que realmente adicionam valor aos produtos e clientes, sendo que as atividades que não agregam valor devem ser eliminadas ou reduzidas, para otimizar os custos da empresa de forma eficiente e eficaz. O rastreamento do consumo de recursos é alocado às atividades, que, por sua vez, são alocadas aos produtos e serviços.

COGAN (1998) narra que, como no custeio tradicional, o ABC é um sistema que processa a alocação em dois estágios. No primeiro estágio determinam-se quais atividades são executadas pelos recursos da empresa, agregando-as em centros de acumulação de custos por atividades.

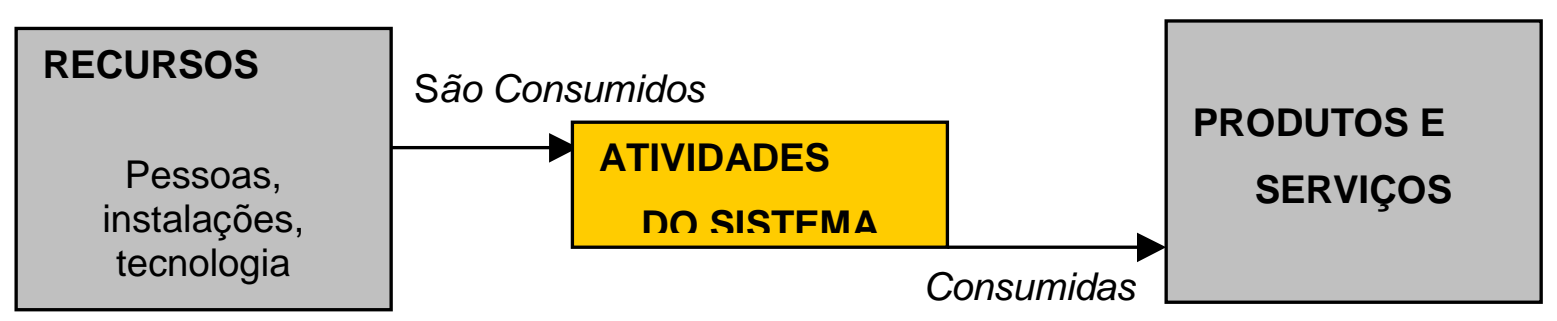

FIGURA 08 - MÉTOdO dO CUSTEIO ABC.

Fonte: CHING (1995). 
No segundo estágio, para cada um destes centros de atividades, atribui-se custos aos produtos baseados em seu consumo de recursos. A figura 08 ilustra o consumo dos recursos pelas atividades e o consumo das atividades pelos produtos/serviços.

Juntamente com esta abordagem feita sobre o $A B C$, deve-se levar em conta outras características.

NAKAGAWA (1997), CHING (1995) e MARTINS (1995) esclarecem que, no sistema $A B C$, deve-se sempre procurar a causa raiz da atividade, fazendo uso dos porquês (por quê esta atividade ocorre?). A causa raiz é a causa que originou a atividade, ou seja, é a causa que deu início à determinada atividade. Ao invés das empresas fazerem cortes de forma indiscriminada como no custeio tradicional, pela visão do $A B C$ elas concentram esforços na busca dos fatores geradores de custos.

Um exemplo comparativo entre o custo tradicional e $A B C$ é mostrado na figura 09:

\begin{tabular}{|c|c|c|c|c|}
\hline \multicolumn{2}{|c|}{ Custeio Tradicional } & \multicolumn{3}{|c|}{ Custeio $A B C$} \\
\hline Manufatura & Valores & Atividades & Agrega Valor & Não Agrega \\
\hline Salários & 200.000 & Fazer Produto & 150.000 & \\
\hline Facilidades & 60.000 & Retrabalho do Produto & & 30.000 \\
\hline Depreciação & 80.000 & Esperar Trabalho & & 72.000 \\
\hline Comunicação & 50.000 & Mover Material & & 17.000 \\
\hline Suprimentos & 20.000 & Estocar Material & & 50.000 \\
\hline & & Excesso Capacidade & & 41.000 \\
\hline & & Empacotar & 50.000 & \\
\hline Total & 410.000 & & 200.000 & 210.000 \\
\hline
\end{tabular}

FIGURA 09 - EXEMPLO DE APURAÇÃO DE CUSTO ABC TRADICIONAL.

Fonte: CHING (1995)

Veja que o $A B C$ mostra as atividades que agregam e não agregam valor. Desta forma, pode-se tomar ações para que as atividades que não agregam valor possam ser reduzidas. No custeio tradicional, no entanto, não é possível esta clareza. 


\subsection{Arranjo físico}

Um outro componente importante a ser considerado para o ganho de produtividade é o correto projeto e planejamento de arranjo físico das diversas áreas que compõem os sistemas de manufatura.

GONÇALVES FILHO (2001) relata que o arranjo físico define o relacionamento físico entre as diversas atividades dos sistemas. Além disso, o arranjo também determina a forma como os recursos pertencentes aos sistemas fluem por meio das operações.

\subsubsection{Introdução e conceituação}

Arranjo Físico é definido, segundo alguns autores, como sendo:

"Arranjo Físico é definido como a disposição de máquinas, equipamentos e serviços de suporte em uma determinada área com o objetivo de minimizar o volume de transporte de materiais no fluxo produtivo de uma fábrica" (FRANCISCHINI \& FEGYVERES, 1997).

"Arranjo Físico se refere ao planejamento do espaço físico a ser ocupado e representa a disposição de máquinas e equipamentos necessários à produção dos produtos/serviços de empresa" (CHIAVENATO, 1991).

Existe uma grande importância nas decisões do arranjo físico sobre vários aspectos. Um deles é que o arranjo físico é freqüentemente uma atividade difícil e de longa duração, devido às dimensões físicas dos recursos de transformação movidos dentro do arranjo. Outro fato é que uma mudança no arranjo físico pode ser difícil e cara, sendo que, quando se toma uma decisão errônea sobre o arranjo físico, tem-se como conseqüência um efeito considerável de longo prazo na operação. Sendo assim os gerentes que irão tomar a decisão sobre o projeto do arranjo físico não podem errar em sua confecção (SLACK et al, 1997). 


\subsubsection{Sistemas de manufatura}

Atualmente, sensíveis mudanças estão ocorrendo no projeto de sistemas de manufatura. Segundo BLACK (1998), tais mudanças são motivadas pelas seguintes tendências:

- o aumento do número e da variedade de produtos continuará, resultando numa queda de tamanho de lote;

- pedidos de exatidão e precisão de produtos para uma melhoria de qualidade continuarão a existir;

- o aumento da variedade de materiais incorrerá em um aumento do número de processos de fabricação;

- o tempo existente entre o projeto do produto e sua fabricação será reduzido graças aos esforços da engenharia simultânea;

- os produtos globais irão alimentar mercados globais.

O sistema de manufatura deve dar as seguintes respostas para as tendências abordadas:

- com a melhoria de produtos existirá a necessidade de uma reestruturação e de melhoria dos sistemas de manufatura;

- o sistema de manufatura deverá entregar produtos com qualidade superior, com um custo unitário menor e dentro de um prazo de entrega pré-estabelecido para seus clientes;

- o sistema deve ser projetado de maneira compreensível, flexível e confiável.

- Definição de sistema. Para BLACK (1998), sistema é a palavra usada para definir ou ilustrar de uma maneira abstrata, uma montagem (ou um arranjo físico) complexa que possui elementos físicos caracterizados por parâmetros mensuráveis. O sistema de manufatura segue esta filosofia (figura 10). Dentre os elementos físicos importantes na manufatura destacam-se: pessoas, processos e equipamentos, estoque e manuseio de materiais. Dentre os parâmetros mensuráveis destacam-se: a taxa de produção, estoque em processo, custo total ou unitário, entre outros. 
BLACK (1998) ainda destaca que o usuário do sistema é o cliente interno e que o usuário dos produtos do sistema é o cliente externo. Para que o sistema de manufatura seja considerado eficaz uma relação amigável entre o cliente interno e o externo deve existir, pois conflitos existentes entre eles, comprometem o sistema. Para modelar e controlar o sistema, os limites ou restrições do sistema devem ser definidos. Além disso, o comportamento do sistema em resposta aos estímulos ou distúrbios do ambiente deve ser previsto por meio de seus parâmetros.

\begin{tabular}{|c|c|c|c|}
\hline ENTRADA & \multicolumn{2}{|c|}{ SISTEMA } & SAÍDA \\
\hline $\begin{array}{l}\text { Material } \\
\text { Demanda } \\
\text { Informação } \\
\text { Política social } \\
\text { Energia }\end{array}$ & \multicolumn{2}{|c|}{$\begin{array}{l}\text { Sistema de manufatura é: } \\
\text { Um arranjo complexo de } \\
\text { elementos físicos } \\
\text { caracterizados por } \\
\text { parâmetros mensuráveis. }\end{array}$} & $\begin{array}{l}\text { Produto e peça consumo } \\
\text { Informação } \\
\text { Serviço ao cliente } \\
\text { Defeito e sucata } \\
\text { CLIENTE } \\
\text { EXTERNO }\end{array}$ \\
\hline $\begin{array}{l}\text { * Elementos físi } \\
\nabla \text { Máquinas-ferr } \\
\text { processament } \\
\nabla \text { Ferramentas e } \\
\nabla \text { Equipamentos } \\
\text { de materiais } \\
\nabla \text { Pessoas (clien }\end{array}$ & $\begin{array}{l}\text { tas para } \\
\text { quinário } \\
\text { novimentação } \\
\text { nternos) }\end{array}$ & $\begin{array}{l}- \text { Par } \\
\nabla \text { Ter } \\
\nabla \text { Tax } \\
\nabla \text { Est } \\
\nabla \% c \\
\nabla \% \text { \% } \\
\nabla \text { Vol } \\
\text { diário } \\
\nabla \text { Cus }\end{array}$ & $\begin{array}{l}\text { s mensuráveis do sistema } \\
\text { atravessamento } \\
\text { rodução } \\
\text { m processo } \\
\text { itos } \\
\text { ega dento do prazo } \\
\text { de produção } \\
\text { lanais / mensais } \\
\text { l ou unitário }\end{array}$ \\
\hline
\end{tabular}

FIGURA 10 - DEFINIÇÃO DE SISTEMA DE MANUFATURA.

Fonte: BLACK (1998).

\subsubsection{Classificação dos tipos de arranjo físico}

Vários autores como GONÇALVES FILHO (2001), BLACK (1998), SLACK et al. (1997), FRANCISCHINI \& FEGYVERES (1997) e CHIAVENATO (1991), classificam quatro tipos principais de arranjo físico existentes: arranjo físico funcional, arranjo físico em linha, arranjo físico de posição fixa, arranjo físico de processo contínuo. O conceito de arranjo físico para todos os autores é o mesmo, porém pode-se 
encontrar nomenclaturas diferentes na bibliografia. A seguir cada tipo de arranjo físico é detalhado.

\subsubsection{Arranjo físico por processo ou funcional}

É o tipo de arranjo mais comum encontrado nas indústrias. Sua característica principal é a produção de uma grande variedade de produtos, que resulta em pequenos lotes de produção. As máquinas são agrupadas por função (todos tornos juntos, todas fresadoras juntas, etc).

O arranjo físico funcional também pode ser definido como aquele que representa as diversas seções (ou máquinas e equipamentos) e o fluxo que o processo segue desde a matéria-prima inicial até o produto acabado. Assim as seções (ou máquinas e equipamentos) figuram como elementos básicos do layout, enquanto os produtos seguem trajetórias diferentes (CHIAVENATO, 1991).

FIORONI \& BATOCCHIO (2000) comentam que no sistema funcional os recursos fabris da empresa com a mesma função são agrupados em setores, onde a matéria-prima é transportada em lotes ao longo dos diferentes setores sofrendo operações específicas em cada um destes setores.

Para FRANCISCHINI \& FEGYVERES (1997), as características do arranjo físico funcional são:

- as máquinas e equipamentos ficam fixos e o produto se movimenta;

- as máquinas e equipamentos são agrupados por função (montagem, usinagem, soldagem);

- grande variabilidade de produtos;

- usado em sistema de produção intermitente (por lote);

- complexo sistema de PCP (Planejamento e Controle da Produção);

- sistema formador de filas de lotes nas máquinas;

- os equipamentos são de média flexibilidade.

Outra característica relatada por GONÇALVES FILHO (2001) é que o arranjo físico funcional é marcado pela complexidade, em virtude do grande número de alternativas possíveis na sua configuração. A figura 11 ilustra tal tipo de arranjo: 


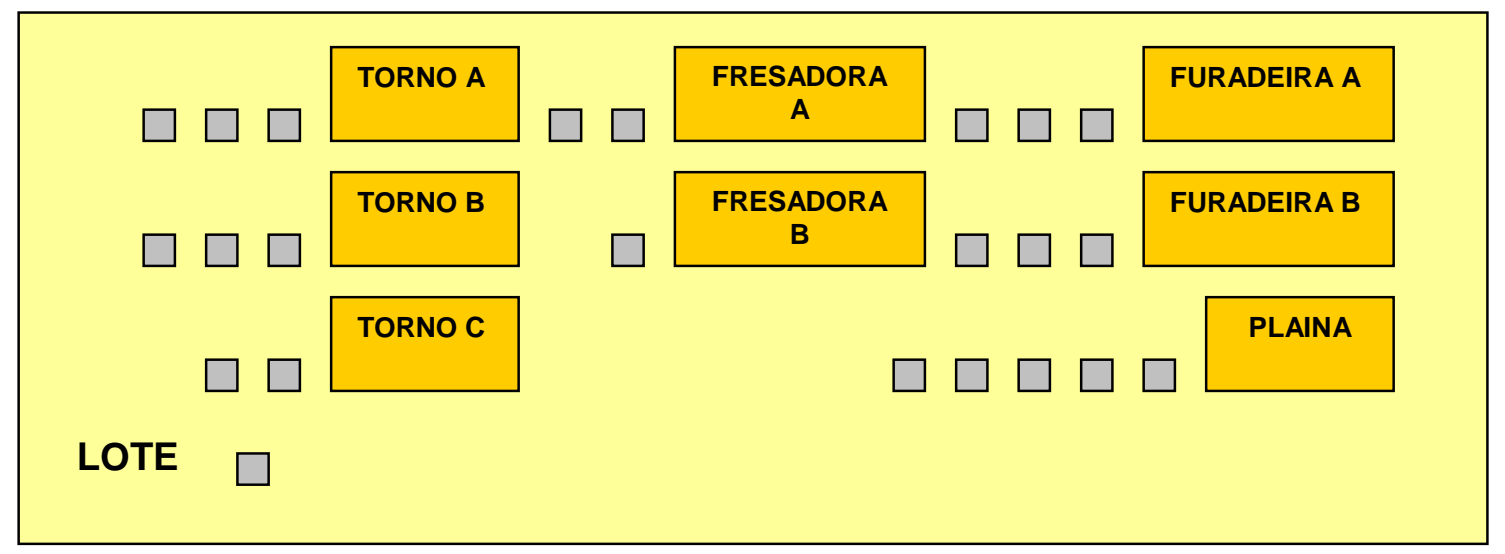

FIGURA 11 - ARRANJO FÍSICO FUNCIONAL.

Fonte: FRANCISCHINI \& FEGYVERES (1997)

Nota-se na figura 11 que filas formam-se no sistema e máquinas são agrupadas juntas.

\subsubsection{Arranjo físico em linha ou por produto}

É o tipo de arranjo caracterizado por grandes lotes de produção e máquinas para fins específicos. Possui menor variabilidade de produtos e maior mecanização. São contínuos ou interrompidos. Quando contínuos produzem um item complexo em grande quantidade. Quando o volume se torna muito grande, em especial em uma linha de montagem, o arranjo físico em linha é chamado de produção em massa. Este sistema pode ter altas taxas de produção (BLACK, 1998).

O arranjo físico em linha (figura 12) também pode ser definido como aquele que representa cada tipo de operação desde a entrada da matéria-prima em uma extremidade até a saída do produto acabado na outra extremidade, indicando a trajetória (etapas de produção) que constitui a menor distância entre esses dois extremos (CHIAVENATO 1991).

Para FRANCISCHINI \& FEGYVERES (1997), as características do arranjo físico em linha são:

- exige grande investimento em máquinas e equipamentos;

- $\quad$ produtos fabricados em grande quantidade e semelhantes entre si; 
- utilizado em sistemas de produção contínua;

- exige balanceamento de linha;

- PCP mais simplificado;

- equipamentos dispostos de acordo com a seqüência de operações.

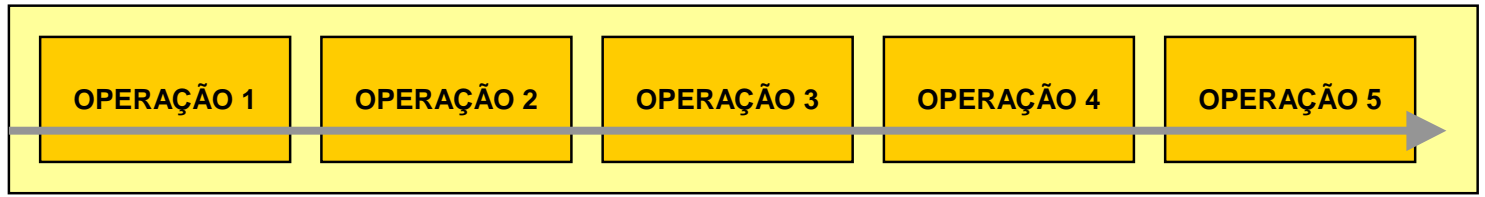

FIGURA 12 - ARRANJO FÍSICO EM LINHA.

Fonte: FRANCISCHINI \& FEGYVERES (1997).

\subsubsection{Arranjo físico de posição fixa ou posicional}

BLACK (1998) relata que o arranjo físico de posição fixa é um típico sistema voltado para o projeto. O produto permanece em uma posição fixa durante a fabricação devido ao seu peso e/ou tamanho. Os recursos, como pessoas, materiais, máquinas são trazidas para o local em que as operações de fabricação serão realizadas. Em outras palavras os recursos são móveis.

FRANCISCHINI \& FEGYVERES (1997) chamam o arranjo físico de posição fixa de arranjo físico posicional, que possui, como características:

- os produtos são fabricados em pequenas quantidades e em grandes dimensões;

- o produto fica fixo, enquanto que os recursos produtivos são dirigidos a ele;

- os equipamentos possuem alta flexibilidade.

\subsubsection{Arranjo físico de processo contínuo}

BLACK (1998) relata que no arranjo físico de processo contínuo o produto flui fisicamente. Os produtos realmente fluem porque eles são líquidos, gasosos ou pós. Este tipo de arranjo é o mais eficiente, porém o menos flexível sistema de manufatura. Possui o mais enxuto e simples sistema de produção, pois, tem o menor estoque em processo tornando-se fácil de ser controlado. As usinas de açúcar, refinarias de petróleo, usinas de processamento químico e a indústria alimentícia são exemplos de indústrias que utilizam este tipo de arranjo físico de 
processo contínuo. A figura 13 a seguir ilustra a aplicação dos quatro tipos de arranjo físico citados dentro da indústria.

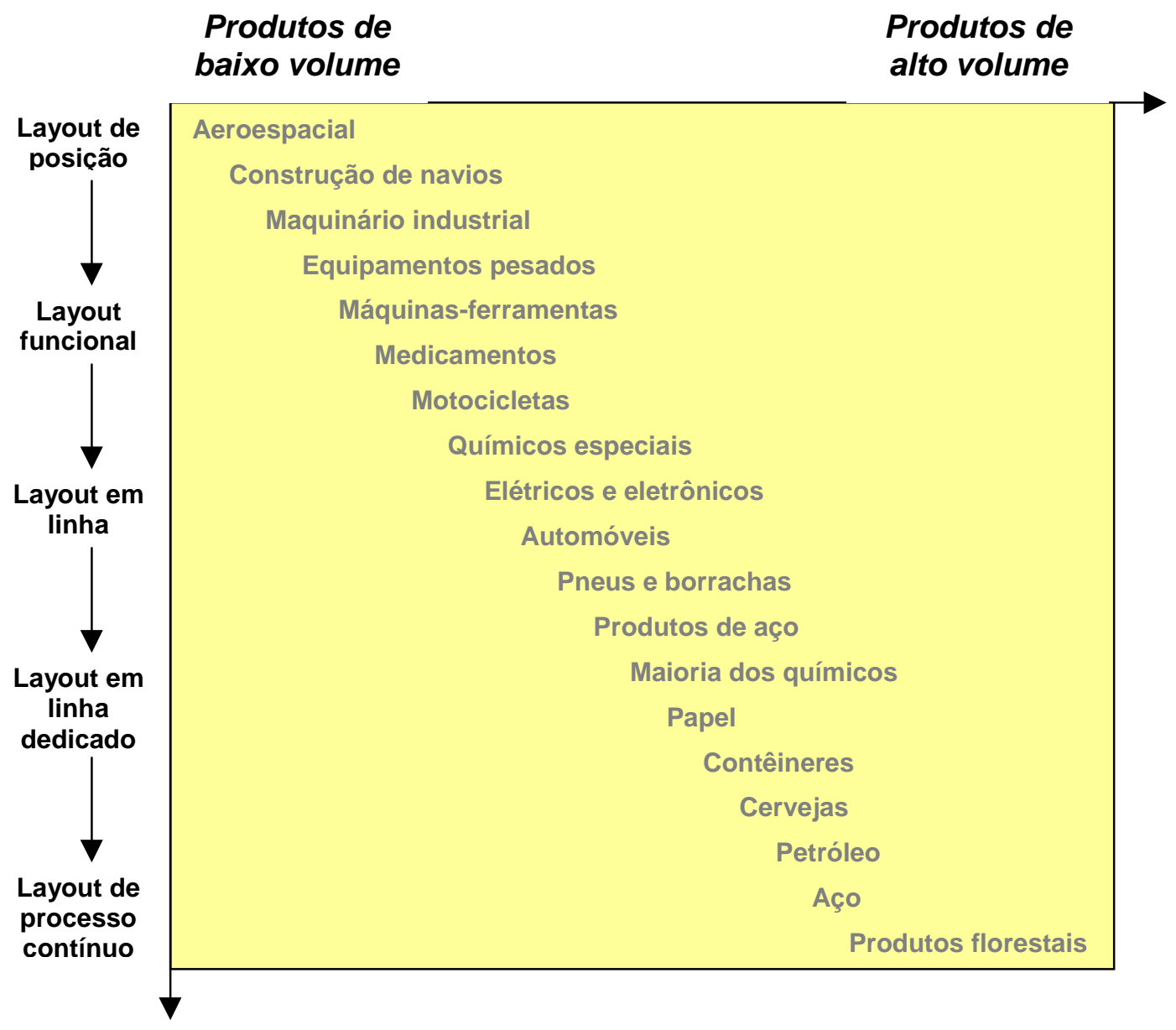

FIGURA 13 - TIPO DE INDÚSTRIA /VOLUME PRODUTOS/ARRANJO FÍSICO.

Fonte: BLACK (1998).

\subsubsection{Arranjo físico celular}

Outro tipo de arranjo físico muito utilizado recentemente é o layout celular. BLACK (1998), FRANCISCHINI \& FEGYVERES (1997) e SLACK et al. (1994) definem o arranjo físico celular como um tipo de arranjo físico com o objetivo de montar minifábricas para diferentes famílias de produtos. Tais famílias são grupos de produtos com características semelhantes entre si, tais como: semelhança geométrica e semelhança de processo de fabricação.

FIORONI \& BATOCCHIO (2000) definem sistema celular como aquele sistema que se destina à fabricação de peças que tenham certa similaridade, em lotes 
pequenos, caracteriza-se pelo agrupamento de todas as máquinas usadas na fabricação de um determinado grupo ou famílias de peças.

BLACK (1998) comenta que tal disposição se parece com o arranjo físico em linha, mas é projetada para possuir flexibilidade. É projetada, muitas vezes, em forma de ' $U$ ', permitindo às pessoas moverem-se de uma máquina para outra, carregando e descarregando peças.

Para BLACK (1998), FRANCISCHINI \& FEGYVERES (1997) e SLACK et al. (1994), o arranjo físico celular possui as seguintes características:

- lotes de tamanho médio;

- produtos e roteiros variados;

- agrupamento, geralmente em forma de "U" das máquinas e equipamentos necessários para a produção da família;

- ajusta-se ao just-in-time;

As vantagens do uso de células são citadas por FRANCISCHINI \& FEGYVERES (1997):

- possuem característica de mutualidade, ou seja, podem ser alteradas em intervalos adequados, tornando-se minifábricas de novos produtos de acordo com a época e a demanda. Ainda, se necessário a célula pode voltar a fabricar os produtos originais com a mesma facilidade com que mudou de produto;

- nas células as máquinas podem ser dispostas de modo a permitir aos operadores controlar várias delas ao mesmo tempo, inclusive aquelas com longo tempo em seu processamento;

- permite um controle produtivo mais simplificado e também mais eficaz, devido ao fluxo de material mais organizado.

LOGENDRAN \& TALKINGTON (1997) definem manufatura celular como sendo uma filosofia focada no agrupamento de peças similares pela forma ou pelo processo.

Segundo MORRIS \& TERSINE (1990) e FRANCISCHINI \& FEGYVERES (1997), para formar famílias, emprega-se a chamada tecnologia de grupo (TG), que é uma estratégia de manufatura que identifica similaridades nos produtos a serem 
fabricados e processados, sendo aplicada na produção de pequenos e médios lotes.

Ainda segundo FRANCISCHINI \& FEGYVERES (1997), cada família de peças pode ser considerada uma peça composta com os atributos de todas as peças do grupo. Justifica-se o emprego da tecnologia de grupo em sistemas de produção que apresentem grande variedade na linha de produtos, grande número de peças e volumes que não justifiquem equipamentos dedicados. A tecnologia de grupo (TG) não é aplicada somente em células de manufatura, mas também em projetos de produtos e na padronização e referência do projeto, assim como na especificação de materiais e no planejamento da fabricação.

GONÇALVES FILHO (1982), BATOCCHIO (1987), BUFFA \& SARIN (1987), FRANCISCHINI \& FEGYVERES (1997) comentam que o conceito de tecnologia de grupo também inclui um sistema de classificação e codificação que é computadorizado. A figura 14 ilustra um arranjo físico celular:

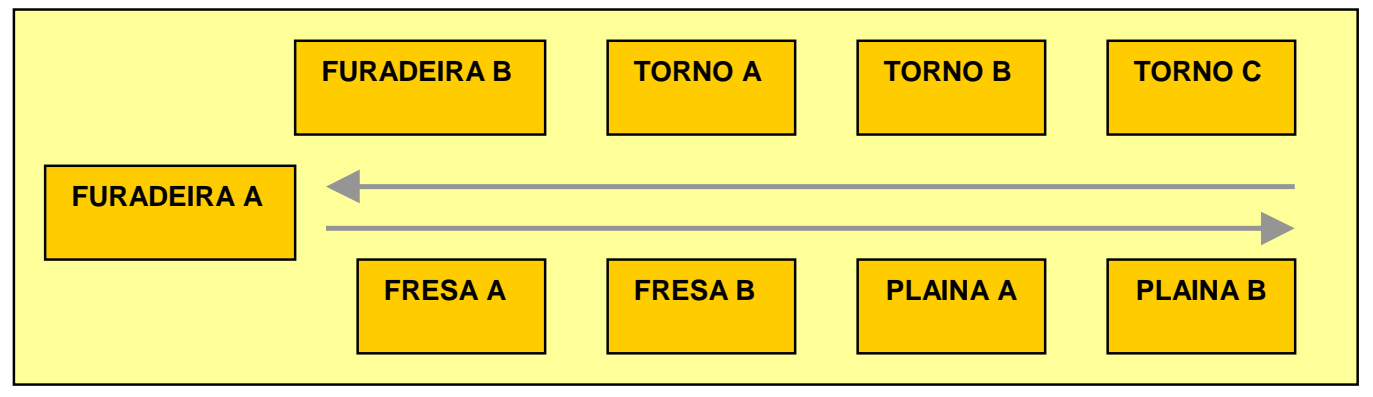

FIGURA 14 - ARRANJO FÍSICO CELULAR.

Fonte: FRANCISCHINI \& FEGYVERES (1997).

Como mostra a figura 14 o fluxo é unidirecional, na forma de um ' $U$ ', sendo que as máquinas estão dispostas na ordem em que as peças serão processadas.

Desta forma, tem-se uma revisão bibliográfica dos três assuntos necessários para o desenvolvimento do trabalho. Tal revisão foi realizada com o objetivo de esclarecer conceitos essenciais no entendimento do trabalho, bem como no entendimento dos capítulos seguintes. Em seguida é necessária a compreensão da formulação de custo proposta, que surgiu do conceito de custo sugerido pela SOCIETY OF MANUFACTURING ENGINEERS como irá relatar o capítulo 3. 


\section{CAPÍTULO 3 - O MODELO DE CUSTO}

\subsection{Generalidades}

Uma empresa possui vários objetivos, entre eles a obtenção da máxima rentabilidade de seus negócios, objetivando a plena satisfação das necessidades dos clientes. Reduzir ao máximo os custos de uma empresa significa gerar uma maior flexibilidade para as alternativas de comercialização de produtos, obtendo, conseqüentemente maior competitividade no mercado ao qual faz parte. Seguindo esta filosofia, percebe-se a importância da adoção de um sistema de custo. Uma proposta de custo é adotada, segundo a formulação de custo sugerida pela SOCIETY OF MANUFACTURING ENGINEERS (1965). Antes de conhecer a formulação de custo da SME é necessário o conhecimento de alguns conceitos básicos relacionados aos sistemas de custo.

\subsection{Introdução e conceituação}

\section{Custo Estimado}

É o custo que se acredita ser o esperado para os diversos itens a serem produzidos pela empresa. A estimativa é realizada com base em dados históricos, os quais são então inferidos para as peças que serão produzidas. É utilizado principalmente para efeito de planejamento e orçamento. 


\section{Custo Real}

É o custo realmente ocorrido durante a produção dos itens fabricados pela empresa. Para poder determiná-lo, é necessário efetuar-se um levantamento das ocorrências. Uma vez conhecidas as ocorrências, pode-se, então, distribuir os custos ocorridos entre os diversos itens produzidos pela empresa. O custo real é sempre medido em relação a um determinado período de tempo. Normalmente, utiliza-se o período de um mês como base de tempo, mas que pode ser alterado, de acordo com as condições específicas de cada organização. A base de tempo mensal é utilizada nos termos que definem a formulação de custo

\section{Comparação entre Custo Real e Custo Estimado}

O custo estimado pode ser utilizado como o valor esperado do custo real, quando não se conhece o histórico real da produção. Entretanto, a inferência sobre um período específico do passado, baseada em valores médios de períodos normalmente mais longos também do passado, pode induzir a erros localizados de grande magnitude. A formulação de ambos os custos é exatamente a mesma. Porém, a diferença básica é que, no caso, do custo real são utilizados os custos devidamente registrados no período em que, deseja-se levantar o custo real, e no caso do custo estimado, são utilizados os valores médios de períodos anteriores, normalmente mais longos, para os diversos componentes da formulação do custo que, agrupados, formam o custo estimado.

\subsubsection{Formulação de custo}

A formulação de custo, tanto real quanto estimado, procura uma divisão de acordo com a abrangência dos mesmos. Divide-se em três grupos principais de abrangência.

O primeiro grupo de custos representa aqueles que podem ser associados ao processo produtivo de uma peça específica.

O segundo grupo de custos é dado pelas despesas que não podem ser associados ao processo produtivo de uma peça específica, mas sim a um grupo de peças. É 
comum que esse grupo de peças seja dado por todas as peças produzidas no período de estudo.

O terceiro grupo de custos é aquele em que os custos não são associáveis ao processo produtivo. Representa o custo que se repete em qualquer período de estudo, independente da ocorrência ou não de produção.

$\mathrm{Na}$ formulação apresenta-se, os três grupos de custos que são representados tipicamente pelos seguintes sub-itens:

- Grupo um: Custo efetivo da produção;

- Grupo dois: Custo fixo da produção, Custo do inventário da produção;

- Grupo três: Custo de engenharia do produto, Custo de distribuição, Custo administrativo.

A divisão dos custos dentro dos grupos, de acordo com a formulação a ser apresentada, tem como objetivo a melhor distribuição possível entre as diversas peças produzidas pela empresa. Deve-se, sempre que possível, não utilizar custos globais, mas sim distribuir suas parcelas pelas respectivas peças que compuseram o custo. Deste modo, obtêm-se relações de custo por unidade de tempo de produção diferentes para as diferentes peças.

É possível, também, determinar o custo real da mesma peça diferenciado para diferentes intervalos de tempo, quando se consideram as particularidades ocorridas no intervalo de tempo em questão.

O levantamento do custo real, ou o levantamento para obter-se o custo estimado é dispendioso, pois é necessária uma medição de todos estes custos no momento que ocorrem. Posteriormente faz-se estimativas dos custos medidos para obter-se o estimado. Um modo de facilitar a determinação destes custos consiste em supor que todos os custos associados ao grupo um citado acima, sejam iguais para todas as peças, ou desprezíveis. Define-se, então, que o custo horário médio em um determinado período é dado pela razão entre a soma de todos os gastos efetuados no período e a soma dos tempos padrões produzidos no mês. 


$$
C_{\text {HorárioMédio }}=\left(\frac{\sum \text { gastos }}{\sum t p}\right)[\mathrm{R} \$]
$$

em que:

$C_{\text {HorárioMédio }}=$ custo horário médio $[\mathrm{R} \$]$;

$\sum$ gastos $=$ somatório de todos os gastos efetuados no período $[\mathrm{R} \$]$;

$\sum t p=$ somatório de tempos padrões das peças produzidos no mês [horas].

O custo real será o produto entre o custo horário médio e o tempo padrão da peça em questão, como mostrado na equação abaixo. A grande vantagem de utilização deste modo de determinação do custo é a facilidade com que ele é realizado. $O$ erro embutido pode ser grande o suficiente para conduzir a empresa a obter prejuízos ou preços não competitivos, quando utilizado como estimativa de custo para efeito de planejamento e/ou orçamento.

$$
C_{R E A L}=\left(C_{\text {Horáriomédio }} \times t p\right)[\mathrm{R} \$]
$$

em que:

$C_{R E A L}=$ custo real $[\mathrm{R} \$]$;

$C_{\text {HorárioMédio }}=$ custo horário médio $[\mathrm{R} \$]$;

$t p=$ tempo padrão da peça em questão [horas].

Do mesmo modo pode-se trabalhar com as receitas, em substituição às despesas, para obter-se preço horário médio de venda. O preço de venda estimado é, então, o produto entre o preço horário médio de venda e o tempo padrão da peça em questão. O preço de venda real é aquele que, realizou-se como fruto de uma negociação comercial. Deve-se ressaltar que o preço de venda real da mesma peça pode assumir valores diferentes nas diversas negociações.

\section{3 Índices do modelo de custo}

Antes da apresentação das fórmulas de custo, sugeridas pela SOCIETY OF MANUFACTURING ENGINEERS, faz-se necessário conhecer alguns índices, pertencentes a estas fórmulas do modelo de custo. São eles: 
A) Índice de Rateio de Custo Mensal para a I-ésima Peça

É um índice usado par distribuir o custo total mensal de um determinado item para cada uma das peças produzidas, utilizando como parâmetro de rateio, o tempo padrão. É calculado pela fórmula:

$$
I R M=\left(\frac{t p_{i}}{\sum_{i=1}^{Z} t p_{i}}\right)
$$

em que:

$I R M$ = índice de rateio de custo mensal [ - ];

$t p_{i}=$ tempo padrão da i-ésima peça $[\mathrm{h}]$;

$\sum t p_{i}=$ soma de tempos padrões das peças efetivamente produzidas no mês [ $\mathrm{h}$ ].

B) Índice de Rateio de Custo por Peça

É um índice usado par distribuir um custo mensal associado a uma única peça pela quantidade produzida da mesma. É calculado pela fórmula:

$$
I R P=\left(\frac{1}{n p}\right)
$$

em que:

$I R P=$ índice de rateio de custo por peça [ - ];

$n p=$ quantidade produzida no mês de uma determinada peça [ - ].

C) Índice de Utilização de MÃO-DE-OBRA Específica

$$
I U M O=\left(\frac{\sum_{i=1}^{n u} t u_{i}}{t d}\right)
$$

em que:

$\sum t u_{i}=$ somatório dos tempos de utilização da mão-de-obra específica [ $\mathrm{h}$ ]; 
$t d$ = tempo disponível mensal da mão-de-obra específica [ $\mathrm{h}$ ].

\subsection{Eficiências do modelo de custo}

\section{A) Eficiência de Produção}

A produção pode ter quedas devido a vários fatores, entre os quais destacam-se:

- falta de material, falta de operador;

- falta de dispositivo;

- $\quad$ falta de insumo (água, gás, ar comprimido,etc.);

- quebra de máquina;

- espera pela montagem;

- espera pela ajustagem;

- espera pela aprovação;

- etc.

Define-se eficiência de produção como:

$$
\eta_{\text {PRODUÇÃO }}=\left(\frac{\sum_{i=1}^{Z} t p_{i}}{\sum_{i=1}^{n} t d_{i}}\right)
$$

em que:

$\sum t p_{i}=$ somatórios dos tempos padrões produzidos no mês [ $\mathrm{h}$ ];

$\sum t d_{i}=$ somatório dos tempos padrões disponíveis no mês [ $\mathrm{h}$ ].

B) Eficiência de retrabalho devido à necessidade da quantidade de retrabalho de uma determinada peça. É dada pela fórmula:

$$
\eta_{\text {RETRABALHO }}=\left(\frac{n p \times t p}{n p \times t p+\sum_{i=1}^{n} t r t_{i}}\right)
$$

em que:

$n p=$ quantidade de peças produzidas no mês [ - ]; 
$t p=$ tempo padrão da peça $[\mathrm{h}]$;

$\sum$ trt $_{i}=$ somatório dos tempos de retrabalho a peça no mês [ $\mathrm{h}$ ].

C) Eficiência devido a perda por refugo de uma determinada peça. É dada pela fórmula:

$$
\eta_{\text {REFUGO }}=\left(1-\left(\frac{n r}{n p}\right)\right)
$$

em que:

$n r=$ quantidade de peças refugadas no mês [ - ];

$n p=$ quantidade de peças produzidas no mês (boas + refugadas) [ - ].

\subsection{Fórmulas do modelo de custo}

Para a SOCIETY OF MANUFACTURING ENGINEERS (1965), o custo real de uma peça é dado pela expressão que segue abaixo:

$$
C_{\text {REAL }}=C_{\text {MANUFATURA }}+C_{\text {ENGENHARIA }}+C_{\text {DISTRIBUIÇÃO }}+C_{\text {ADMINISTRATIVO }}
$$

em que:

$C_{\text {MANUFATURA }}=$ custo de manufatura $[\mathrm{R} \$]$;

$C_{\text {ENGENHARIA }}=$ custo de engenharia $[\mathrm{R} \$] ;$

$C_{\text {DISTRIBUIÇÃo }}=$ custo de distribuição $[\mathrm{R} \$]$;

$C_{\text {ADMINISTRATIVo }}=$ custos de administração $[\mathrm{R} \$]$.

Os custos administrativos referem-se aos custos de escritório, refeitório, ambulatório, assistência médica, frota administrativa, benefícios indiretos, propaganda, capital de giro, inventário da peça, etc.

O custo de manufatura, por sua vez, é calculado seguindo a fórmula ilustrada abaixo:

$$
C_{\text {MANUFATURA }}=C_{\text {EfetivoPRODUÇÃo }}+C_{\text {FixoPRODUÇÃO }}+C_{\text {InventárioPRODUÇÃo }}
$$

em que: 
$C_{\text {EfetivoPRODUÇÃO }}=$ custo efetivo de produção $[\mathrm{R} \$] ;$

$C_{\text {FixoPRODUÇÃo }}=$ custo fixo de produção $[\mathrm{R} \$] ;$

$C_{\text {InventarioPRODUÇÃO }}=$ custo de inventário de produção $[\mathrm{R} \$]$.

No custo de manufatura temos o custo efetivo da produção pertencente ao grupo um, o custo fixo e o custo de inventário da produção, pertencentes ao grupo dois. Neste trabalho, é enfocado o custo de manufatura (fabricação). Os demais custos (engenharia, distribuição e administrativo), pertencentes ao grupo três não serão estudados neste trabalho. É utilizado apenas o custo de manufatura porque é necessário medir apenas um conjunto de custos, para ilustrar os procedimentos de modelagem.

\subsubsection{Custo efetivo de produção}

O custo efetivo de produção pertence ao grupo um da formulação de custo sugerida pela SOCIETY OF MANUFACTURING ENGINEERS (1965) e, é calculado seguindo a fórmula:

$$
C_{\text {EfetivoPRODUÇÃO }}=\left(\frac{C_{\text {PRODUÇÃO }}}{\eta_{\text {RODUÇ̃̃OO }}}\right)[\mathrm{R} \$]
$$

em que:

$C_{P R O D U C ̧ \tilde{A} O}=$ custo de produção $[\mathrm{R} \$] ;$

$\eta_{P R O D U C ̧ \tilde{A} O}=$ rendimento da produção [ - ].

A eficiência será detalhada posteriormente em outro item. O custo de produção, por sua vez é calculado seguindo a fórmula:

$C_{\text {PRODUÇÃo }}=C_{\text {VARIÁVEL }}+C_{\text {MONTAGEM }}+C_{\text {AJUSTAGEM }}+C_{\text {CONTQUAL }}+C_{\text {EMBALAGEM }}+C_{\text {DESPACHO }}$ $[R \$]$, em que:

$C_{\text {VARIÁVEL }}=$ custo variável $[\mathrm{R} \$]$;

$C_{\text {MONTAGEM }}=$ custo de montagem do produto $[\mathrm{R} \$]$; 
$C_{\text {AJUSTAGEM }}=$ custo de ajustagem da máquina $[\mathrm{R} \$]$;

$C_{\text {CONTQUAL }}=$ custo de controle de qualidade $[\mathrm{R} \$]$;

$C_{E M B A L A G E M}=$ custo de embalagem $[\mathrm{R} \$] ;$

$C_{\text {DESPACHO }}=$ custo de despacho $[\mathrm{R} \$]$.

O custo variável, segue a fórmula abaixo:

$$
C_{\text {VARIÁVEL }}=\left[\frac{\left(t p p \times\left(C_{\text {MÁQUINA }}+C_{\text {ENERGIA }}+C_{\text {MÃO-DE-OBRA }}\right)+C_{\text {FERRAMENTAL }}+C_{\text {MATERIAL }}\right)}{\eta_{\text {RETRABALHO }} \times \eta_{\text {REFUGO }}}\right]
$$

[R\$], em que:

tpp = total de peças produzidas [ - ];

$C_{\text {MÁQUINA }}=$ custo de máquina $[\mathrm{R} \$]$;

$C_{\text {ENERGIA }}=$ custo de energia $[\mathrm{R} \$]$;

$C_{M \tilde{A} O-D E-O B R A}=$ custo de mão-de-obra $[\mathrm{R} \$]$;

$C_{\text {FERRAMENTAL }}=$ custo de ferramental [R $\left.\$\right]$;

$C_{\text {MATERIAL }}=$ custo de material $[\mathrm{R} \$]$;

$\eta_{\text {RETRABALHO }}=$ rendimento de retrabalho [ - ];

$\eta_{\text {REFUGO }}=$ rendimento de refugo [ - ].

O custo de mão-de-obra do operador inclui outras considerações. Além do salário base, a legislação brasileira prevê que uma empresa assuma outros custos, que podem ser subdivididos em adicionais e encargos. Além destes existem também compensações financeiras como incentivo à produção e participação nos lucros. Estes custos devem ser calculados como salário-hora. Entre eles destacam-se:

- adicional pela hora extra;

- adicional noturno;

- adicional de insalubridade;

- período de férias;

- adicional de férias;

- décimo terceiro salário; 
- descanso semanal remunerado;

- incentivo pela produção;

- participação nos lucros e resultados (PLR);

- absenteísmo;

- diversas taxas e impostos que recaem diretamente sobre folha de pagamento.

Portanto pode-se assumir a expressão para representar o custo de mão-de-obra segundo a SOCIETY OF MANUFACTURING ENGINEERS (1965) como sendo:

$$
C_{\text {MÃO-DE-OBRA }}=C_{\text {SALÁRIO }}+C_{\text {ADICIONAIS }}+C_{\text {INCENTIVOS }}+C_{\text {ENCARGOS }}[\mathrm{R} \$]
$$

em que:

$C_{\text {SALÁRIO }}=$ custo de salário $[\mathrm{R} \$$;

$C_{\text {ADICIONAIS }}=$ custo de adicionais $[\mathrm{R} \$]$;

$C_{\text {INCENTIVOS }}=$ custo de incentivos $[\mathrm{R} \$]$;

$C_{\text {ENCARGOS }}=$ custo de encargos $[\mathrm{R} \$]$.

Para o custo de máquina tem-se a fórmula:

$$
C_{\text {MÁQUINA }}=C_{\text {JURO }}+C_{\text {DEPRECIAÇÃo }}+C_{\text {MANUTENÇÃo }}+C_{\text {ESPAÇO }}[\mathrm{R} \$]
$$

em que:

$C_{\text {JURO }}=$ custo financeiro de investimento na máquina (custo de juro) [R\$];

$C_{\text {DEPRECIAÇ̃̃o }}=$ custo de depreciação de máquina [R $\$$ ];

$C_{\text {MANUTENÇÃOPREVENTIVA }}=$ custo de manutenção corretiva, preventiva e preditiva [R $\$$ ];

$C_{E S P A C ̧ O}=$ custo de espaço $[\mathrm{R} \$]$.

Para o custo de energia tem-se a fórmula:

$$
C_{\text {ENERGIA }}=P O T \times \text { tempo } \times C_{\text {energia } / H O R A}
$$

em que:

$P O T=$ potência consumida (elétrica, hidráulica, ar comprimido, etc.) [kW];

tempo $=$ tempo total de uso de energia $[\mathrm{h}]$; 
$C_{\text {energia }_{\text {HORA }}}=$ custo de energia $[\mathrm{R} \$ / \mathrm{kW} . \mathrm{h}]$.

Para o custo de ferramenta tem-se a fórmula:

$$
C_{\text {FERRAMENTAL }}=\left\lfloor\left(C_{\text {DEPRECIAÇÃO }}+C_{\text {TROCA }}+C_{\text {AFIAÇÃO }}\right) \times I R P\right\rfloor[\mathrm{R} \$]
$$

em que:

$C_{\text {DEPRECIAÇÃO }}=$ custo de depreciação de ferramenta $[\mathrm{R} \$]$;

$C_{\text {TROCA }}=$ custo de troca de ferramenta [R $\left.\$\right]$;

$C_{A F I A C ̧ \tilde{A} O}=$ custo de afiação de ferramenta $[\mathrm{R} \$]$;

$I R P=$ índice de rateio de peça $[\mathrm{R} \$]$.

O custo de montagem é dado pela fórmula:

$$
C_{\text {MONTAGEM }}=\left(\frac{C_{\text {MONTAGEMunitário }} \times n m}{n p}\right)[\mathrm{R} \$]
$$

em que:

$C_{\text {MONTAGEMunitário }}=$ custo de uma montagem do produto $[\mathrm{R} \$]$;

$n m$ = número de montagens efetuadas no mês [ - ];

$n p$ = quantidade produzida no mês de uma determinada peça [ - ].

O custo unitário de montagem, por sua vez, é dado por:

$$
C_{\text {MONTAGEMunitário }}=C_{\text {MÃO-DE-OBRAmontador }} \times t_{\text {MONTAGEM }}
$$

em que:

$C_{M \tilde{A} O-D E-O B R A m o n t a d o r}=$ custo da mão-de-obra do montador $[\mathrm{R} \$ / \mathrm{h}]$;

$t_{\text {MONTAGEM }}=$ tempo utilizado na montagem $[\mathrm{h}]$.

O custo de mão-de-obra do montador, por sua vez, é dado por:

$$
C_{\text {MÃO-DE-OBRAmontador }}=\left(\frac{C_{\text {SALÁRIOmontador }}}{I U M O}\right)[\mathrm{R} \$]
$$

em que: 
$C_{\text {SALÁRIOmontador }}=$ salário - hora do montador (custo de mão-de-obra do operador) $[\mathrm{R} \$ / \mathrm{h}]$

IUMO = índice de utilização de mão-de-obra [ - ].

O custo de ajustagem, é dado pela fórmula:

$$
C_{\text {AJUSTAGEM }}=\left(\frac{\sum_{i=1}^{n A J U S T A G E M} C_{\text {AJUSTAGEMindividual }}}{n p}\right)[\mathrm{R} \$]
$$

em que:

$\sum C_{\text {AJUSTAGEMindividual }}=$ somatório dos custos individuais das ajustagens no mês [R\$]; $n p$ = quantidade produzida no mês de uma determinada peça [ - ].

O custo de ajustagem individual, por sua vez, é dado por:

$$
C_{\text {AJUSTAGEMidividual }}=C_{\text {MÃO-DE-OBRAajustador }} \times t_{\text {AJUSTAGEM }}[\mathrm{R} \$]
$$

em que:

$C_{\text {MÃO-DE-OBRAajustador }}=$ custo da mão-de-obra do ajustador $[\mathrm{R} \$ / \mathrm{h}]$;

$t_{\text {AJUSTAGEM }}=$ tempo utilizado na ajustagem $[\mathrm{h}]$.

O custo de mão-de-obra do ajustador, por sua vez, é dado por:

$$
C_{\text {MÃO-DE-OBRAajustador }}=\left(\frac{C_{\text {SALÁRIOajustador }}}{I U M O}\right)[\mathrm{R} \$]
$$

em que:

$C_{\text {SALÁRIOajustador }}=$ salário/hora do ajustador (custo de mão-de-obra do operador) $[\mathrm{R} \$ / \mathrm{h}]$

$I U M O$ = índice de utilização de mão-de-obra [ - ].

O custo de controle de qualidade é dado pela fórmula: 


$$
C_{\text {CONT.QUALIDADE }}=\left(\frac{C_{\text {CONT.QUALIDADE.Unitário }} \times n c q+C_{\text {DEPRECIAÇÃO.DISPOSITIVO.CQ }}}{n p}\right)[\mathrm{R} \$]
$$

em que:

$C_{\text {CONT QUALIDADE }}=$ custo do controle de qualidade $[\mathrm{R} \$]$;

$C_{\text {CONT.QUALIDADE.Unitário }}=$ custo unitário do controle de qualidade $[\mathrm{R} \$]$;

$n c q$ = número de controles de qualidade efetuados no mês [ - ];

$C_{\text {DEPRECIAÇÃo.DISPOSITIVOCQ }}=$ custo de depreciação do dispositivo de controle de qualidade $[\mathrm{R} \$]$;

$n p$ = quantidade produzida no mês de uma determinada peça [ - ].

O custo de controle de qualidade unitário, por sua vez, é dado por:

$$
C_{\text {CONT.QUALIDADE.Unitario }}=C_{\text {MÃo-DE-OBRA.CONTROLADOR.Q }} \times t_{\text {CONTROLE.QUALIDADE }}[\mathrm{R} \$]
$$

em que:

$C_{\text {MÃO-DE-OBRA.CONTROLADOR.Q }}=$ custo da mão-de-obra do controlador de qualidade $[\mathrm{R} \$ / \mathrm{h}]$

$t_{\text {CONTROLE.QUALIDADE }}=$ tempo utilizado no controle de qualidade [ - ].

O custo de mão-de-obra do controlador de qualidade, por sua vez, é dado por:

$$
C_{\text {MÃO-DE-OBRA.CONTROLADOR.Q }}=\left(\frac{C_{\text {SALÁRIO.CONTROLADOR.Q }}}{I U M O}\right)[\mathrm{R} \$]
$$

em que:

$C_{\text {SALÁRIO.CONTROLADOR.Q }}=$ salário - hora do controlador de qualidade (como custo de mão-de-obra do operador) [R $\$ / h]$;

IUMO = índice de utilização de mão-de-obra [ - ].

O custo de controle de embalagem é dado pela fórmula:

$$
C_{\text {EMBALAGEM }}=\left(\frac{C_{\text {EMBALAGEM Unitário }} \times n e}{n p}\right) \quad[\mathrm{R} \$]
$$


em que:

$C_{\text {EMBALAGEM .Unitário }}=$ custo unitário da embalagem $[\mathrm{R} \$]$;

$n e=$ número de embalagens efetuadas no mês [ - ];

$n p=$ quantidade produzida no mês de uma determinada peça [ - ].

O custo de embalagem unitário, por sua vez, é dado por:

$$
C_{E M B A L A G E M . \text { Unitário }}=C_{M \tilde{A} O-D E-O B R A . E M B A L A D O R} \times t_{\text {EMBALAGEM }}[\mathrm{R} \$]
$$

em que:

$C_{M \tilde{A} O-D E-O B R A . E M B A L A D O R}=$ custo da mão-de-obra do embalador $[\mathrm{R} \$ / \mathrm{h}]$;

$t_{\text {EMBALAGEM }}=$ tempo utilizado na embalagem [ - ].

O custo de mão-de-obra do embalador, por sua vez, é dado por:

$$
C_{M \tilde{A} O-D E-O B R A . E M B A L A D O R}=\left(\frac{C_{\text {SALÁRIO.EMBALADOR }}}{I U M O}\right)[\mathrm{R} \$]
$$

em que:

$C_{\text {SALÁRIO.EMBALADOR }}=$ salário - hora do embalador (como custo de mão-de-obra do operador) $[\mathrm{R} \$ / \mathrm{h}]$;

IUMO = índice de utilização de mão-de-obra [ - ].

O custo de controle de despacho é dado pela fórmula:

$$
C_{\text {DESPACHO }}=\left(\frac{C_{\text {DESPACHO.EMBALAGEM.Unitário }} \times n d}{n p}\right)[\mathrm{R} \$]
$$

em que:

$C_{\text {DESPACHO.EMBALAGEM.Unitário }}=$ custo do despacho de uma embalagem (unitário) [R $\$$;

nd = número de embalagens despachadas no mês [ - ];

$n p=$ quantidade produzida no mês de uma determinada peça [ - ].

O custo de despacho unitário, por sua vez, é dado por: 
$C_{\text {DESPACHO.EMBALAGEM.Unitário }}=C_{\text {MÃO-DE-OBRA.DESPACHADOR }} \times t_{\text {DESPACHO }}[\mathrm{R} \$]$

em que:

$C_{\text {MÃO-DE-OBRA.DESPACHADOR }}=$ custo da mão-de-obra do despachador $[\mathrm{R} \$ / \mathrm{h}]$;

$t_{\text {DESPACHO }}=$ tempo utilizado no despacho [ - ].

O custo de mão-de-obra do despachador, por sua vez, é dado por:

$$
C_{\text {MÃO-DE-OBRA.DESPACHADOR }}=\left(\frac{C_{\text {SALÁRIO.DESPACHADOR }}}{I U M O}\right)[\mathrm{R} \$]
$$

em que:

$C_{\text {SALÁRIO.DESPACHADOR }}=$ salário - hora do despachador (como custo de mão-de-obra do operador) $[\mathrm{R} \$ / \mathrm{h}]$;

IUMO = índice de utilização de mão-de-obra [ - ].

\subsubsection{Custo fixo de produção}

O custo fixo de produção pertence ao grupo dois da formulação de custo sugerida pela SOCIETY OF MANUFACTURING ENGINEERS (1965). Esta parcela de custo não faz parte do escopo do trabalho que pretende estudar apenas a manufatura. No entanto, apresenta-se a fórmula de custo fixo de produção a seguir:

$$
C_{\text {FIXO.PRODUÇÃO }}=\left(\begin{array}{l}
C_{\text {MATERIAL.INDIRETO }}+C_{\text {SALÁRIO.INDIRETO }}+C_{\text {CONSERVAÇÃO }}+ \\
C_{\text {DEPRECIAÇÃO }}+C_{\text {SEGUROS }}+C_{\text {IMPOSTOS }}+C_{\text {INSUMOS }}+ \\
C_{\text {PERDA.MATÉRIA.PRIMA }}+C_{\text {TRANSPORTE.INDIRETO }}+C_{\text {LAYOUT }}
\end{array}\right) \times I R M[\mathrm{R} \$]
$$

em que:

$C_{\text {MATERIAL.INDIRETO }}=$ custo de materiais indiretos $[\mathrm{R} \$]$; abrange os custos de lubrificantes, parafusos e outros artigos de consumo geral ou que entram na produção em proporções diminutas e indefinidas.

$C_{\text {SALÁRIO.INDIRETO }}=$ custo dos salários indiretos $[\mathrm{R} \$]$; abrange os salários mensais da equipe envolvida com a produção, mas que não constitui a mão-de-obra diretamente ali utilizada. Entre os profissionais envolvidos neste item destacam-se: 
gerente de fábrica, supervisor de produção, programador de produção, planejador de produção, mestre, equipe de manutenção (mecânico, eletricista, etc.), equipe de limpeza, responsável pelo transporte, conservação e distribuição de materiais, calculista, projetista e desenhista, apontador, engenheiros de fabricação, etc.

$C_{\text {CONSERVAÇ̃̃o }}=$ custo de conservação $[\mathrm{R} \$]$; abrange os seguintes itens de custo: manutenção corretiva de máquinas, manutenção predial, manutenção de equipamentos de movimentação e armazenamento de material, manutenção de equipamentos de suporte (caldeira, compressor, transformador, etc.).

$C_{\text {DEPRECIAÇ̃̃o }}=$ custo de depreciação $[\mathrm{R} \$]$;

$C_{\text {SEGUROS }}=$ custo de seguros $[\mathrm{R} \$]$;

$C_{\text {IMPOSTOS }}=$ custo de impostos [R $\$$ ]; abrange os impostos não incidentes sobre a folha de pagamento, mas principalmente aqueles que são baseados no faturamento e lucro da empresa, bem como impostos de valor fixo, como o imposto predial e outros.

$C_{\text {INSUMOS }}=$ custo de insumos (eletricidade, água, vapor, energia hidráulica) $[\mathrm{R} \$]$;

$C_{\text {PERDA.MATÉRIA.PRIMA }}=$ custo de perda de matéria-prima $[\mathrm{R} \$]$; não inclui a perda de matéria-prima por refugo, mas aquela que é perdida na forma de retalho e sobras não utilizáveis.

$C_{\text {TRANSPORTE.INDIRETO }}=$ custo de transporte interno $[\mathrm{R} \$]$; abrange principalmente os custos operacionais dos equipamentos de movimentação e armazenamento de materiais.

$C_{\text {LAYOUT }}=$ custo de alteração de layout $[\mathrm{R} \$]$. 


\subsubsection{Custo de inventário de produção}

O custo de inventário de produção pertence ao grupo dois da formulação de custo sugerida pela SOCIETY OF MANUFACTURING ENGINEERS (1965). Esta parcela de custo não faz parte do escopo do trabalho que pretende estudar apenas a manufatura (fabricação).

\section{$C_{\text {INVENTÁRIO.PRODUÇÃO }}=$ custo de inventário de produção $[\mathrm{R} \$]$}

Após a apresentação do modelo de custo da SME neste capítulo apresenta-se a seguir um capítulo referente aos procedimentos de modelagem dos sistemas de manufatura. 


\section{CAPÍTULO 4 - PROCEDIMENTOS DE MODELAGEM DE SISTEMAS DE} MANUFATURA

\subsection{Generalidades}

Como foi comentado no capítulo 1, depois de adotado um modelo de custo para o trabalho, faz-se necessária a aplicação deste modelo nos sistemas de manufatura. Os sistemas de manufatura escolhidos para aplicação foram o funcional e o celular, pois os dois são largamente utilizados nas empresas. As atividades de cada um destes sistemas devem ser conhecidas para o processo de modelagem, sendo que - $A B C$ será adotado. Por fim, os pré-requisitos de modelagem, relatados no capítulo 1 , devem ser considerados.

Este capítulo tem o objetivo de apresentar estas idéias. Resumidamente tem-se, que tais procedimentos são:

1. adotar um único modelo de custo dentre os existentes;

2. identificar o escopo de aplicação do modelo de custo adotado;

3. adotar um ou mais sistemas de manufatura a serem estudados;

4. identificar as atividades custeáveis do(s) sistema(s) de manufatura adotado(s);

5. identificar os pré-requisitos necessários à modelagem ;

6. aplicar em modelos de simulação;

7. adotar um software de simulação;

8. planejar o experimento. 


\subsection{Escopo de aplicação do modelo de custo}

O modelo de custo apresentado no capítulo anterior é composto de quatro custos principais. A fórmula global para este modelo é dada pela fórmula ( 1 ):

$$
C_{\text {REAL }}=C_{\text {MANUFATURA }}+C_{\text {ENGENHARIA }}+C_{\text {DISTRIBUIÇÃo }}+C_{\text {ADMINISTRATIVO }}[\mathrm{R} \$]
$$

em que:

$C_{\text {MANUFATURA }}=$ custo de manufatura $[\mathrm{R} \$]$;

$C_{\text {ENGENHARIA }}=$ custo de engenharia $[\mathrm{R} \$]$;

$C_{\text {DISTRIBUIÇÃO }}=$ custo de distribuição $[\mathrm{R} \$]$;

$C_{\text {ADMINISTRATIVO }}=$ custos de administração $[\mathrm{R} \$]$.

Para o escopo do trabalho considerar-se-á apenas os custos de manufatura do modelo de custo da SOCIETY OF MANUFACTURING ENGINEERS (1965), que é dado pela fórmula ( 2 ):

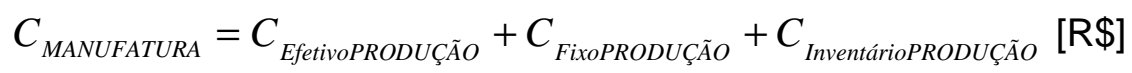

em que:

$C_{\text {EfetivoPRODUÇÃo }}=$ custo efetivo de produção [R\$];

$C_{\text {FixoPRODUÇÃo }}=$ custo fixo de produção $[\mathrm{R} \$] ;$

$C_{\text {InventárioPRODUÇÃO }}=$ custo de inventário de produção $[\mathrm{R} \$]$.

Devido à existência de um grande número de custos dentro da manufatura, o presente trabalho considerar-se-á apenas o custo efetivo de produção, conforme a fórmula ( 3 ) resumida abaixo:

$$
C_{\text {MANUFATURA }}=C_{\text {EfetivoPRODUÇÃo }}[\mathrm{R} \$]
$$

O custo efetivo de produção, por sua vez, é dado pela fórmula ( 4 ):

$$
C_{\text {EfetivoPRODUÇÃO }}=\left(\frac{C_{\text {PRODUÇÃO }}}{\eta_{\text {PRODUÇÃO }}}\right)[\mathrm{R} \$]
$$


em que:

$C_{\text {PRODUÇÃO }}=$ custo de produção $[\mathrm{R} \$]$;

$\eta_{P R O D U C ̧ \tilde{A} O}=$ rendimento da produção [ - ].

O custo de produção, por sua vez, é dado conforme a fórmula ( 5 ):

$C_{\text {PRODUÇÃO }}=C_{\text {VARIÁVEL }}+C_{\text {MONTAGEM }}+C_{\text {AJUSTAGEM }}+C_{\text {CONTQUAL }}+C_{\text {EMBALAGEM }}+C_{\text {DESPACHO }}$ $[R \$$,

em que:

$C_{\text {VARIÁVEL }}=$ custo variável $[\mathrm{R} \$]$;

$C_{\text {MONTAGEM }}=$ custo de montagem do produto $[\mathrm{R} \$]$;

$C_{\text {AJUSTAGEM }}=$ custo de ajustagem da máquina $[\mathrm{R} \$]$;

$C_{\text {CONTQUAL }}=$ custo de controle de qualidade $[\mathrm{R} \$]$;

$C_{E M B A L A G E M}=$ custo de embalagem [R $\$$;

$C_{D E S P A C H O}=$ custo de despacho $[\mathrm{R} \$]$.

Novamente pela existência de um grande número de custos, no presente trabalho considerar-se-á apenas o custo variável e o custo de ajustagem. Assim tem-se a fórmula ( 6 ) resumida abaixo:

$$
C_{\text {PRODUÇÃO }}=C_{\text {VARIÁVEL }}+C_{\text {AJUSTAGEM }}[\mathrm{R} \$]
$$

O custo variável é dado conforme a fórmula ( 7 ):

$$
C_{\text {VARIÁVEL }}=\left[\frac{\left(t p p \times\left(C_{\text {MÁQUINA }}+C_{\text {ENERGIA }}+C_{\text {MÃO-DE-OBRA }}\right)+C_{\text {FERRAMENTAL }}+C_{\text {MATERIAL }}\right)}{\eta_{\text {RETRABALHO }} \times \eta_{\text {REFUGO }}}\right]
$$

[R\$]

em que:

tpp = total de peças produzidas [ - ];

$C_{\text {MÁQUINA }}=$ custo de máquina $[\mathrm{R} \$]$; 
$C_{\text {ENERGIA }}=$ custo de energia $[\mathrm{R} \$]$;

$C_{M \tilde{O} O-D E-O B R A}=$ custo de mão-de-obra [R\$];

$C_{\text {FERRAMENTAL }}=$ custo de ferramental $[\mathrm{R} \$]$;

$C_{\text {MATERIAL }}=$ custo de material $[\mathrm{R} \$]$;

$\eta_{\text {RETRABALHO }}=$ rendimento de retrabalho [ - ];

$\eta_{\text {REFUGO }}=$ rendimento de refugo [ - ].

O custo de mão-de-obra, por sua vez, é dado conforme a fórmula ( 8 ):

$$
C_{\text {MÃO-DE-OBRA }}=C_{\text {SALARIO }}+C_{\text {ADICIONAIS }}+C_{\text {INCENTIVOS }}+C_{\text {ENCARGOS }}[\mathrm{R} \$]
$$

em que:

$C_{\text {SALARIO }}=$ custo de salário $[\mathrm{R} \$]$;

$C_{\text {ADICIONAIS }}=$ custo de adicionais $[\mathrm{R} \$]$;

$C_{\text {INCENTIVOS }}=$ custo de incentivos $[\mathrm{R} \$]$;

$C_{\text {ENCARGOS }}=$ custo de encargos $[\mathrm{R} \$]$.

Para o custo de máquina tem-se a fórmula ( 9 ):

$$
C_{\text {MÁqUINA }}=C_{\text {JURO }}+C_{\text {DEPRECIAÇ̄̃o }}+C_{\text {MANUTENÇ̃̃o }}+C_{\text {ESPAÇO }} \quad[\mathrm{R} \$]
$$

em que:

$C_{\text {JURO }}=$ custo financeiro de investimento na máquina (custo de juro) [R\$];

$C_{\text {DEPRECIAÇ̃̃o }}=$ custo de depreciação de máquina $[\mathrm{R} \$]$;

$C_{\text {MANUTENÇ̃OPREVENTIVA }}=$ custo de manutenção corretiva, preventiva e preditiva [R $\left.\$\right]$;

$C_{E S P A C ̧ O}=$ custo de espaço $[\mathrm{R} \$]$.

Para o custo de energia tem-se a fórmula ( 10 ):

$$
C_{\text {ENERGIA }}=P O T \times \text { tempo } \times C_{\text {energia }_{\text {HOORA }}}
$$

em que:

$P O T$ = potência consumida (elétrica, hidráulica, ar comprimido, etc.) [kW]; 
tempo $=$ tempo total de uso de energia $[\mathrm{h}]$;

$C_{\text {energia }_{/ H O R A}}=$ custo de energia $[\mathrm{R} \$ / \mathrm{kW} . \mathrm{h}]$.

Para o custo de ferramenta tem-se a fórmula ( 11 ):

$$
C_{\text {FERRAMENTAL }}=\left\lfloor\left(C_{\text {DEPRECIAÇ̃̃O }}+C_{\text {TROCA }}+C_{\text {AFIAÇÃO }}\right) \times I R P\right\rfloor[\mathrm{R} \$]
$$

em que:

$C_{\text {DEPRECIAÇÃO }}=$ custo de depreciação de ferramenta $[\mathrm{R} \$]$;

$C_{\text {TROCA }}=$ custo de troca de ferramenta $[\mathrm{R} \$]$;

$C_{A F I A C ̧ A ̃ O}=$ custo de afiação de ferramenta $[\mathrm{R} \$]$;

$I R P$ = índice de rateio de peça [ - ].

O custo de ajustagem é dado conforme a fórmula ( 12 ):

$$
C_{\text {AJUSTAGEM }}=\left(\frac{\sum_{i=1}^{n A J U S T A G E M} C_{\text {AJUSTAGEMINDIVIDUAL }}}{n p}\right)[\mathrm{R} \$]
$$

em que:

$\sum C_{\text {AJUSTAGEMindividual }}=$ somatório dos custos individuais das ajustagens no mês [R $\$$ ]; $n p$ = quantidade produzida no mês de uma determinada peça [ - ].

O custo de ajustagem individual, por sua vez, é dado pela fórmula ( 13 ):

$$
C_{\text {AJUSTAGEMidividual }}=C_{\text {MÃO-DE-OBRAajustador }} \times t_{\text {AJUSTAGEM }}[\mathrm{R} \$]
$$

em que:

$C_{M \tilde{A} O-D E-O B R A a j u s t a d o r}=$ custo da mão-de-obra do ajustador $[\mathrm{R} \$ / \mathrm{h}]$;

$t_{\text {AJUSTAGEM }}=$ tempo utilizado na ajustagem [ - ].

O custo de mão-de-obra do ajustador, por sua vez, é dado pela fórmula ( 14 ): 


$$
C_{\text {MÃODEOBRAajustador }}=\left(\frac{C_{\text {SALÁRIOajustador }}}{I U M O}\right)[\mathrm{R} \$]
$$

em que:

$C_{\text {SALÁRIOajustador }}=$ salário/hora do ajustador (custo de mão-de-obra do operador) $[\mathrm{R} \$ / \mathrm{h}]$

IUMO = índice de utilização de MÃO-DE-OBRA [ - ].

Observação: O custo de material está diretamente relacionado com o custo da matéria-prima. Portanto, a quantidade (volume) de matéria-prima usada na manufatura é diretamente proporcional ao custo de material. As fórmulas para o rendimento de refugo, o rendimento de retrabalho e também o índice de utilização de mão-de-obra ( IUMO ), encontram-se no capítulo 3 deste trabalho.

Sendo assim, levando-se em consideração o escopo do trabalho (apenas na manufatura ou fabricação), o modelo de custo da SOCIETY OF MANUFACTURING ENGINEERS (1965) resume-se aos custos ilustrados em destaque na figura 15 a seguir: 


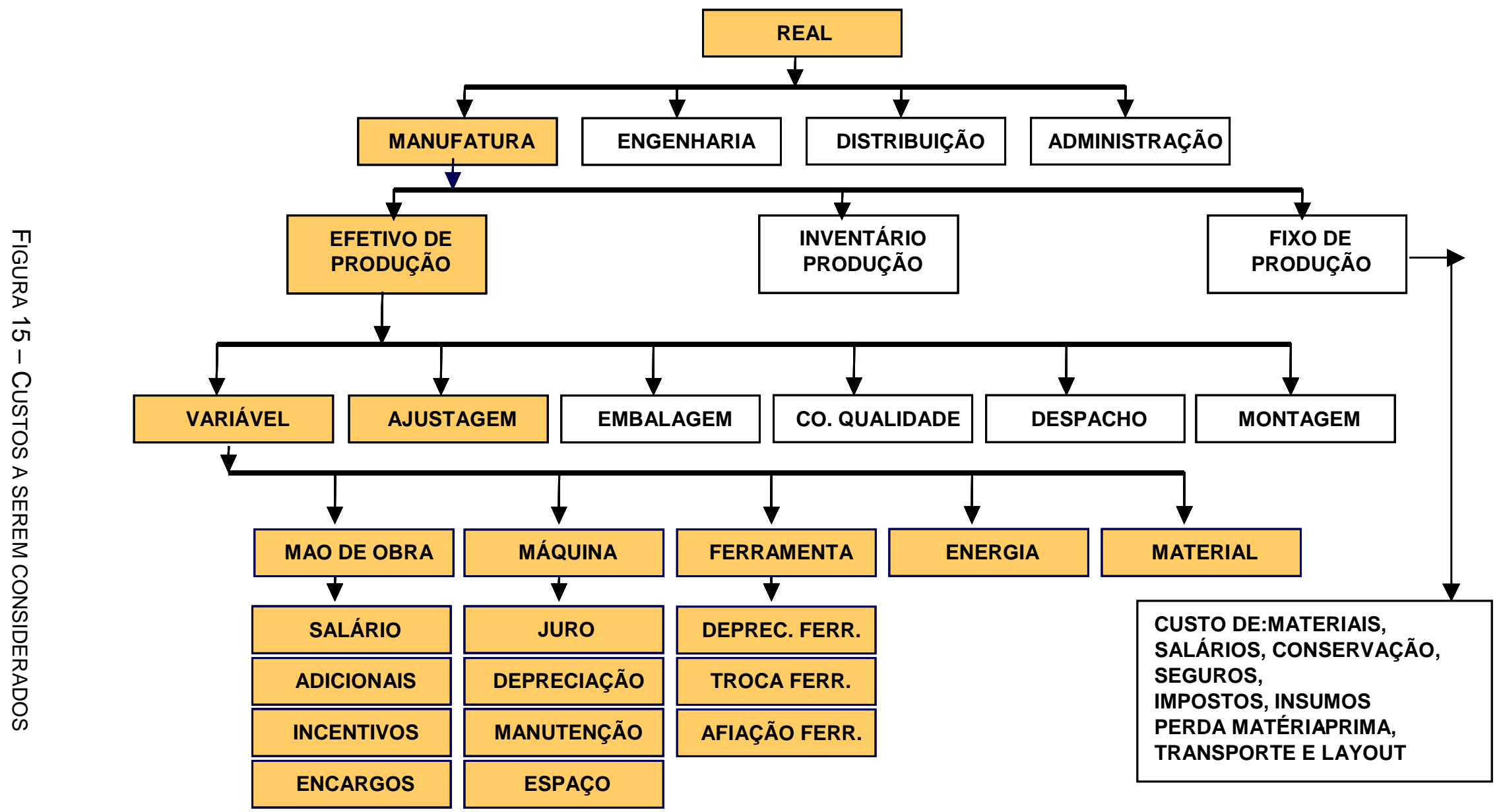




\subsection{Sistemas de manufatura a serem estudados}

Para escopo deste trabalho aplica-se o modelo de custo em dois sistemas de manufatura: Com arranjo físico funcional e com arranjo físico celular.

Sabe-se que na configuração celular, fatores geradores de custos podem ser considerados dentro de um modelo. Fatores como o custo total de investimento, custo de mão-de-obra direta, custo de reorganização do chão-de-fábrica (reorganização do layout), custo de mão-de-obra indireta, custo de trabalho em processo (work-in-process), custo de setup, custo de energia, etc, podem ser incluídos no modelo de custo. Porém, um modelo de custo que permite incluir todos estes custos encontraria dificuldades na obtenção de dados, (NEEDY et al 1998).

Desta forma para a modelagem do sistema celular serão identificadas apenas algumas atividades custeáveis que serão detalhadas posteriormente. O mesmo procedimento será adotado para a modelagem do sistema. É importante ressaltar que, GONÇALVES FILHO (2001), BLACK (1998), SLACK et al. (1997), FRANCISCHINI \& FEGYVERES (1997) e CHIAVENATO (1991), comentam que as características dos dois sistemas devem ser obedecidas.

\subsection{As atividades dos sistemas funcional e celular}

Para os dois sistemas, pode-se determinar as atividades existentes e posteriormente identificar seus respectivos direcionadores de custo. Com os direcionadores de custos pode-se fazer medidas e, assim, determinar-se os custos existentes.

Este trabalho segue o princípio do $A B C$ e a filosofia de GUNASEKARAN \& SARHADI (1998), comentada no capítulo 2, que identifica primeiramente as atividades e posteriormente procura custeá-las segundo seus direcionadores de custo.

Os custos finais que serão medidos devem estar presentes no modelo de custo da SOCIETY OF MANUFACTURING ENGENEERS (1965) e também presentes no escopo de aplicação do modelo, o qual foi definido no item 4.2 deste capítulo e ilustrado na figura 15. 
As tabelas 01 e 02 ilustram as atividades custeáveis de cada sistema de manufatura, os respectivos direcionadores de custo, e o seu custo associado. Tal custo associado deve pertencer ao modelo de custo da SOCIETY OF MANUFACTURING ENGENEERS (1965). Dentro das atividades relacionadas, temse: atividades produtivas, como por exemplo, o processamento (usinagem), setup (preparação) e manuseio de materiais e também as atividades de suporte, como por exemplo, a espera em fila, o transporte dentro do sistema, etc.

Para o sistema funcional as atividades são:

Tabela 01 - Atividades/Direcionadores do Arranjo físico funcional

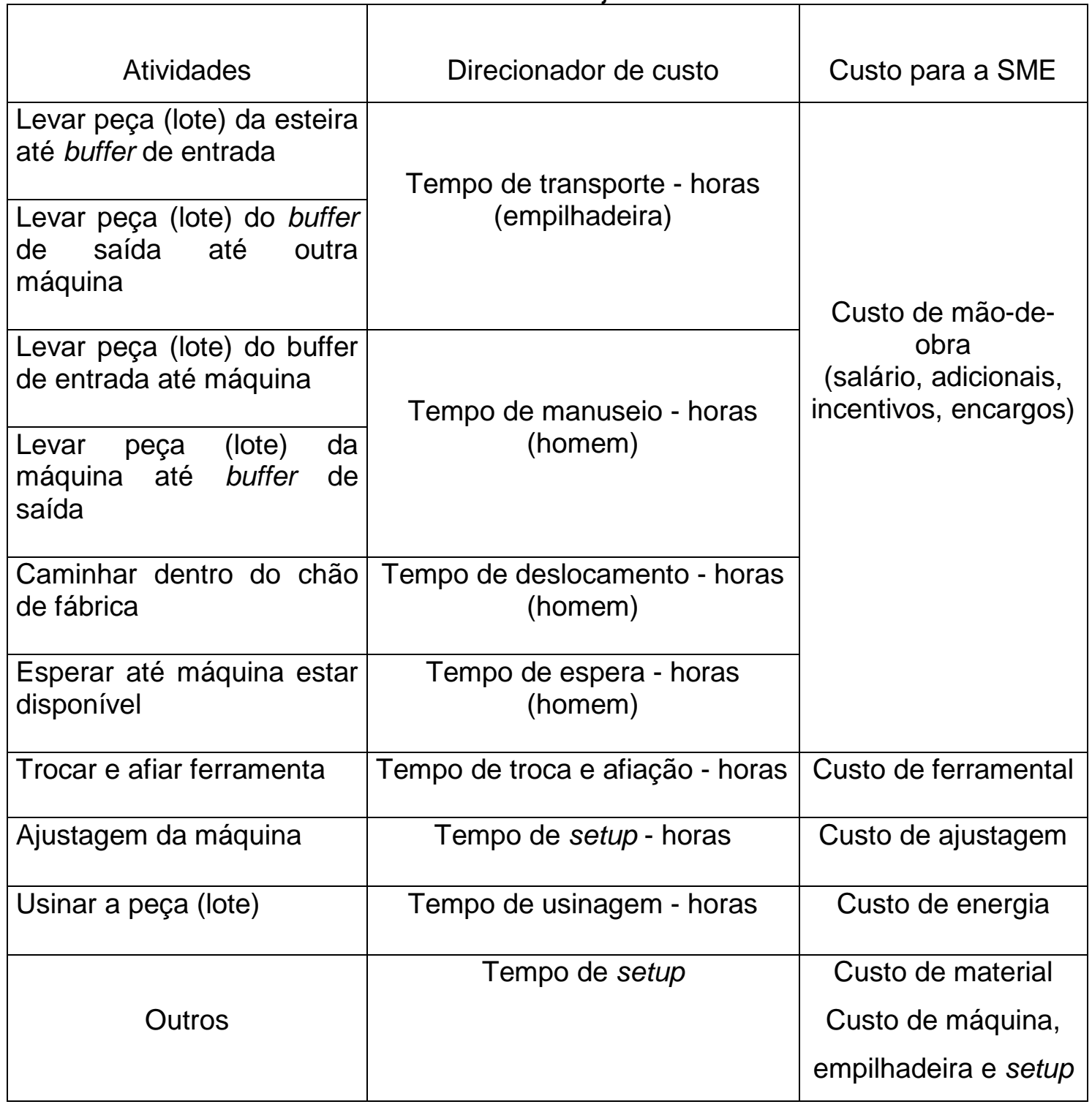


Para o sistema celular as atividades são:

Tabela 02 - Atividades/Direcionadores do Arranjo físico celular

\begin{tabular}{|c|c|c|}
\hline Atividades & Direcionador de custo & Custo para a SME \\
\hline $\begin{array}{l}\text { Transporte da peça (unitária) } \\
\text { na esteira da célula }\end{array}$ & $\begin{array}{l}\text { Tempo de transporte - horas } \\
\text { (homem) }\end{array}$ & $\begin{array}{l}\text { Custo de mão-de-obra } \\
\text { (salário, adicionais, } \\
\text { incentivos, encargos) }\end{array}$ \\
\hline Usinar a peça (unitária) & Tempo de usinagem - horas & Custo de energia \\
\hline Trocar e afiar ferramenta & $\begin{array}{c}\text { Tempo de troca e afiação - } \\
\text { horas }\end{array}$ & $\begin{array}{l}\text { Custo de ferramental e } \\
\text { MÃO-DE-OBRA }\end{array}$ \\
\hline Ajustagem da máquina & Tempo de ajustagem - horas & $\begin{array}{l}\text { Custo de ajustagem e } \\
\text { MÃO-DE-OBRA }\end{array}$ \\
\hline \begin{tabular}{|l|} 
Levar peça (unitária) da \\
esteira até máquina
\end{tabular} & \multirow{2}{*}{$\begin{array}{l}\text { Tempo de manuseio - horas } \\
\text { (homem) }\end{array}$} & \multirow{3}{*}{$\begin{array}{l}\text { Custo de mão-de-obra } \\
\text { (salário, adicionais, } \\
\text { incentivos, encargos) }\end{array}$} \\
\hline $\begin{array}{l}\text { Levar peça (unitária) da } \\
\text { máquina até a esteria }\end{array}$ & & \\
\hline $\begin{array}{l}\text { Esperar até máquina estar } \\
\text { disponível }\end{array}$ & $\begin{array}{c}\text { Tempo de espera - horas } \\
\text { (homem) }\end{array}$ & \\
\hline Outros & Tempo de setup & $\begin{array}{c}\text { Custo de material } \\
\text { Custo de máquina, } \\
\text { empilhadeira e de setup }\end{array}$ \\
\hline
\end{tabular}

\subsection{Pré-requisitos da modelagem}

Tendo-se o modelo de custo da SOCIETY OF MANUFACTURING ENGINEERS (1965), e as atividades custeáveis do sistema celular e funcional definidas, deve-se estabelecer, para a modelagem, alguns pré-requisitos necessários. Estes prérequisitos comentados no capítulo 1 estão relacionados ao processo de fabricação da peça, ao arranjo físico, ao sistema de custo e a programação da produção. Tais pré-requisitos fazem parte de uma primeira etapa da modelagem, assim como também, o estudo do software de simulação e estudo dos sistemas de manufatura enumerados. 
Quanto ao processo de fabricação da peça (máquina, operação, tempo de usinagem, tempo de setup) a modelagem deve possuir flexibilidade quanto à definição da quantidade de peças e de lote de peças que se quer produzir e quanto aos processos de fabricação que se deseja seguir. Para o caso específico do arranjo físico celular, o sistema deve ser independente também da quantidade de famílias. Tais famílias devem seguir o conceito de tecnologia de grupo abordado no capítulo 2.

Quanto ao arranjo físico, a modelagem deve ser capaz de representar as atividades típicas, específicas do tipo de arranjo a ser adotado. Todas as características particulares de cada arranjo físico devem ser possíveis de ser representadas (modeladas).

Quanto ao custo, a formulação de custo a ser adotada da SOCIETY OF MANUFACTURING ENGINEERS (1965), deve englobar as atividades geradoras de custo dos sistemas de manufatura a serem estudados.

Quanto à programação da produção, a modelagem deve possuir um caráter de flexibilidade quanto à quantidade de processos e quanto à ordem destes processos. Para o caso específico do arranjo físico celular, o sistema deve ser independente também da ordem de entrada das famílias.

Em uma segunda etapa da modelagem, tem-se a utilização de dados de entrada para os modelos, onde os resultados obtidos com a simulação devem fornecer análises quanto à proposta inicial do trabalho. Desta forma, durante a realização do estudo, as alterações dos dados de entrada podem ocorrer, sendo que os modelos de simulação serão capazes de medir as atividades da mesma forma. Os prérequisitos citados anteriormente serão incorporados no estudo e na aplicação da simulação.

\subsection{Proposta de aplicação em modelos de Simulação}

Os modelos de simulação à serem criados devem incorporar todos os prérequisitos de modelagem e todas as atividades geradoras de custo dos sistemas de manufatura. Um modelo de simulação representará um arranjo físico funcional e 
outro modelo representará um arranjo físico celular. Os modelos geram resultados na forma de tempos, que serão traduzidos na forma de custo.

Como comentado por BANKS (1996) modelos de simulação possuem uma classificação. Os modelos a serem criados possuem classificação de matemáticos, dinâmicos, determinísticos e discretos. Recursos como homem, máquina, empilhadeiras, filas e esteiras transportadoras devem ser utilizados.

\subsubsection{Variáveis do sistema}

O modelo funcional e o modelo celular podem possuir variáveis específicas. A tabela 03 ilustra estas variáveis e o respectivo pré-requisito associado.

Tabela 03 - Variáveis dos modelos

\begin{tabular}{|c|c|l|}
\hline Layout & $\begin{array}{c}\text { Pré-requisito de } \\
\text { modelagem quanto à: }\end{array}$ & \multicolumn{1}{|c|}{ Variáveis } \\
\hline Funcional e celular & arranjo & Número de homens \\
\hline Funcional e celular & peça & Número de peças do lote \\
\hline Funcional e celular & peça & Processo de fabricação \\
\hline Funcional e celular & programação & Número de processos \\
\hline Funcional e celular & programação & Ordem de processos \\
\hline Celular & peça & Número de famílias \\
\hline Celular & programação & Ordem das famílias \\
\hline Funcional e celular & arranjo & Tempo de setup \\
\hline Funcional e celular & arranjo & Tempo de processamento \\
\hline Funcional e celular & arranjo & Número de empilhadeiras \\
\hline
\end{tabular}

\subsubsection{Base de dados}

Os dados para a construção dos modelos serão extraídos do trabalho de PORTO (1990), que apresenta uma massa de dados do processo de fabricação e o lote de várias peças, além de um conjunto de máquinas, com seus respectivos tempos de processamento para cada operação e tempos de setup. Tal conjunto de dados contém treze processos de fabricação. No entanto, serão considerados, para os modelos de simulação no máximo, oito processos de fabricação.

A tabela 04 ilustra o processo de fabricação, o lote das peças, o código das peças e o respectivo produto: 
Tabela 04 - Dados de lote/processo de fabricação.

Fonte: PORTO (1990).

\begin{tabular}{|l|c|l|l|}
\hline Peça-código & Lote & \multicolumn{1}{|c|}{ Processo de Fabricação } & \multicolumn{1}{|c|}{ Produto } \\
\hline $01-3312024$ & 112 & $23 / 23 / 13 / 13 / 35 / 35 / 45 / 57 / 57 / 62$ & engrenagem \\
\hline $05-3313378$ & 382 & $23 / 23 / 35 / 41 / 45 / 45 / 57 / 53 / 62 / 46 / 04 / 13$ & engrenagem \\
\hline $06-3313867$ & 646 & $04 / 23 / 62 / 35 / 53 / 23$ & engrenagem \\
\hline $08-3314133$ & 774 & $23 / 23 / 35 / 41 / 45 / 45 / 62 / 62 / 46 / 04 / 13$ & engrenagem \\
\hline $10-3314176$ & 816 & $23 / 23 / 27 / 35 / 41 / 45 / 45 / 04 / 13$ & engrenagem \\
\hline $11-3314652$ & 3055 & $60 / 27 / 13 / 13 / 35 / 74 / 23 / 27$ & engrenagem \\
\hline $12-3314837$ & 3314 & $04 / 27 / 13 / 57 / 74 / 41 / 23 / 27$ & engrenagem \\
\hline $13-3314896$ & 272 & $13 / 23 / 23 / 35 / 41 / 45 / 45 / 53 / 53 / 04 / 13$ & engrenagem \\
\hline
\end{tabular}

$\mathrm{Na}$ tabela 05 apresenta-se a descrição das máquinas, sua numeração, sua disponibilidade e sua quantidade.

Tabela 05 - Dados de disponibilidade/quantidade/nome de máquina.

\begin{tabular}{|r|l|c|c|c|}
\hline Máq. & \multicolumn{1}{|c|}{ Descrição } & $\begin{array}{c}\text { Quantidade } \\
\text { Máquinas }\end{array}$ & $\begin{array}{c}\text { Disponibilidade } \\
\text { Máquina horas }\end{array}$ & $\begin{array}{c}\text { Disponibilidade } \\
\text { Total horas }\end{array}$ \\
\hline 04 & Torno revolver warner & 2 & 168,75 & 337,50 \\
\hline 13 & Torno automático fay & 2 & 173,833 & 521,50 \\
\hline 23 & Torno controle numérico petra & 2 & 168,75 & 337,50 \\
\hline 27 & Brochadeira horizontal lapointe & 1 & 234,00 & 234,00 \\
\hline 35 & Fellows shaper 7a & 2 & 168,75 & 337,50 \\
\hline 38 & Lorenz shaper sn4 & 2 & 168,75 & 337,50 \\
\hline 41 & Pfauter hobber pa-300 & 2 & 168,75 & 337,50 \\
\hline 43 & Liebherr hobber 1-301 & 1 & 168,75 & 337,50 \\
\hline 45 & Chanfradora cross \#6 & 1 & 180,00 & 234,00 \\
\hline 46 & Rotary shaver red ring & 2 & 168,75 & 337,00 \\
\hline 53 & Fresadora universal milwaukee & 2 & 146,25 & 292,50 \\
\hline 57 & Fresadora horizont. kent owens & 2 & 168,75 & 337,50 \\
\hline 60 & Furadeira simples baker & 2 & 168,75 & 337,50 \\
\hline 62 & Furadeira simples fosdick & 2 & 168,75 & 337,50 \\
\hline 74 & Furadeira radial rocco & & & \\
\hline
\end{tabular}


Os tempos de processamento unitário de cada operação nas máquinas e os tempos de setup são ilustrados na tabela 06 a seguir:

Tabela 06 - Dados de processamento e setup.

Fonte: PORTO (1990).

\begin{tabular}{|c|c|c|c|c|c|c|c|c|c|c|c|c|c|}
\hline \multicolumn{14}{|c|}{ Peça } \\
\hline \multirow{3}{*}{01} & Máquina (numeração) & 23 & 23 & 13 & 13 & 35 & 35 & 45 & 57 & 57 & 62 & & \\
\hline & Processamento (seg.) & 108 & 108 & 72 & 108 & 108 & 72 & 72 & 36 & 36 & 36 & & \\
\hline & Setup (horas) & 0.90 & 0.90 & 4.00 & 4.00 & 1.00 & 1.00 & 1.00 & 0.83 & 0.83 & 1.00 & & \\
\hline \multirow{3}{*}{05} & Máquina (numeração) & 23 & 23 & 35 & 41 & 45 & 45 & 57 & 53 & 62 & 46 & 04 & 13 \\
\hline & Processamento (seg.) & 108 & 144 & 180 & 252 & 72 & 36 & 36 & 72 & 36 & 72 & 324 & 324 \\
\hline & Setup (horas) & 0.90 & 1.00 & 4.00 & 1.00 & 1.00 & 1.00 & 0.83 & 0.83 & 0.75 & 1.00 & 1.00 & 4.00 \\
\hline \multirow{3}{*}{06} & Máquina (numeração) & 04 & 23 & 62 & 35 & 53 & 23 & & & & & & \\
\hline & Processamento (seg.) & 324 & 72 & 36 & 1152 & 108 & 108 & & & & & & \\
\hline & Setup (horas) & 1.00 & 1.00 & 0.75 & 1.00 & 0.83 & 0.90 & & & & & & \\
\hline \multirow{3}{*}{08} & Máquina (numeração) & 23 & 23 & 35 & 41 & 45 & 45 & 62 & 62 & 46 & 04 & 13 & \\
\hline & Processamento (seg.) & 108 & 108 & 216 & 468 & 72 & 72 & 72 & 36 & 72 & 180 & 180 & \\
\hline & Setup (horas) & 0.90 & 0.90 & 1.00 & 1.00 & 1.00 & 1.00 & 0.75 & 0.75 & 1.00 & 0.90 & 0.90 & \\
\hline \multirow{3}{*}{10} & Máquina (numeração) & 23 & 23 & 27 & 35 & 41 & 45 & 45 & 04 & 13 & & & \\
\hline & Processamento (seg.) & 36 & 144 & 36 & 72 & 252 & 36 & 72 & 324 & 324 & & & \\
\hline & Setup (horas) & 0.90 & 0.90 & 0.75 & 1.00 & 1.00 & 1.00 & 1.00 & 1.00 & 4.00 & & & \\
\hline \multirow{3}{*}{11} & Máquina (numeração) & 60 & 27 & 13 & 13 & 35 & 74 & 23 & 27 & & & & \\
\hline & Processamento (seg.) & 36 & 36 & 72 & 72 & 108 & 72 & 108 & 36 & & & & \\
\hline & Setup (horas) & 1.00 & 0.80 & 4.00 & 4.00 & 1.00 & 0.75 & 0.90 & 0.83 & & & & \\
\hline \multirow{3}{*}{12} & Máquina (numeração) & 04 & 27 & 13 & 57 & 74 & 41 & 23 & 27 & & & & \\
\hline & Processamento (seg.) & 72 & 36 & 36 & 36 & 72 & 108 & 108 & 36 & & & & \\
\hline & Setup (horas) & 1.00 & 0.75 & 2.00 & 0.83 & 0.75 & 1.00 & 0.90 & 0.75 & & & & \\
\hline \multirow{3}{*}{13} & Máquina (numeração) & 23 & 23 & 35 & 41 & 45 & 45 & 53 & 53 & 04 & 13 & & \\
\hline & Processamento (seg.) & 72 & 72 & 324 & 432 & 36 & 72 & 72 & 72 & 324 & 180 & & \\
\hline & \begin{tabular}{|l} 
Setup (horas) \\
\end{tabular} & 0.90 & 0.90 & 1.00 & 1.00 & 1.00 & 1.00 & 0.83 & 0.83 & 1.00 & 4.00 & & \\
\hline
\end{tabular}

Nota-se na tabela 06, que a coluna um representa o número da peça, a coluna dois representa a nomenclatura dos dados. As colunas restantes contêm dados de máquina (numeração) com seu respectivo processo de fabricação, o processamento e setup realizados em cada operação. Tanto o modelo de simulação funcional quanto o modelo de simulação celular serão construídos com 
este conjunto de dados. Posteriormente, no planejamento de experimento devem ser realizadas as alterações nas variáveis dos modelos. A numeração do processo de fabricação $(01,05,06,08,10,11,12,13)$ e o conjunto de máquinas são mantidos.

\subsection{Escolha do software de simulação}

Vários softwares de simulação estão disponíveis no mercado atualmente. LOBÃO (2000) relata que este grande número de softwares existentes é conseqüência do grande desenvolvimento tecnológico e aumento do poder de processamento dos computadores pessoais. Alguns destes softwares comerciais de simulação podem ser enumerados: ARENA, PROMODEL, AUTOMOD, WITNESS, etc.

As características destes softwares de simulação, segundo LOBÃO (2000), são apresentadas a seguir:

- possuem interface gráfica de comunicação com o usuário;

- o projeto do modelo é orientado ao objeto;

- o software possui capacidade de animação do modelo;

- relatórios são fornecidos após a execução da simulação;

- possibilidade de uso das ferramentas estatísticas para tratamento dos dados utilizados na simulação, etc.

PHILLIPS (1998), afirma que o AutoMod difere dos outros softwares de simulação por lidar com elementos físicos de um sistema em termos físicos (gráficos) e elementos lógicos de um sistema em temos lógicos. Diferentemente de muitas outras linguagens de simulação, a poderosa interface gráfica do AutoMod captura com precisão as características relativas à distância, tamanho, e espaço em três dimensões. Tais características, são:

- sistema de veículos guiados automaticamente (AGVS);

- esteiras transportadoras (Conveyors);

- sistema de armazenagem automática (ASRS);

- robôs e ponte rolante;

- esteiras transportadoras do tipo Power and Free;

- sistema de desenho (Static). 
Baseado nestas características, o software adotado para o trabalho será 0 AutoMod, na versão 8.6.

\subsection{Planejamento de experimento}

Baseado nas variáveis dos modelos construídos e a base de dados, realizam-se alguns experimentos visando validar a proposta inicial deste trabalho. Tal experimento é usado também como sendo um teste de funcionamento dos modelos. Vale ressaltar que o objetivo de fazer experimentos não é comparar o sistema funcional com o sistema celular em termos de custos. Do capítulo 2 sabese que um sistema funcional possui agrupamento de funções. Assim, os experimentos do modelo funcional contêm a quantidade de homens em cada função, a quantidade de processos de fabricação, a programação da produção (ordem de chegadas), o respectivo lote de peças de cada processo, e a quantidade de empilhadeiras. Propõem-se, então, dois experimentos nas tabelas 07 e 08 :

Experimento $\mathrm{N}^{\circ} 01$ - Contém oito processos de fabricação, com suas respectivas ordens de fabricação, quantidade de peças por lote, quantidade de empilhadeiras e de homens por função. Possui também a seqüência de fabricação de cada processo e a divisão do arranjo físico em cinco funções com as quantidades de máquinas.

Tabela 07 - Dados para o experimento 1 do sistema funcional

\begin{tabular}{|c|c|c|c|c|}
\hline 8 processos & ordem & Lote & \multicolumn{2}{|c|}{ Processo de Fabricação } \\
\hline 01 & 01 & 100 & \multicolumn{2}{|c|}{23 / 23 / $13 / 13 / 35 / 35 / 45 / 57 / 57 / 62$} \\
\hline 05 & 02 & 60 & \multicolumn{2}{|c|}{$23 / 23 / 35 / 41 / 45 / 45 / 57 / 53 / 62 / 46 / 04 / 13$} \\
\hline 06 & 03 & 60 & \multicolumn{2}{|c|}{$04 / 23$ / 62 / 35 / 53 / 23} \\
\hline 08 & 04 & 50 & \multicolumn{2}{|c|}{$23 / 23 / 35 / 41 / 45 / 45 / 62 / 62 / 46 / 04 / 13$} \\
\hline 10 & 05 & 50 & \multicolumn{2}{|c|}{$23 / 23 / 27 / 35 / 41 / 45 / 45 / 04 / 13$} \\
\hline 11 & 06 & 80 & \multicolumn{2}{|c|}{$60 / 27 / 13 / 13 / 35 / 74 / 23 / 27$} \\
\hline 12 & 07 & 60 & \multicolumn{2}{|c|}{$04 / 27 / 13 / 57 / 74 / 41 / 23 / 27$} \\
\hline 13 & 08 & 40 & \multicolumn{2}{|c|}{$13 / 23 / 23 / 35 / 41 / 45 / 45 / 53 / 53 / 04 / 13$} \\
\hline \multirow{5}{*}{\multicolumn{3}{|c|}{ Quantidade de homens }} & Função torno (6 máquinas) & 02 \\
\hline & & & Função fresa (6 máquinas) & 02 \\
\hline & & & Função furadeira (6 máquinas) & 01 \\
\hline & & & Função shaper (5 máquinas) & 02 \\
\hline & & & Função hobber (4 máquinas) & 01 \\
\hline \multicolumn{3}{|c|}{ Quantidade de empilhadeiras } & \multicolumn{2}{|c|}{1 empilhadeira } \\
\hline
\end{tabular}


Experimento $\mathrm{N}^{\circ} 02$ - Contém cinco processos de fabricação, com suas respectivas ordens de fabricação, quantidade de peças por lote, quantidade de empilhadeiras e de homens por função. Possui também a seqüência de fabricação de cada processo e a divisão do arranjo físico em cinco funções com suas respectivas quantidades de máquinas.

Tabela 08 - Dados para o experimento 2 do sistema funcional

\begin{tabular}{|c|c|c|c|c|}
\hline 5 processos & ordem & Lote & \multicolumn{2}{|c|}{ Processo de Fabricação } \\
\hline 01 & 01 & 100 & \multicolumn{2}{|c|}{$23 / 23 / 13 / 13 / 35 / 35 / 45 / 57 / 57 / 62$} \\
\hline 05 & 02 & 100 & \multicolumn{2}{|c|}{$23 / 23 / 35 / 41 / 45 / 45 / 57 / 53 / 62 / 46 / 04 / 13$} \\
\hline 06 & 03 & 100 & \multicolumn{2}{|c|}{$04 / 23$ / 62 / 35 / 53 / 23} \\
\hline 08 & 04 & 100 & \multicolumn{2}{|c|}{23 / 23 / 35 / $41 / 45 / 45 / 62 / 62 / 46 / 04 / 13$} \\
\hline 10 & 05 & 100 & \multicolumn{2}{|c|}{$23 / 23 / 27 / 35 / 41 / 45 / 45 / 04 / 13$} \\
\hline \multirow{5}{*}{\multicolumn{3}{|c|}{ Quantidade de homens }} & Função torno (6 máquinas) & 02 \\
\hline & & & Função fresa (6 máquinas) & 02 \\
\hline & & & Função furadeira (6 máquinas) & 01 \\
\hline & & & Função shaper (5 máquinas) & 02 \\
\hline & & & Função hobber (4 máquinas) & 01 \\
\hline \multicolumn{3}{|c|}{ Quantidade de empilhadeiras } & \multicolumn{2}{|c|}{1 empilhadeira } \\
\hline
\end{tabular}

Com o mesmo conjunto de máquinas da base de dados ilustrada anteriormente foi possível confeccionar uma célula de fabricação com 10 máquinas. Os experimentos do modelo celular contêm a quantidade de processos de fabricação, a família do respectivo processo, a prioridade de chegada de cada família, o lote de peças de cada processo, e a quantidade de homens utilizados na célula.

Propõem-se, então, para o modelo celular, dois experimentos que seguem nas tabelas 09 e 10:

Experimento $\mathrm{N}^{\circ} 01$ - Contém oito processos de fabricação, com a identificação da respectiva família a que pertence, a prioridade de entrada de cada família, a quantidade de peças por lote de cada processo, a seqüência de fabricação de cada processo, a quantidade de homens existentes na célula e o uso de esteiras transportadoras para 0 transporte das peças. A quantidade de máquinas para 0 experimento é de 10 máquinas da base de dados. 
Tabela 09 - Dados para o experimento 1 do sistema celular

\begin{tabular}{|c|c|c|c|c|}
\hline 8 Processos & Família & Lote & Prioridade & Processo de Fabricação da célula \\
\hline 01 & 2 & 100 & 1 & $23 / 23 / 13 / 13 / 35$ \\
\hline 05 & 2 & 100 & 1 & $23 / 23 / 35 / 41$ \\
\hline 06 & 1 & 100 & 0 & $04 / 23$ \\
\hline 08 & 2 & 100 & 1 & $23 / 23 / 35 / 41$ \\
\hline 10 & 2 & 100 & 1 & $23 / 23 / 27 / 35 / 41$ \\
\hline 11 & 1 & 100 & 0 & $60 / 27 / 13 / 13 / 35$ \\
\hline 12 & 1 & 100 & 0 & $04 / 27 / 13$ \\
\hline 13 & 1 & 100 & 0 & $13 / 23 / 23 / 35 / 41$ \\
\hline \multicolumn{6}{|l}{ Quantidade de homens } & \multicolumn{3}{l}{ 3 homens na célula } \\
\hline
\end{tabular}

Experimento $\mathrm{N}^{\circ} 02$ - Contém 6 processos de fabricação, com a identificação da respectiva família a que pertence, a prioridade de entrada de cada família, a quantidade de peças por lote de cada processo, a seqüência de fabricação de cada processo, a quantidade de homens existentes na célula e o uso de esteiras transportadoras para 0 transporte das peças. A quantidade de máquinas para 0 experimento também é de 10 máquinas da base de dados.

Tabela 10 - Dados para o experimento 2 do sistema celular

\begin{tabular}{|c|c|c|c|c|}
\hline 8 Processos & Família & Lote & Prioridade & Processo de Fabricação da célula \\
\hline 06 & 3 & 120 & 2 & $04 / 23$ \\
\hline 08 & 2 & 130 & 1 & $23 / 23 / 35 / 41$ \\
\hline 10 & 1 & 150 & 0 & $23 / 23 / 27 / 35 / 41$ \\
\hline 11 & 1 & 150 & 0 & $60 / 27 / 13 / 13 / 35$ \\
\hline 12 & 3 & 125 & 2 & $04 / 27 / 13$ \\
\hline 13 & 2 & 125 & 1 & $13 / 23 / 23 / 35 / 41$ \\
\hline \multicolumn{2}{|l|}{ Quantidade de homens } & \multicolumn{3}{l}{ 1 esteira transportadora } \\
\hline
\end{tabular}

Assim têm-se os procedimentos de modelagem e os experimentos necessários na construção dos modelos de simulação. Posteriormente é necessário aplicar tais procedimentos de modelagem e experimentos buscando resultados de custo com a simulação. O capítulo 5 irá mostrar em detalhes como foram feitos os modelos do sistema funcional e celular. 


\subsection{Generalidades}

Conhecendo os procedimentos de modelagem descritos no capítulo 4, faz-se necessário, nesta etapa, a aplicação destes procedimentos em modelos de simulação. Como já comentado, os modelos geram resultados na forma de tempos capazes de serem traduzidos na forma de custo. Os tempos obtidos da simulação são os fatores de medida das atividades presentes no modelo funcional e celular. Sendo possível medir as atividades, pode-se realizar o relacionamento delas com os custos. Assim, este capítulo tem o objetivo de relatar os detalhes que envolveram a confecção dos modelos e suas características, além de analisar os resultados obtidos na forma de custos.

\subsection{Considerações sobre custos}

Algumas considerações são necessárias para a mensuração dos custos. Como já relatado, os custos a serem medidos estão ilustrados na figura 15 do capítulo 4 . As fórmulas para os cálculos destes custos estão presentes no item 4.2 do capítulo $4 \mathrm{e}$ serão usadas para os cálculos neste capítulo.

De acordo com a SOCIETY OF MANUFACTURING ENGINEERS (1965), e com o escopo de aplicação do trabalho, usam-se as fórmulas: (3), (4), (6), (7), (8), (9), 
(10), (11), (12), do capítulo 4. Os rendimentos de retrabalho, refugo e produção não são considerados para efeito de cálculo, devido a falta de informação relativa à retrabalho, refugo e tempos padrões disponíveis no mês. O índice de rateio do custo também será desconsiderado, pois o custo será ilustrado para o lote de peças não sendo necessário utilizar o rateio de custo para cada peça.

Os custos de MÃO-DE-OBRA são calculados como salário/hora segundo SOCIETY OF MANUFACTURING ENGINEERS (1965). Para FERRARESI (1970) o custo total de salário de mão-de-obra é calculado pela fórmula:

$$
C_{\text {SALÁRIO_TOTAL }}=\left(S_{H}+S_{M}\right) \times\left(T_{\text {OPERAÇÃO }}+T_{\text {SETUP }}\right)
$$

em que:

$C_{\text {SALÁRIO_TOTAL }}=$ custo salário total $[\mathrm{R} \$]$;

$S_{H}=$ salário homem $[\mathrm{R} \$ /$ horas $]$;

$S_{M}=$ salário máquina $[\mathrm{R} \$ /$ horas $]$;

$T_{\text {OPERAÇÃO }}=$ tempo de operação [horas];

$T_{\text {SETUP }}=$ tempo de preparação [horas].

De acordo com uma empresa multinacional da região de São Carlos, o salário/hora médio de um operador é de $3,00 \mathbf{R} \$ \mathbf{h}$ e o salário/hora médio da máquina é da ordem de $10,00 \mathbf{R} \$ \mathbf{h}$ para todas as máquinas. É importante observar que, dependendo da máquina, o salário/hora da máquina será diferente. Porém, para efeito de custo considera-se a média. O tempo de operação e o tempo de preparação são dados para todas as peças do lote produzido. O custo de incentivos, custo de encargos e custo de adicionais não estão presentes nos dados fornecidos sendo nulos no cálculo de custo. Como resultado o custo de mão-deobra será composto do custo de salário total.

A potência, usada no cálculo do custo de energia é dada em KWH (kilowatts hora) e a tarifa/preço é de acordo com a CPFL (Companhia Paulista de Força e Luz) de $\mathbf{0 , 1 9 2 2 9 0}$. O tempo gasto com energia das máquinas corresponde, ao tempo gasto no processamento total das peças. Segundo uma empresa multinacional da região de São Carlos, uma máquina consome em média 100 Kwh. Assim basta multiplicar 
Capítulo 5 - Modelagem de sistemas de manufatura orientada pelo custeio das atividades

o consumo médio, pelo tempo de processamento para obter-se a quantidade consumida. Por fim, multiplica-se a quantidade consumida das máquinas pela tarifa/preço.

De acordo com a mesma empresa multinacional da região de São Carlos, cada hora de uso da ferramenta deprecia seu valor em média de $0,2 \%$. O custo médio das ferramentas usadas é de 1000,00 R\$. Portanto o valor de depreciação por hora é de $2,00 \mathbf{R} \$ \mathbf{h}$. Para a modelagem o tempo de depreciação da ferramenta corresponde ao tempo gasto no processamento total das peças. Assim basta multiplicar o valor de depreciação por hora pelo tempo total de processamento.

O custo de material é dado pela quantidade de matéria-prima multiplicada pelo valor unitário de matéria-prima. Segundo a ANTAR 1 , o custo unitário médio de matéria-prima, para fabricar engrenagens é da ordem de 10,00 R\$. Assim basta multiplicar este valor pela quantidade consumida.

O custo de ajustagem também deve ser custeado segundo o escopo do trabalho. Porém, o tempo de ajustagem não está presente nos dados fornecidos. Assim sendo, o custo de ajustagem será nulo na modelagem.

\subsection{Modelos de simulação}

Para a modelagem dos sistemas funcional e celular, foram criados dois modelos de simulação: um modelo do sistema funcional e um modelo do sistema celular. Como comentado por BANKS et al. e (1996) LAW \& KELTON (1998) no capítulo 2, um modelo é definido como sendo a representação de um sistema real, com o propósito de estudo deste sistema.

Seguindo esta definição, os modelos foram criados com o intuito de representar os sistema funcional e celular. Assim, os modelos obedecem às regras e características específicas de cada sistema, como, por exemplo, regras relativas ao setup de máquinas, possibilidade de famílias de peças, entre outras características. Para o modelo funcional usou-se agrupamento de funções, que foi dividido em 5 partes distintas como: tornos, fresas, furadeiras, shapper, e hobber. Usou-se no

\footnotetext{
${ }^{1}$ ANTARI - Comércio de Metais Ltda, João Salles, 369, São Carlos, SP, Brasil.
} 
Capítulo 5 - Modelagem de sistemas de manufatura orientada pelo custeio das atividades

modelo recursos como, máquinas, empilhadeira, homens além de recursos de desenho.

Representou-se no modelo tanto as peças, quanto os respectivos processos de fabricação, programação da produção (ordem de chegadas), manuseio de peças, o setup das operações, o processamento das peças e quantidade de lotes. Por fim, aplicaram-se os experimentos 1 e 2, citados no capítulo 4 (vide tabela 7 e 8 ) do sistema funcional. Como resultado obtiveram-se alguns tempos relacionados com as atividades custeáveis deste sistema.

A tabela 1 do capítulo 4 ilustra estas atividades custeáveis do sistema funcional, sendo que cada atividade possui uma medida de tempo. O tempo de transporte para o modelo funcional será relativo ao transporte da empilhadeira. Não foram retirados tempos de troca e afiação, pois não foram modeladas troca e afiação de ferramenta. Assim, os tempos resultantes do modelo foram:

- tempo de setup;

- tempo de usinagem;

- tempo de manuseio de peças pelos operadores;

- tempos de espera em fila;

- tempo de transporte.

Do mesmo modo para o modelo celular usaram-se recursos como, máquinas, esteiras transportadoras, homens e desenho. Representou-se no modelo, chegada de peças, seus respectivos processos de fabricação, o setup das operações e o processamento das peças. Aplicou-se os experimentos 1 e 2 na célula, citados no capítulo 4 (vide tabela 9 e 10) e obteve-se tempos relativos as atividades geradoras de custos.

A tabela 2, do capítulo 4 mostra as atividades custeáveis do sistema celular. Da mesma forma, cada atividade possui uma medida de tempo. O tempo de transporte para o modelo celular está acumulado com as esperas. Logo, os tempos retirados do modelo foram:

- tempo de setup; 
- tempo de usinagem;

- tempo de manuseio de peças pelos operadores;

- tempos de espera na esteira;

Para obter-se, os custos relativos às atividades, necessitou-se posteriormente na próxima etapa, aplicar as recomendações sobre custos enumeradas no item 5.2 deste capítulo. Por fim, conseguiu-se resultados na forma de custos, que por sua vez, tiveram como orientação às atividades custeáveis dos sistemas.

A seguir algumas imagens do modelo celular serão ilustrados nas figuras 16 e 17. A figura 16 mostra a vista superior do modelo, ilustrando operadores, máquinas, peças e esteira transportadora.

Percebe-se no detalhe 10 operador colocando a peça na esteira. No detalhe 20 operador coloca a peça na máquina para ser processada e no detalhe 3 as peças esperam na esteira.

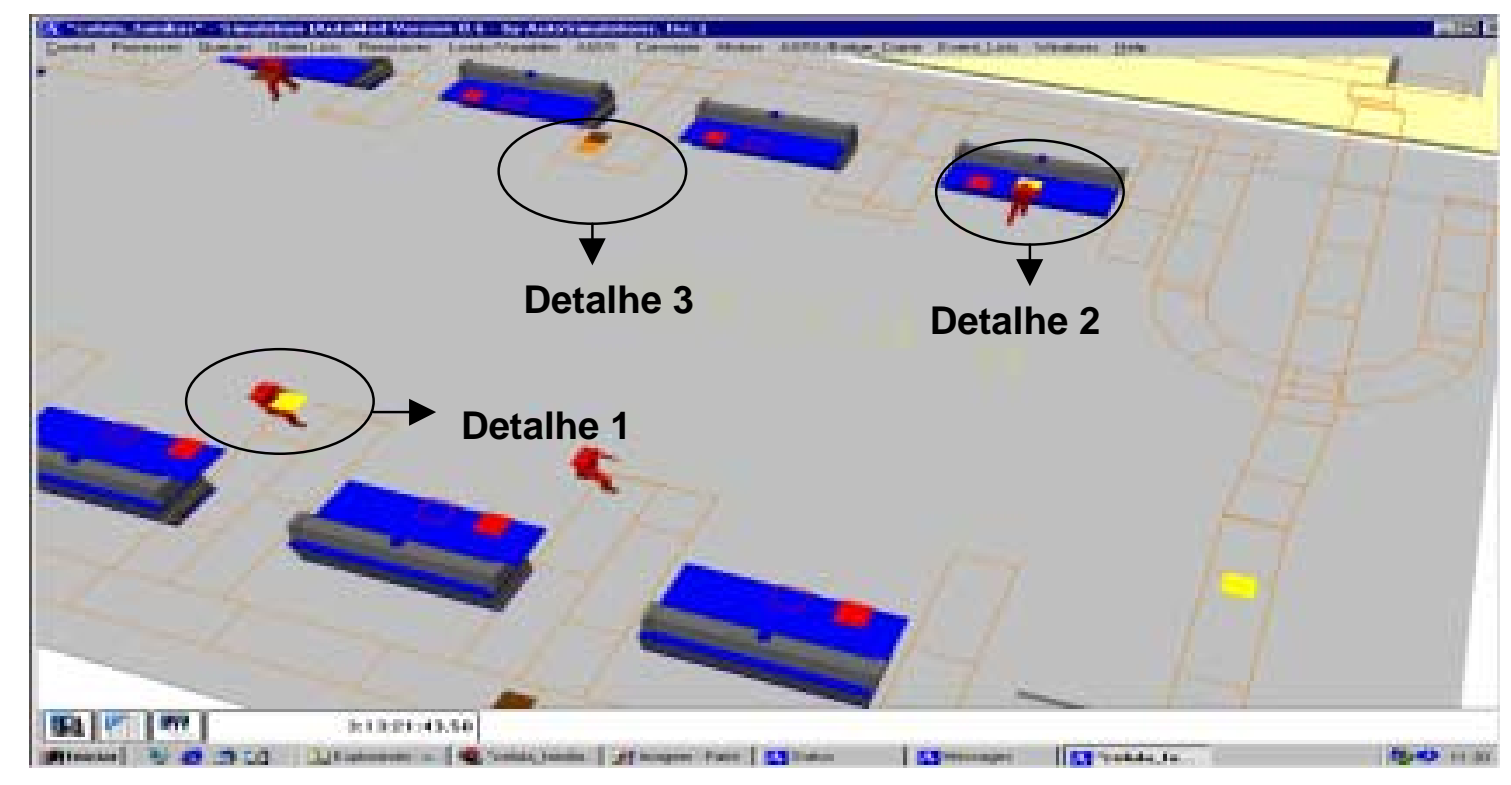

FIGURA 16 - VISTA SUPERIOR DO MODELO CELULAR

A figura 17 mostra a vista lateral da célula de fabricação. Nota-se no detalhe que a célula é constituída de 10 máquinas e apresenta a forma de um ' $U$ '. 


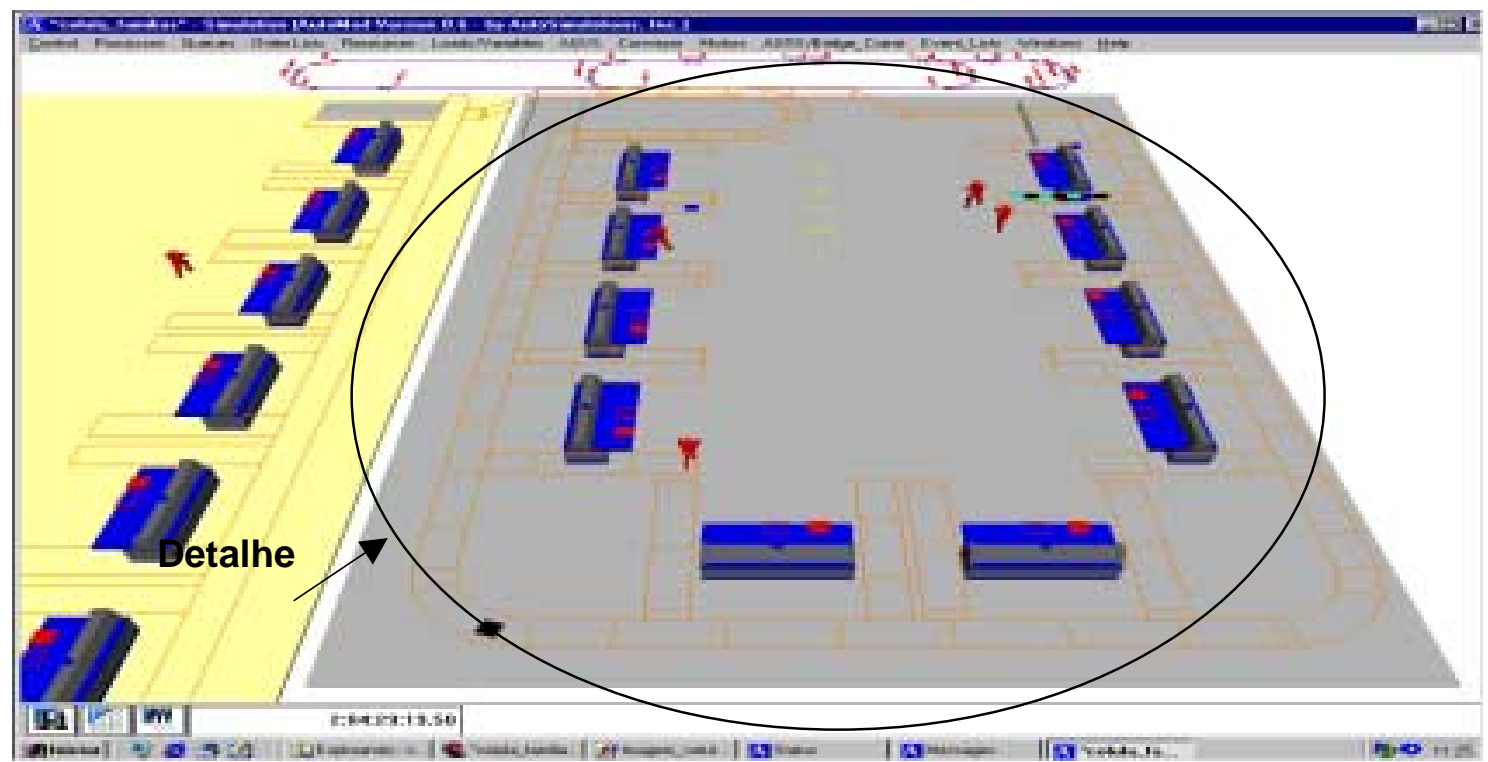

FIGURA 17 - VISTA LATERAL DO MODELO CELULAR

Da mesma forma ilustra-se uma imagem do modelo funcional na figura 18. Nota-se na vista superior deste modelo a divisão do chão e fábrica em funções, por meio da diferenciação de cores (verde e cinza). Observa-se no modelo a empilhadeira trabalhando e também o operador retirando a peça da máquina no detalhe 1 . No detalhe 2 nota-se o buffer de entrada e o buffer de saída de duas máquinas, onde a empilhadeira coloca o lote de peças para sofrer operações. Quando a operação for completada para todo lote a empilhadeira retira o lote de peças, levando-o para a máquina responsável pela próxima operação.

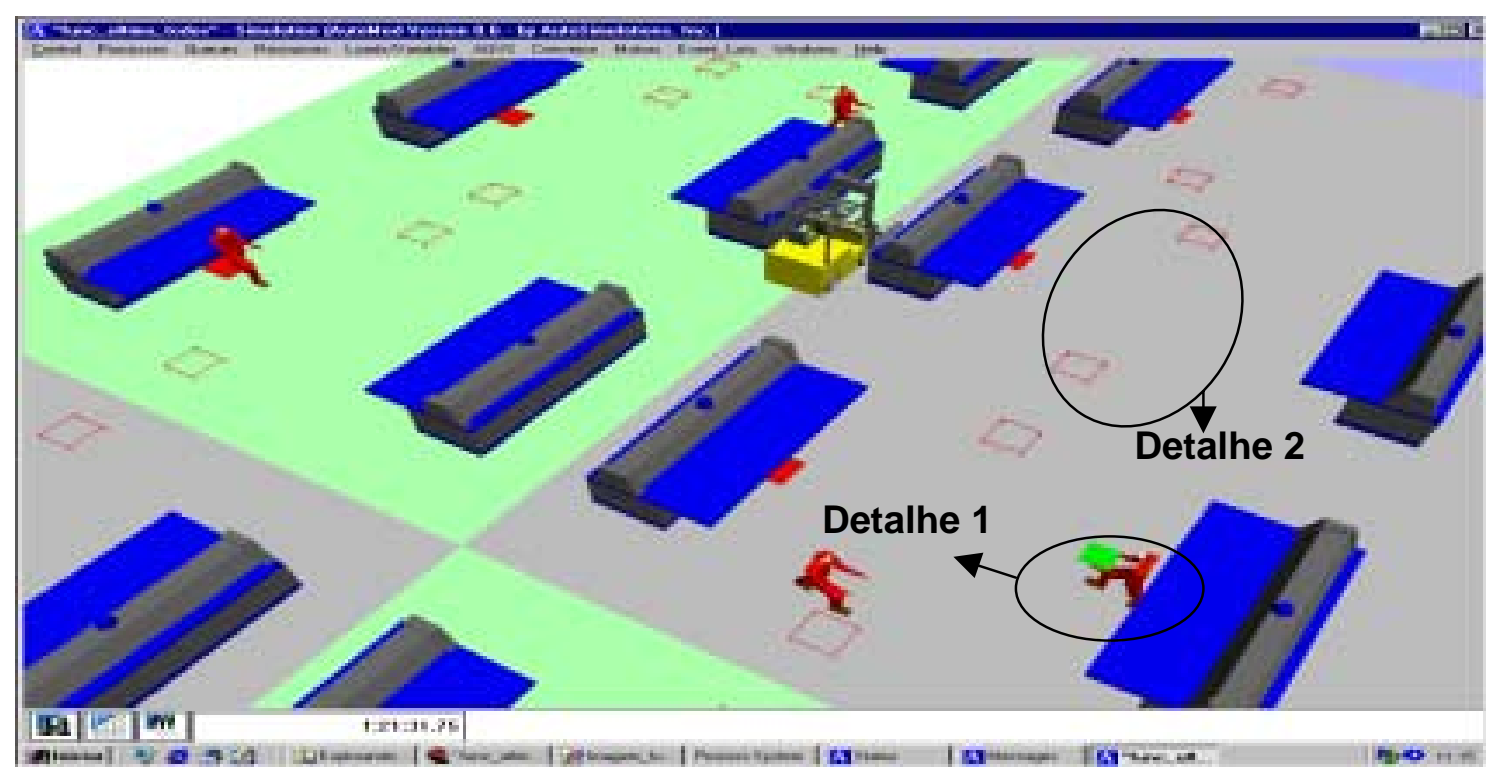

FIGURA 18 - VISTA SUPERIOR DO MODELO FUNCIONAL 
Capítulo 5 - Modelagem de sistemas de manufatura orientada pelo custeio das atividades

\subsection{Análise dos resultados}

Este item ilustra todos os resultados associados aos experimentos propostos. Tais resultados referem-se aos tempos e custos ocorridos com a simulação dos modelos funcional e celular. Tais tempos (segundos) referem-se às peças 1, 5, 6, 8, 10, 11, $12,13$.

O lote de cada peça, o tempo de setup e o tempo de processamento em ambos os sistemas representam os dados de entrada dos experimentos. Para o modelo funcional os seguintes resultados da simulação são ilustrados na figura 19 que segue abaixo:

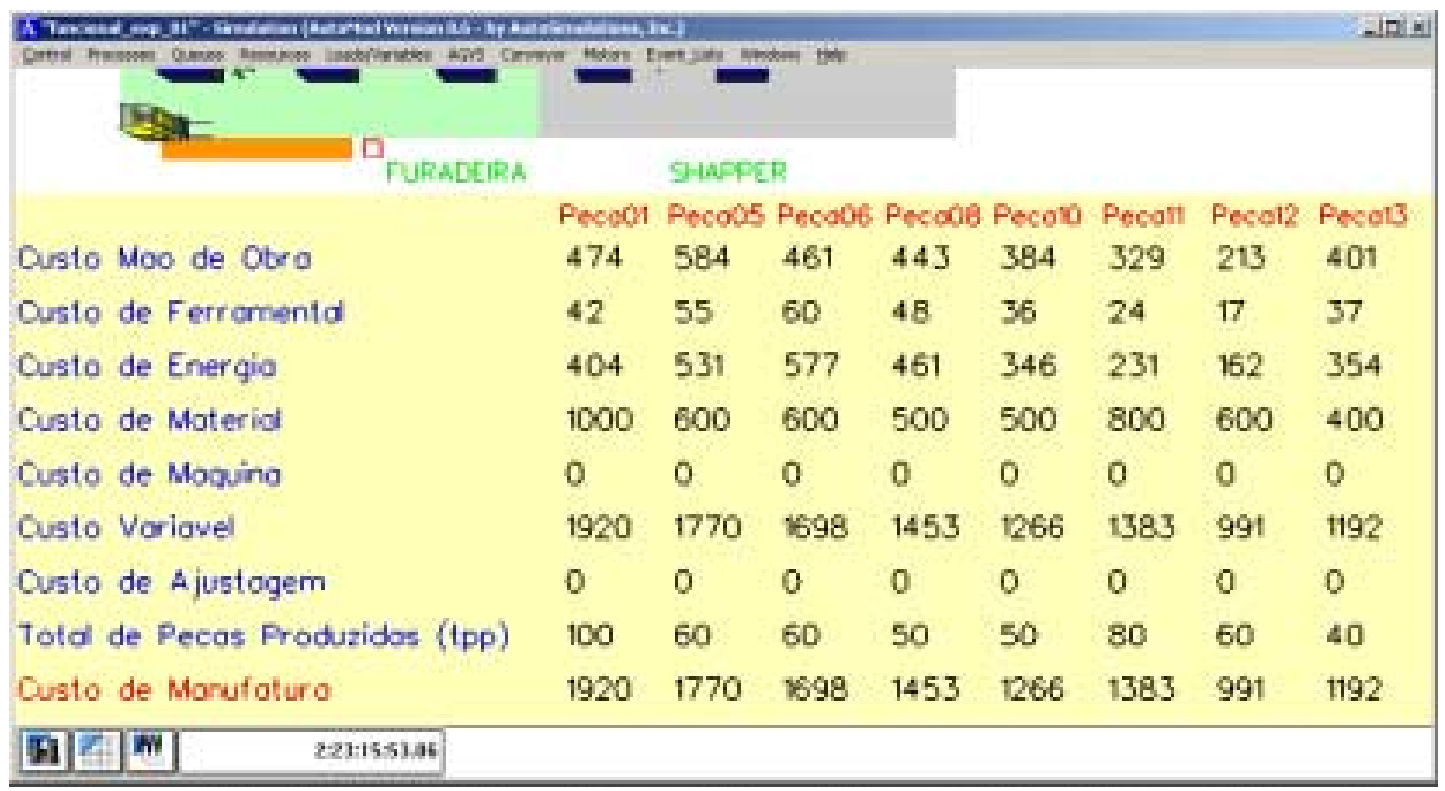

FIGURA 19 - RESULTADOS DE CUSTO DO MODELO FUNCIONAL (EXPERIMENTO 1)

A figura 19 mostra resultados de custos $(R \$)$, onde todas as peças foram custeadas. Mediram-se os custos de mão-de-obra, de ferramental, de energia, de material e o custo variável. O total de peças produzidas (tpp) e o custo total (destacado em vermelho) também são ilustrados. Apenas o custo de máquina e o custo de ajustagem como comentado anteriormente não foram medidos (ambos apresentam o valor zero na figura 19).

Na figura 20 é ilustrado o experimento 2 para o sistema funcional. Da mesma forma o custo de máquina e o custo de ajustagem não são medidos. Observa-se que 
como proposto no experimento 2 (tabela 7, capítulo 4), as peças 11, 12 e 13 não possuem resultados.

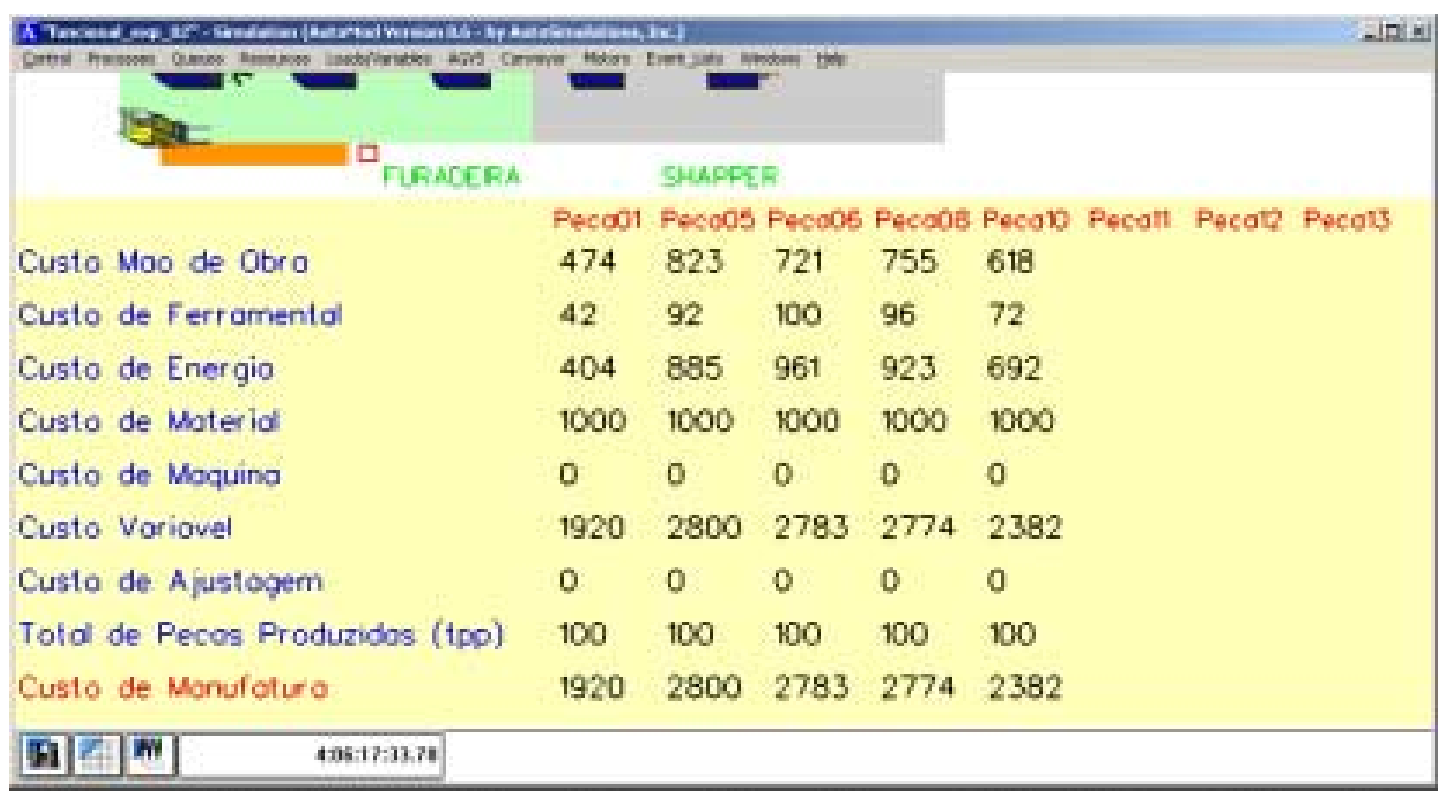

FIGURA 20- RESULTADOS DE CUSTO DO MODELO FUNCIONAL (EXPERIMENTO 2)

Para o modelo celular os seguintes resultados da simulação são ilustrados na figura 21 que segue:

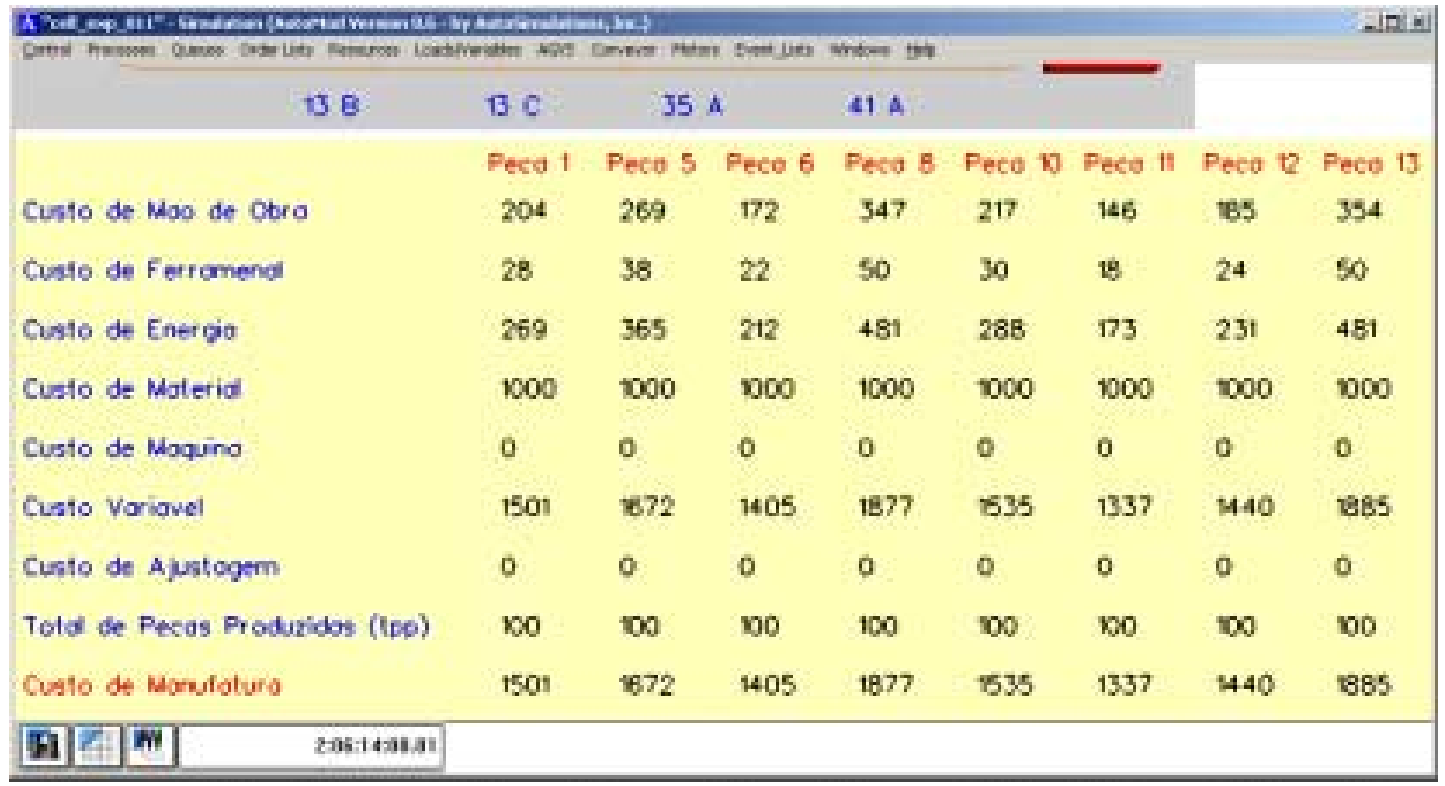

FIGURA 21- RESULTADOS DE CUSTO DO MODELO CELULAR (EXPERIMENTO 1) 

atividades

Da mesma forma, foi desconsiderado por falta de informações o custo de máquina, sendo nulo nos resultados. Neste experimento 1 da figura 21 (tabela 9, capítulo 4) todas as peças foram custeadas.

Na figura 22 são ilustrados os resultados do experimento 2 (tabela 10) do sistema celular:

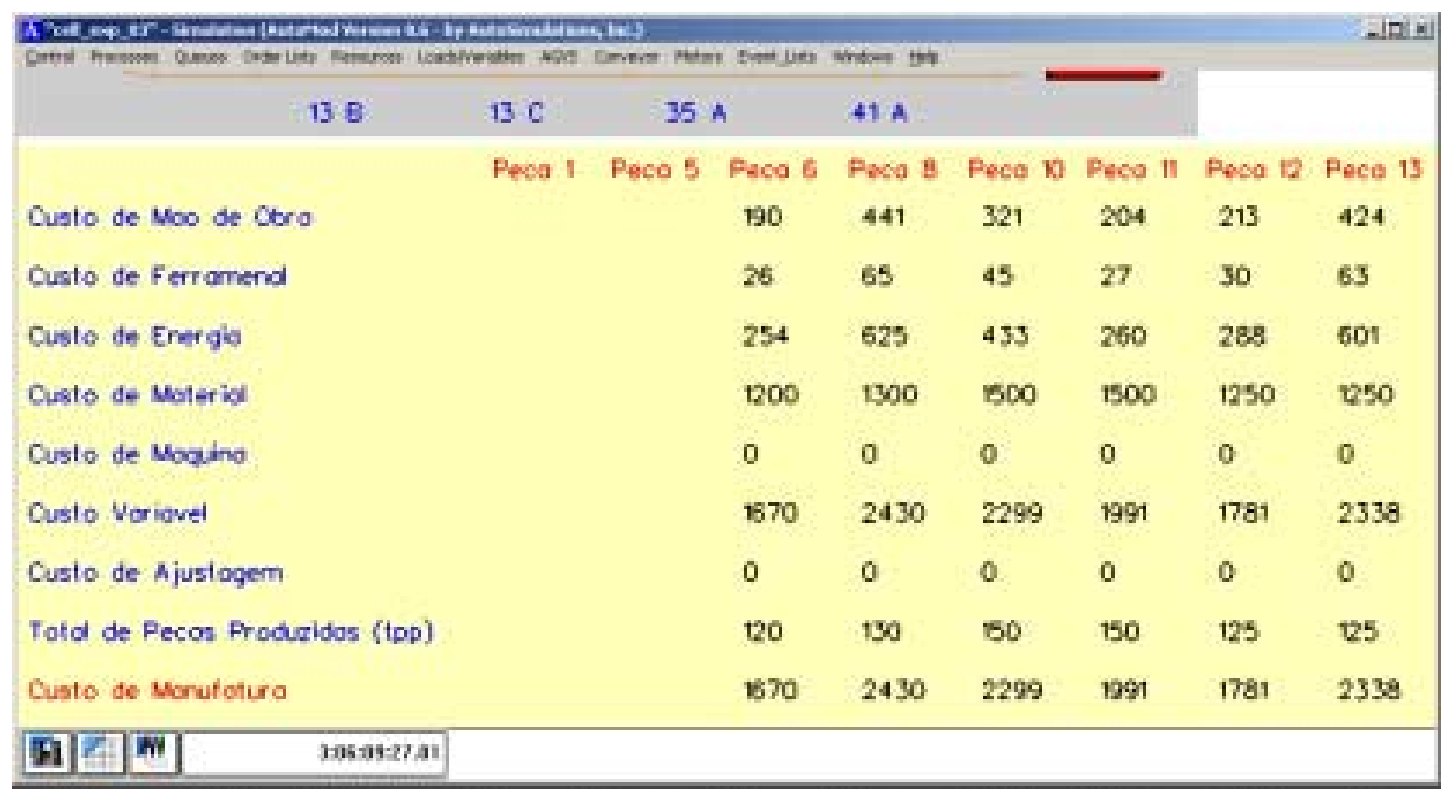

FIGURA 22- RESULTADOS DE CUSTO DO MODELO CELULAR (EXPERIMENTO 2)

Percebe-se que as peças 1 e 5 da figura 22 não possuem resultados, como foi proposto no experimento 2 (tabela 10, capítulo 4).

O tempo de transporte não é considerado para efeito de custo dentro do modelo de custo da SOCIETY OF MANUFACTURING ENGINEERS (1965), porém os tempos de transporte são retirados dos modelos de simulação.

Para o modelo funcional os tempos de transporte da empilhadeira são dados em três partes: Tempo de transporte para levar o lote até o destino, o tempo de transporte para buscar peças semi-acabadas e o tempo de transporte indo estacionar. Ainda tem-se o tempo disponível do recurso para realizar outras tarefas. As tabelas 11 e 12 ilustram os resultados de transporte para o sistema de arranjo físico funcional. 
Capítulo 5 - Modelagem de sistemas de manufatura orientada pelo custeio das atividades

Tabela 11 - Tempos de transporte/sistema funcional/experimento1.

\begin{tabular}{|c|c|c|c|c|c|c|c|c|c|}
\hline \multicolumn{3}{|c|}{$\begin{array}{l}\text { Levando lote de peças } \\
\text { até destino }\end{array}$} & \multicolumn{3}{|c|}{$\begin{array}{c}\text { Buscando lote de peças } \\
\text { prontas }\end{array}$} & \multicolumn{3}{|c|}{ Indo estacionar } & $\begin{array}{l}\text { Dispo } \\
\text { nível }\end{array}$ \\
\hline $\begin{array}{c}\% \\
\text { total } \\
\text { de } \\
\text { tempo }\end{array}$ & $\begin{array}{c}\text { Viagens } \\
\text { feitas }\end{array}$ & $\begin{array}{c}\text { Tempo } \\
\text { médio } \\
\text { por } \\
\text { viagem }\end{array}$ & $\begin{array}{c}\text { \% total } \\
\text { de } \\
\text { tempo }\end{array}$ & $\begin{array}{c}\text { Viagens } \\
\text { feitas }\end{array}$ & $\begin{array}{c}\text { Tempo } \\
\text { médio } \\
\text { por } \\
\text { viagem }\end{array}$ & $\begin{array}{c}\text { \% total } \\
\text { de } \\
\text { tempo }\end{array}$ & $\begin{array}{c}\text { Viagens } \\
\text { feitas }\end{array}$ & $\begin{array}{c}\text { Tempo } \\
\text { médio } \\
\text { por } \\
\text { viagem }\end{array}$ & 0.981 \\
\hline 0.009 & 81 & 28.78 & 0.010 & 82 & 30.36 & 0.000 & 0 & 0.00 & \\
\hline
\end{tabular}

Percebe-se pela tabela 11 que $0,9 \%$ do tempo, a empilhadeira está levando o lote de peças até o destino e que $1 \%$ do tempo, a empilhadeira está buscando o lote de peças prontas. Portanto o tempo total de transporte é de $1,9 \%$ e $98,81 \%$ do tempo a empilhadeira está disponível para outras tarefas.

Tabela 12 - Tempos de transporte/sistema funcional/experimento 2.

\begin{tabular}{|c|c|c|c|c|c|c|c|c|c|}
\hline \multicolumn{3}{|c|}{$\begin{array}{l}\text { Levando lote de peças } \\
\text { até destino }\end{array}$} & \multicolumn{3}{|c|}{$\begin{array}{c}\text { Buscando lote de peças } \\
\text { prontas }\end{array}$} & \multicolumn{3}{|c|}{ Indo estacionar } & $\begin{array}{l}\text { Dispo } \\
\text { nível }\end{array}$ \\
\hline $\begin{array}{c}\% \\
\text { total } \\
\text { de } \\
\text { tempo }\end{array}$ & $\begin{array}{c}\text { Viagens } \\
\text { feitas }\end{array}$ & $\begin{array}{c}\text { Tempo } \\
\text { médio } \\
\text { por } \\
\text { viagem }\end{array}$ & $\begin{array}{c}\% \text { total } \\
\text { de } \\
\text { tempo }\end{array}$ & $\begin{array}{c}\text { Viagens } \\
\text { feitas }\end{array}$ & $\begin{array}{c}\text { Tempo } \\
\text { médio } \\
\text { por } \\
\text { viagem }\end{array}$ & $\begin{array}{c}\text { \% total } \\
\text { de } \\
\text { tempo }\end{array}$ & $\begin{array}{c}\text { Viagens } \\
\text { feitas }\end{array}$ & $\begin{array}{c}\text { Tempo } \\
\text { médio } \\
\text { por } \\
\text { viagem }\end{array}$ & 0.992 \\
\hline 0.004 & 52 & 27.26 & 0.004 & 52 & 27.83 & 0.000 & 0 & 0.00 & \\
\hline
\end{tabular}

Percebe-se pela tabela 12 que $0,4 \%$ do tempo, a empilhadeira está levando o lote de peças até o destino e que $0,4 \%$ do tempo, a empilhadeira está buscando o lote de peças prontas. Portanto o tempo total de transporte é de 0,8\% e 99,20\% do tempo a empilhadeira está disponível para outras tarefas. 


\section{CAPÍTULO 6 - CONCLUSÕES}

Os objetivos iniciais propostos para este trabalho foram: propor procedimentos de modelagem de sistemas de manufatura discreta, orientada pelo custeio das atividades e processos. Tais procedimentos de modelagem foram viáveis de serem utilizados, uma vez que, os modelos de simulação mostraram-se flexíveis em relação aos pré-requisitos de modelagem abordados. As variáveis presentes nos pré-requisitos de modelagem foram também possíveis de variação (figuras 19, 20, 21 e 22).

De uma forma geral, pode-se afirmar que estes objetivos foram atingidos, pois as atividades geradoras de custos (atividades produtivas e de suporte) nos tradicionais sistemas de manufatura foram medidas.

Especificamente, pode-se comentar algumas observações.

Nos experimentos evidenciou-se a flexibilidade dos modelos por meio das atividades geradoras de custos. No momento de se alterar variáveis, como, o lote de peças e o número de peças a serem fabricadas os modelos corresponderam ao esperado, realizando o que foi pedido no experimento 1 e 2 , tanto no modelo funcional quanto no modelo celular. Vale destacar que em particular no modelo celular a quantidade de famílias foi modificada de um experimento para outro atendo ao esperado. Tais experimentos foram realizados com o intuito de apenas 
mostrarem a flexibilidade dos modelos em relação aos pré-requisitos de modelagem abordados no capítulo 1.

As características dos Automod atenderam as expectativas com relação à confecção dos modelos, uma vez que, os deslocamentos modelados são reais. As características típicas e as atividades do arranjo físico funcional e celular (setup, famílias, usinagem, transporte, esperas em buffer) foram atendidas mesmo com as alterações na entrada de dados sugerida nos experimentos.

O sistema $A B C$ de custos mostrou-se eficiente, sendo capaz de identificar quais atividades agregaram valor e quais não agregaram. Um exemplo de atividade que não agregou valor foi a grande quantidade de tempo e custo perdidos com esperas em buffer e esperas nas esteiras transportadoras, ilustrando que tal atividade deve possuir uma atenção e supervisão maior por parte da alta administração.

O modelo de custo da SOCIETY OF MANUFACTURING ENGINEERS (1965) estruturado por atividades foi atendido de forma eficiente, pois na modelagem dos sistemas de manufatura mostrou-se adequado de aplicar. De uma forma geral tudo que foi modelado possuiu relação com o modelo de custo. Vale destacar que somente o que foi modelado foi possível de ser medido em tempos e em custos.

Os passos da simulação abordados no capítulo 2 foram atendidos e seguidos na confecção dos modelos celular e funcional. $O$ fato de se seguir tais passos foi um fator determinante no sucesso de elaboração dos modelos e conseqüentemente na obtenção de resultados.

Com relação às dificuldades relatadas na modelagem pode-se destacar a necessidade de conhecimento do software de simulação adotado, pois o Automod exige conhecimento em programação. Outra dificuldade no processo de modelagem foi identificar as atividades típicas dos arranjos funcional e celular.

Conseguiu-se assim medir custos por meio dos modelos de simulação e os resultados em termos de custos foram satisfatórios mediante a proposta inicial, sendo que os pré-requisitos de modelagem foram atendidos dentro do trabalho. Pode-se ressaltar que os procedimentos propostos são viáveis de serem aplicados 
em trabalhos futuros. Um arranjo físico em linha e um arranjo físico posicional podem ser novas configurações possíveis de serem modeladas futuramente usando-se os mesmos procedimentos utilizados neste trabalho. Um fato que deve ser ressaltado sempre é o que o caráter de flexibilidade deve estar sempre presente no processo de modelagem dos vários sistemas de manufatura a serem adotados.

Sugestão de continuidade:

- ampliar os custos a serem medidos;

- aplicar os procedimentos de modelagem para outros tipos de arranjo físico (linha e posicional, por exemplo);

- ampliar a modelagem para outros setores da empresa, além da fabricação. 


\section{REFERÊNCIAS BIBLIOGRÁFICAS}

AKBAY, K. S. (1996). Using simulation optimization to find the best solution, IIE. Solutions p.24 - 29, may.

ANDERSON, E. G.; MORRICE, D. J. (1999). A simulation model to study the dynamics in a service-oriented supply chain. Winter Simulation Conference Proceedings, p.742-748.

ANDRADE, M. C.; PESSANHA FILHO, R. C.; ESPOZEL, A. M.; MAIA, L. O. A.; QASSIM, R. Y. (1999). Activity-based costing for production learning. International Journal of Production Economics, v. 62, p.175-180.

BANKS, J. (1999). Introduction to simulation. Winter Simulation Conference Proceedings, p.7-13.

BANKS, J.; CARSON, J. S.; NELSON, B. L. (1996). Discrete-event system simulation. 2. ed. New Jersey, Prentice Hall, 548 p.

BARRETO, J. B. (1974). Contabilidade de custos na empresa industrial. Universidade do Estado da Guanabara, Rio de Janeiro, 87 p.

BATOCCHIO, A. (1987). Codificação interativa de peças usando computador e tecnologia de grupo. São Carlos. 170p. Dissertação de Mestrado - Escola de Engenharia de São Carlos, Universidade de São Paulo.

BLACK, J. T. (1998). O projeto da fábrica com futuro. Porto Alegre, Bookman, 288 p.

BUFFA, E. S.; SARIN R. K. (1987). Modern production operations management. New York, USA, John Wiley \& Sons, $834 \mathrm{p}$.

CHIAVENATO, I. (1991). Iniciação à administração da produção. São Paulo, Makron, $145 \mathrm{p}$. 
CHING, H. Y. (1995). Gestão baseada em custeio por atividades (ABM). São Paulo, Atlas.

COGAN, S. (1998). Modelos de ABC/ABM: Inclui modelos resolvidos e metodologia original de reconciliação de dados para o $A B C / A B M$. Rio de Janeiro, Qualitymark, $176 \mathrm{p}$.

DUTRA, R. G. (1995). Custos: uma abordagem prática. 4. ed. São Paulo, Atlas, 191 p.

FRANCISCHINI, P. G.; FEGYVERES, A. (1997). Arranjo físico. In: CONTADOR, J. C. (Coordenador). Gestão de operações. São Paulo, Fundação Vanzolini / Edgar Blücher, 591 p., Cap. 12.

FERRARESI, D.; (1970). Fundamentos da usinagem dos metais. São Paulo, Edgar Blücher, $751 \mathrm{p}$.

FIORONI, M. M., BATOCCHIO, A. (2000). Arquitetura dos sistemas de manufatura. In: CONGRESSO NACIONAL DE ENGENHARIA MECÂNICA, Natal, agosto, 2000. Anais. Rio Grande do Norte. 591 p., Cap. 12.

CARVAlho, A. C. B.; PORTO, A. J. V.; KIGUTI, A. P. M.; IANAMASU, R. Y. (1998). Proposta de pesquisa sobre o uso da simulação e sua aplicação com usuários. In: CONGRESSO NACIONAL DE ENGENHARIA DE PRODUÇÃO, Niterói, setembro, 1998. Anais. Rio de Janeiro, Cd-Rom.

GALLORO, R. R. S.; GALLORO, V. D. (2000). Introdução à contabilidade de custos. In: SILVA JR, J. B. (Coordenador). Custos: Ferramentas de Gestão. São Paulo, Atlas, 244 p., Cap. 5.

GARCIA, M. L.; CENTENO, M.A.; PEÑALOZA, G. (1999). A simulation of the product distribution in the newspaper industry. Winter Simulation Conference Proceedings, p.1268-1271. 
GONÇALVES FILHO, E. V. (1982). Introdução à tecnologia de grupo: um novo enfoque em sistemas de produção. São Carlos. 143p. Dissertação de Mestrado - Escola de Engenharia de São Carlos, Universidade de São Paulo.

GONÇALVES FILHO, E. V. (2001). Arranjo físico da fábrica: um modelo para o processo de projeto e um algoritmo genérico para a formação de células de fabricação. São Carlos. 133p. Tese (Livre docência) - Escola de Engenharia de São Carlos, Universidade de São Paulo.

GORDON, G. (1978). System Simulation. New Jersey, USA, Prentice Hall, 324 p.

GUNASEKARAN, A.; SARHADI M. (1998). Implementation of activity-based costing in manufacturing. International Journal of Production Economics. v. 56-57, p 231-242.

GUNASEKARAN, A.; SINGH, D. (1999). Design of a activity-based costing in a small company: a case study. Computers \& Industrial Engineering, v. 37, p. 413-416.

HARREL, C. R.; BATEMAN, R.E.; GOGG, T.J.; MOTT, J.R.A. (1992). System improvement using simulation. Orem, Utah, USA, PROMODEL Corporation.

HERAGU, S. (1997). Facilities design. Boston, USA, MA, PWS Publishing Company.

INGELS, D. M. (1985). What every engineer should know about computer modeling and simulation. New York, USA, Marcel Dekker Inc..

LAW, A. M.; KELTON, W. D. (1991). Simulation modeling and analysis. 2. ed. USA, McGraw-Hill, 759 p.

LIMA, J. G. (1970). Custos (cálculos, sistemas, e análises). 2. ed. São Paulo, Atlas, $270 \mathrm{p}$. 
LIMA, R. G. (2000). Informações de Custos para Decisões, In: SILVA JR, J. B. (Coordenador). Custos: Ferramentas de Gestão. São Paulo, Atlas, 244 p., Cap. 3.

LOBÃO, E. C. (2000). Discussão, sistematização e modelamento do processo de realização de estudos de simulação. São Carlos. 198p. Tese (Doutorado) Escola de Engenharia de São Carlos, Universidade de São Paulo.

LOBÃO, E. C.; PORTO, A. J. V. (1997). Proposta para sistematização de estudos em simulação. In: CONGRESSO NACIONAL DE ENGENHARIA DE PRODUÇÃO, Gramado, dezembro, 1997. Anais. Rio Grande do Sul, Cd-Rom.

LOGENDRAN, R.; TALKINGTON D. (1997). Analysis of cellular and functional manufacturing systems in the presence of machine breakdown. International Journal of Production Economics, v. 53, p.239-256.

MANDARINO, U. (1971). Custos, 2. ed. São Paulo, Atlas, 138 p.

MARTINS, E. (1985). Contabilidade de custos, 2. ed. São Paulo, Atlas, 351 p.

MONKS, J. G. (1987). Administração da produção. São Paulo, McGraw-Hill, Cap.7: Planejamento e análise de processos (simulação).

MORRIS, J. S.; TERSINE, R. J. (1990). A simulation analysis of factors influencing the attractiveness of group technology cellular layouts. Management Science, vol. 36, n.12, p.1567-1578, dez.

NAKAGAWA, M. (1997). Custeio baseado em atividades. São Paulo, Atlas.

NEEDY, K. L.; BILLO, R. E.; WARNER, R. C. (1998). A cost model for the evaluation of alternative cellular manufacturing configurations. Computers ind. Engng, vol. 34, n.1, p. 19-134.

NOVASKI, O. (1991). Custos de usinagem. Campinas, Universidade Estadual de Campinas/UNICAMP, $149 \mathrm{p}$. 
PEDGEN, C. D.; SHANNON, R. E.; SADOWSKI, R. P. (1990). Introduction to simulation using siman. New York, USA, McGraw Hill, 615 p.

PHILLIPS, T. (1998). Automod by autosimulations. Winter Simulation Conference Proceedings, p. 213-218.

PORTO, A. J. V. (1990). Desenvolvimento de um método de integração do planejamento e controle da produção, baseado na flexibilidade do processo de fabricação. São Carlos. Tese (Doutorado) - Escola de Engenharia de São Carlos, Universidade de São Paulo.

PORTO, A. J. V. (1998). Notas de aula de Simulação de Eventos Discretos: Disciplina oferecida no programa de Pós-Graduação do departamento de Engenharia Mecânica da Escola de Engenharia de São Carlos (EESC), Universidade de São Paulo, São Carlos.

PRITSKER, A. A. B. (1986). Introduction to simulation and SLAM-II. 3. ed. New York, USA, John Wiley. \& Sons.

PRITSKER, A. A. B. (1992). SLAM II - Quick reference manual. Indiana, USA, Pritsker Corporation.

RIBEIRO, L. P. G.; FERREIRA, J. C. E.; MOURA, E. B. (2001). O uso da simulação para estimar custos de fabricação considerando planos de processos alternativos. In: CONGRESSO BRASILEIRO DE ENGENHARIA DE FABRICAÇÃO, Curitiba, abril, 2001. Anais. Paraná, Cd-Rom.

SANTOS, J. J. (1974). Análise de custos. São Paulo, Pioneira, 110 p.

SCRIBER, T. J. (1991). An Introduction to Simulation Using GPSS/H. USA, John Wiley \& Sons, $437 \mathrm{p}$.

SLACK, N.; CHAMBERS S.; HARLAND, C.; HARRISON, A.; JOHNSTON, R. (1994). Administração da Produção. São Paulo, Atlas, 726 p. 
SOCIETY MANUFACTURING ENGINEERS, (1965). Die design handbook. 2. ed. New York, USA, McGraw-Hill Book Company.

SPENDDING, T. A.; SUN, G. Q. (1999). Application of discrete event simulation to the activity based costing of manufacturing systems. Computers \& Industrial Engineering, v. 58, p. 289-301.

TOMMASI, M. (2000). Custeio gerencial: conceituação, considerações e perspectivas. In: SILVA JR, J. B. (Coordenador). Custos: Ferramentas de Gestão. São Paulo, Atlas, 244 p., Cap. 1.

ULGEN, O. M.; GUNAL, A.; SHORE, J. (1996). Pitfalls of simulation modeling and how to avoid them by using a robust simulation methodology. AutoSimulations Symposium Proceedings.

VIVEROS, U. de. (2000). Enfoque gerencial da contabilidade de custos. In: SILVA JR, J. B. (Coordenador). Custos: Ferramentas de Gestão. São Paulo, Atlas, 244 p., Cap. 13. 


\section{APÊNDICE - RESULTADOS DE EXPERIMENTOS}

Neste apêndice, encontram-se os resultados descritos em detalhes dos tempos (segundos) e custos ( $R \$$ ) para os dois sistemas de manufatura considerados no trabalho.

Para o Experimento 1 do modelo funcional tem-se os resultados em tempos:

FUNCIONAL - EXPERIMENTO 1 - TEMPOS DA PEÇA 1 (segundos)

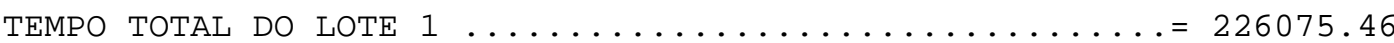

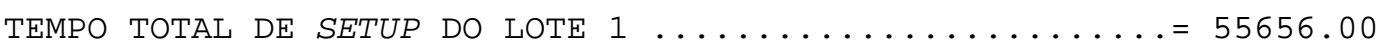

TEMPO TOTAL DE PROCESSAMENTO DO LOTE $1 \ldots \ldots \ldots \ldots \ldots \ldots=75600.00$

TEMPO TOTAL DE MANUSEIO PARA CARREGAR AS MÁQUINAS $\ldots \ldots \ldots=2666.67$

TEMPO TOTAL DE MANUSEIO PARA DESCARREGAR AS MÁQUINAS . . = 2666.67

TEMPO DE ESPERA ACUMULADA NO BUFFER DO LOTE $1 \ldots \ldots \ldots . . .225476 .65$

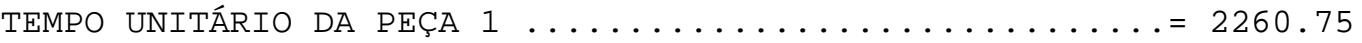

TEMPO UNITÁRIO DE SETUP DA PEÇA $1 \ldots \ldots \ldots \ldots \ldots \ldots \ldots \ldots \ldots \ldots \ldots . \ldots \ldots$

TEMPO UNITÁRIO DE PROCESSAMENTO DA PEÇA $1 \ldots \ldots \ldots \ldots \ldots=756.00$

TEMPO UNITÁRIO DE MANUSEIO PARA CARREGAR AS MÁQUINAS $\ldots=26.67$

TEMPO UNITÁRIO DE MANUSEIO PARA DESCARREGAR AS MÁQUINAS $=26.67$

TEMPO DE ESPERA ACUMULADA NO BUFFER DA PEÇA $1 \ldots \ldots \ldots . \ldots=2254.77$

Lote de peças $1=100$

Processo de Fabricação (Máquinas) = $23 \quad 23 \quad 13 \quad 13 \quad 35 \quad 3545 \quad 57 \quad 57 \quad 62$

FUNCIONAL - EXPERIMENTO 1 - TEMPOS DA PEÇA 5 (segundos)

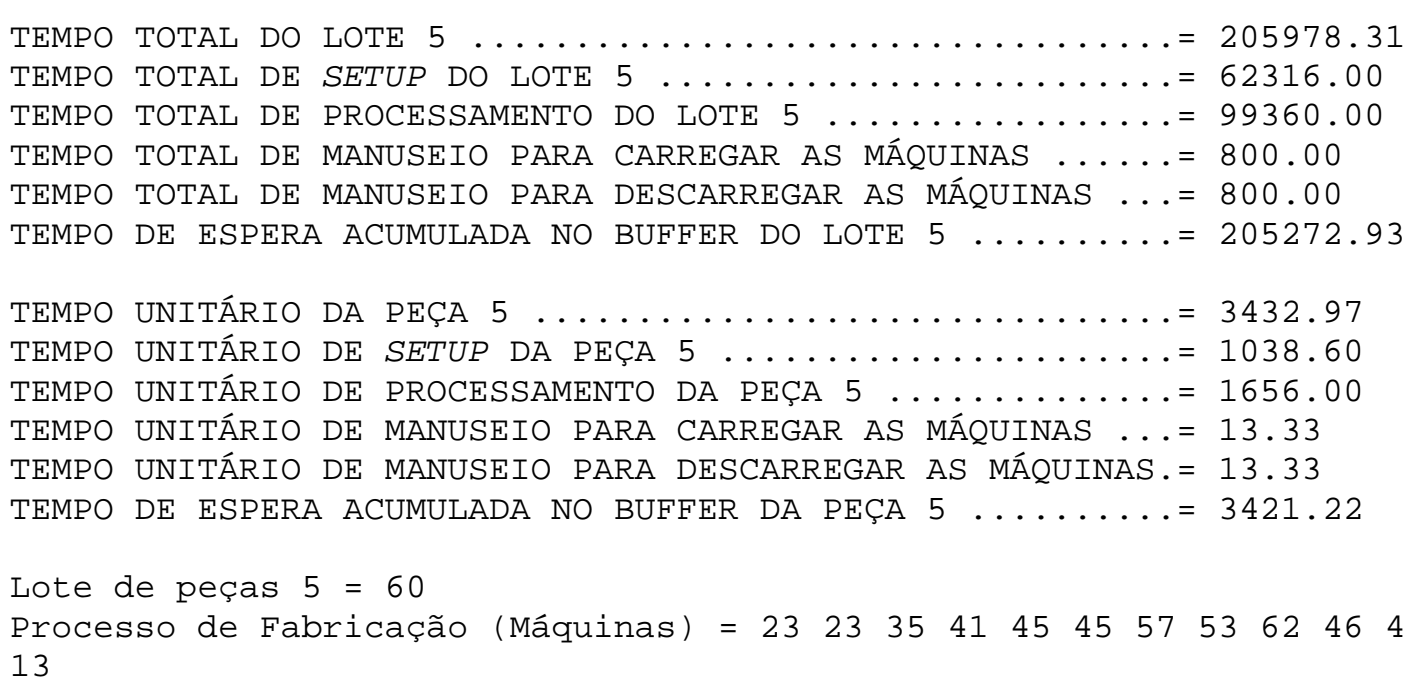

FUNCIONAL - EXPERIMENTO 1 - TEMPOS DA PEÇA 6 (segundos)

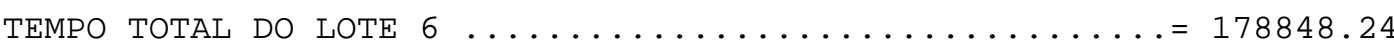

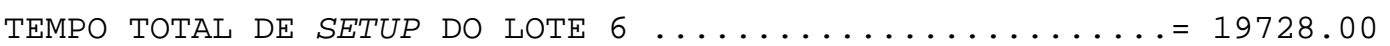

TEMPO TOTAL DE PROCESSAMENTO DO LOTE $6 \ldots \ldots \ldots \ldots \ldots \ldots=108000.00$ 
TEMPO TOTAL DE MANUSEIO PARA CARREGAR AS MÁQUINAS .....=960.00 TEMPO TOTAL DE MANUSEIO PARA DESCARREGAR AS MÁQUINAS $\ldots=960.00$ TEMPO DE ESPERA ACUMULADA NO BUFFER DO LOTE $6 \ldots \ldots \ldots \ldots=178568.62$

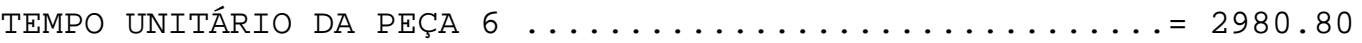

TEMPO UNITÁRIO DE SETUP DA PEÇA $6 \ldots \ldots \ldots \ldots \ldots \ldots \ldots \ldots \ldots \ldots \ldots \ldots \ldots \ldots . \ldots \ldots$

TEMPO UNITÁRIO DE PROCESSAMENTO DA PEÇA $6 \ldots \ldots \ldots \ldots \ldots \ldots=1800.00$

TEMPO UNITÁRIO DE MANUSEIO PARA CARREGAR AS MÁQUINAS $\ldots=16.00$

TEMPO UNITÁRIO DE MANUSEIO PARA DESCARREGAR AS MÁQUINAS $=16.00$

TEMPO DE ESPERA ACUMULADA NO BUFFER DA PEÇA $6 \ldots \ldots \ldots . \ldots=2976.14$

Lote de peças $6=60$

Processo de Fabricação (Máquinas) = $4 \begin{array}{lllll}4 & 62 & 35 & 53 & 23\end{array}$

\section{FUNCIONAL - EXPERIMENTO 1 - TEMPOS DA PEÇA 8 (segundos)}

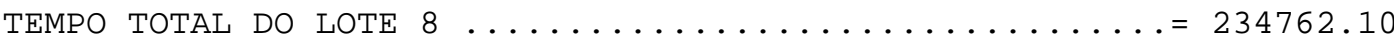

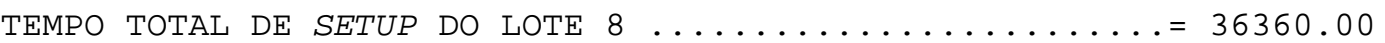

TEMPO TOTAL DE PROCESSAMENTO DO LOTE $8 \ldots \ldots \ldots \ldots \ldots \ldots \ldots=86400.00$

TEMPO TOTAL DE MANUSEIO PARA CARREGAR AS MÁQUINAS .....=1466.67

TEMPO TOTAL DE MANUSEIO PARA DESCARREGAR AS MÁQUINAS . . = 1466.67

TEMPO DE ESPERA ACUMULADA NO BUFFER DO LOTE $8 \ldots \ldots \ldots \ldots=234013.83$

TEMPO UNITÁRIO DA PEÇA $8 \ldots \ldots \ldots \ldots \ldots \ldots \ldots \ldots \ldots \ldots \ldots \ldots \ldots . \ldots \ldots \ldots$

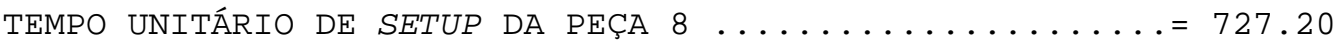

TEMPO UNITÁRIO DE PROCESSAMENTO DA PEÇA $8 \ldots \ldots \ldots \ldots \ldots \ldots=1728.00$

TEMPO UNITÁRIO DE MANUSEIO PARA CARREGAR AS MÁQUINAS $\ldots=29.33$

TEMPO UNITÁRIO DE MANUSEIO PARA DESCARREGAR AS MÁQUINAS $=29.33$

TEMPO DE ESPERA ACUMULADA NO BUFFER DA PEÇA $8 \ldots \ldots \ldots \ldots=4680.28$

Lote de peças $8=50$

Processo de Fabricação (Máquinas) = $23 \quad 23 \quad 3541454562 \quad 6246413$

FUNCIONAL - EXPERIMENTO 1 - TEMPOS DA PEÇA 10 (segundos)

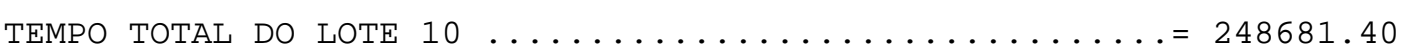

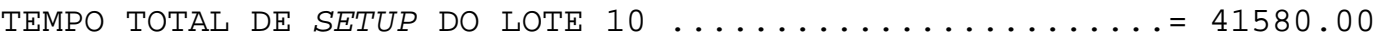

TEMPO TOTAL DE PROCESSAMENTO DO LOTE $10 \ldots \ldots \ldots \ldots \ldots \ldots=64800.00$

TEMPO TOTAL DE MANUSEIO PARA CARREGAR AS MÁQUINAS $\ldots \ldots \ldots=1200.00$

TEMPO TOTAL DE MANUSEIO PARA DESCARREGAR AS MÁQUINAS $\ldots=1200.00$

TEMPO DE ESPERA ACUMULADA NO BUFFER DO LOTE $10 \ldots \ldots \ldots=248025.73$

TEMPO UNITÁRIO DA PEÇA $10 \ldots \ldots \ldots \ldots \ldots \ldots \ldots \ldots \ldots \ldots \ldots \ldots \ldots . \ldots \ldots \ldots$

TEMPO UNITÁRIO DE SETUP DA PEÇA $10 \ldots \ldots \ldots \ldots \ldots \ldots \ldots . \ldots . \ldots . \ldots . \ldots$

TEMPO UNITÁRIO DE PROCESSAMENTO DA PEÇA $10 \ldots \ldots \ldots \ldots \ldots . \ldots 1296.00$

TEMPO UNITÁRIO DE MANUSEIO PARA CARREGAR AS MÁQUINAS $\ldots=24.00$

TEMPO UNITÁRIO DE MANUSEIO PARA DESCARREGAR AS MÁQUINAS $=24.00$

TEMPO DE ESPERA ACUMULADA NO BUFFER DA PEÇA $10 \ldots \ldots . \ldots=4960.51$

Lote de peças $10=50$

Processo de Fabricação (Máquinas) = $\begin{array}{llllllllll}23 & 23 & 27 & 35 & 41 & 45 & 45 & 4 & 13\end{array}$

FUNCIONAL - EXPERIMENTO 1 - TEMPOS DA PEÇA 11 (segundos) 


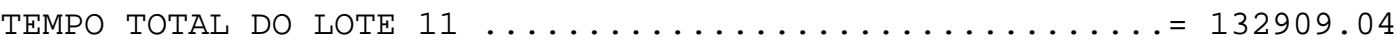

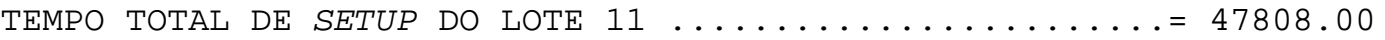

TEMPO TOTAL DE PROCESSAMENTO DO LOTE $11 \ldots \ldots \ldots \ldots \ldots \ldots \ldots=43200.00$

TEMPO TOTAL DE MANUSEIO PARA CARREGAR AS MÁQUINAS ....=1706.67

TEMPO TOTAL DE MANUSEIO PARA DESCARREGAR AS MÁQUINAS ...=1706.67

TEMPO DE ESPERA ACUMULADA NO BUFFER DO LOTE $11 \ldots \ldots \ldots . . .132482 .32$

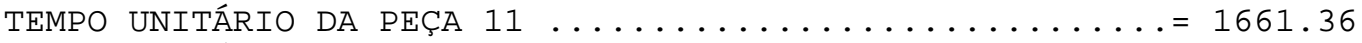

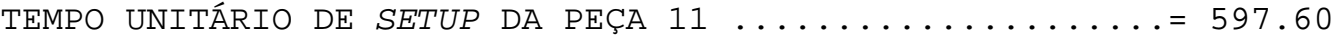

TEMPO UNITÁRIO DE PROCESSAMENTO DA PEÇA $11 \ldots \ldots \ldots \ldots \ldots=540.00$

TEMPO UNITÁRIO DE MANUSEIO PARA CARREGAR AS MÁQUINAS . = $=21.33$

TEMPO UNITÁRIO DE MANUSEIO PARA DESCARREGAR AS MÁQUINAS $=21.33$

TEMPO DE ESPERA ACUMULADA NO BUFFER DA PEÇA $11 \ldots \ldots \ldots=1656.03$

Lote de peças $11=80$

Processo de Fabricação (Máquinas) = $\begin{array}{lllllllll}60 & 27 & 13 & 13 & 35 & 74 & 23 & 27\end{array}$

FUNCIONAL - EXPERIMENTO 1 - TEMPOS DA PEÇA 12 (segundos)

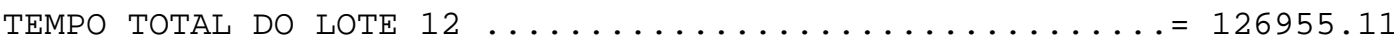

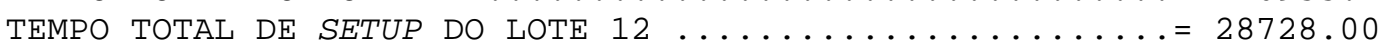

TEMPO TOTAL DE PROCESSAMENTO DO LOTE $12 \ldots \ldots \ldots \ldots \ldots \ldots=30240.00$

TEMPO TOTAL DE MANUSEIO PARA CARREGAR AS MÁQUINAS $\ldots \ldots \ldots=1280.00$

TEMPO TOTAL DE MANUSEIO PARA DESCARREGAR AS MÁQUINAS . . = 1280.00

TEMPO DE ESPERA ACUMULADA NO BUFFER DO LOTE $12 \ldots \ldots \ldots=126469.58$

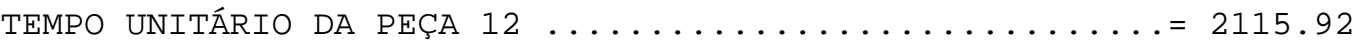

TEMPO UNITÁRIO DE SETUP DA PEÇA $12 \ldots \ldots \ldots \ldots \ldots \ldots \ldots \ldots \ldots . \ldots \ldots$

TEMPO UNITÁRIO DE PROCESSAMENTO DA PEÇA $12 \ldots \ldots \ldots \ldots \ldots=504.00$

TEMPO UNITÁRIO DE MANUSEIO PARA CARREGAR AS MÁQUINAS $\ldots=21.33$

TEMPO UNITÁRIO DE MANUSEIO PARA DESCARREGAR AS MÁQUINAS. $=21.33$

TEMPO DE ESPERA ACUMULADA NO BUFFER DA PEÇA $12 \ldots \ldots . \ldots=2107.83$

Lote de peças $12=60$

Processo de Fabricação (Máquinas) = $4 \begin{array}{lllllll}4 & 27 & 57 & 74 & 41 & 23 & 27\end{array}$

\section{FUNCIONAL - EXPERIMENTO 1 - TEMPOS DA PEÇA 13 (segundos)}

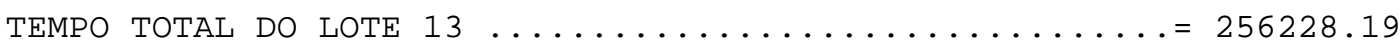

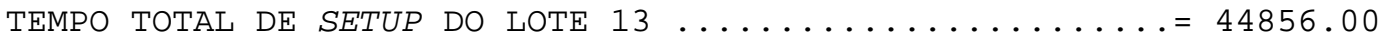

TEMPO TOTAL DE PROCESSAMENTO DO LOTE $13 \ldots \ldots \ldots \ldots \ldots \ldots=66240.00$

TEMPO TOTAL DE MANUSEIO PARA CARREGAR AS MÁQUINAS .....= 1112.85

TEMPO TOTAL DE MANUSEIO PARA DESCARREGAR AS MÁQUINAS...=1112.85

TEMPO DE ESPERA ACUMULADA NO BUFFER DO LOTE $13 \ldots \ldots \ldots=255711.80$

TEMPO UNITÁRIO DA PEÇA $13 \ldots \ldots \ldots \ldots \ldots \ldots \ldots \ldots \ldots \ldots \ldots \ldots \ldots \ldots \ldots$

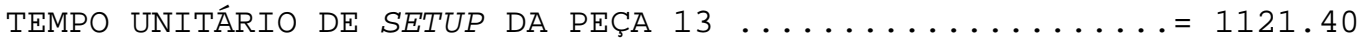

TEMPO UNITÁRIO DE PROCESSAMENTO DA PEÇA $13 \ldots \ldots \ldots \ldots \ldots \ldots=1656.00$

TEMPO UNITÁRIO DE MANUSEIO PARA CARREGAR AS MÁQUINAS . . = 27.82

TEMPO UNITÁRIO DE MANUSEIO PARA DESCARREGAR AS MÁQUINAS $=27.82$

TEMPO DE ESPERA ACUMULADA NO BUFFER DA PEÇA $13 \ldots \ldots \ldots . .6392 .79$

Lote de peças $13=40$

Processo de Fabricação (Máquinas) = $23 \quad 23 \quad 35414545 \quad 5353413$ 
Para o Experimento 1 do modelo funcional tem-se os resultados em custos:

FUNCIONAL - EXPERIMENTO 1 - CUSTOS DA PEÇA 1 (reais)

\begin{tabular}{|c|c|c|}
\hline & TOTAL DE & $8 \mathrm{R} \$$ \\
\hline JSTO & DE DEPRECIAÇÃO DE FERRAMENTAL ...... & $=42.00 \mathrm{R} \$$ (REAIS) \\
\hline $\mathrm{TO}$ & DE TROCA DE FERRAMENTAL $\ldots \ldots \ldots \ldots \ldots$ & $=0.00 \mathrm{R} S \quad(\mathrm{REAIS})$ \\
\hline $\mathrm{TOO}$ & DE AFIAÇÃO DE FERRAMENTAL & $=0.00 \mathrm{R} S \quad(\mathrm{REAIS})$ \\
\hline JSTO & TOTAL DE FERRAMENTAL & $=42.00 \mathrm{RS} \quad(\mathrm{REAIS})$ \\
\hline STO & 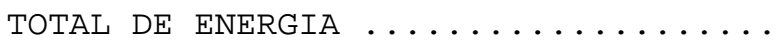 & $=403.81 \mathrm{R} \$$ (REAIS) \\
\hline STO & TOTAL DE MATERIAL .. & $=1000.00 \mathrm{RS}$ (REAIS) \\
\hline JSTO & TOTAL DE MÁQUINA .... & $=0.00 \mathrm{R} \$ \quad(\mathrm{REAIS})$ \\
\hline STO & TOTAL DE AJUSTAGEM $\ldots \ldots \ldots \ldots \ldots \ldots$ & $=0.00 \mathrm{R} S \quad(\mathrm{REAIS})$ \\
\hline JMER & DE PEÇAS PRODUZIDAS (TPP) & $=$ \\
\hline & TAL & $79 \mathrm{R} \$$ \\
\hline & TOTAL EFETIVO DE PRODUÇÃO & $.79 \mathrm{R} \$$ \\
\hline & TOTAL MANUFATURA $\ldots \ldots \ldots \ldots \ldots$ & $=1919.79 \mathrm{R} \$$ (REAIS) \\
\hline & $\ldots \ldots \ldots \ldots$ & $=1919.79 \mathrm{RS}$ (REAIS) \\
\hline
\end{tabular}

FUNCIONAL - EXPERIMENTO 1 - CUSTOS DA PEÇA 5 (reais)

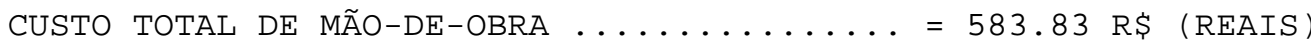

CUSTO DE DEPRECIAÇÃO DE FERRAMENTAL ...... 55.20 R\$ (REAIS)

CUSTO DE TROCA DE FERRAMENTAL ............................ 0.00 (REAIS)

CUSTO DE AFIAÇÃO DE FERRAMENTAL ........................ 0.00 (REAIS)

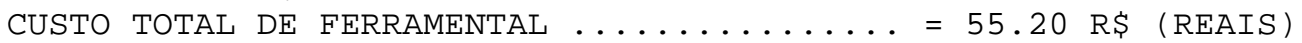

CUSTO TOTAL DE ENERGIA ............

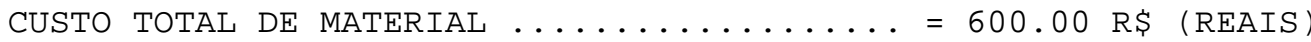

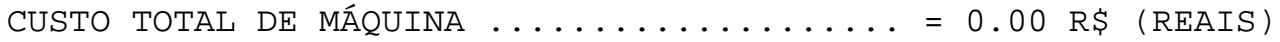

CUSTO TOTAL DE AJUSTAGEM ...................... 0.00 RS (REAIS)

NÚMERO DE PEÇAS PRODUZIDAS (TPP) .......

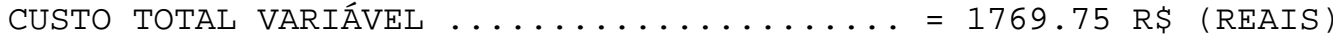

CUSTO TOTAL EFETIVO DE PRODUÇÃO .............................

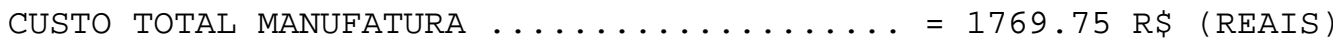

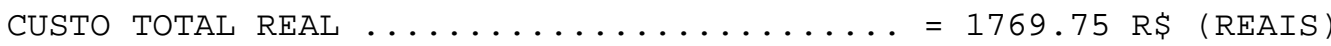

FUNCIONAL - EXPERIMENTO 1 - CUSTOS DA PEÇA 6 (reais)

CUSTO TOTAL DE MÃO-DE-OBRA ............................ 461.24 (REAIS)

CUSTO DE DEPRECIAÇÃO DE FERRAMENTAL ...... 60.00 R\$ (REAIS)

CUSTO DE TROCA DE FERRAMENTAL ......................... 0.00 (REAIS)

CUSTO DE AFIAÇÃO DE FERRAMENTAL .........

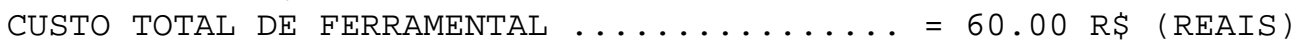

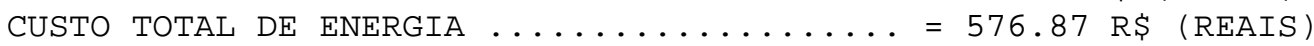

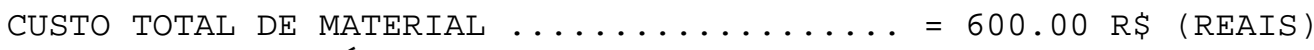

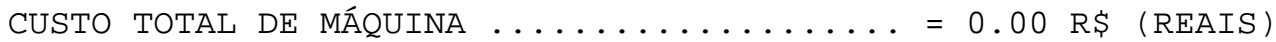

CUSTO TOTAL DE AJUSTAGEM ............................ 0.00 (REAIS)

NÚMERO DE PEÇAS PRODUZIDAS (TPP) ....... $=60$

CUSTO TOTAL VARIÁVEL ................................... 1698.11 (REAIS)

CUSTO TOTAL EFETIVO DE PRODUÇÃO ......... 1698.11 R\$ (REAIS) 
CUSTO TOTAL MANUFATURA .............

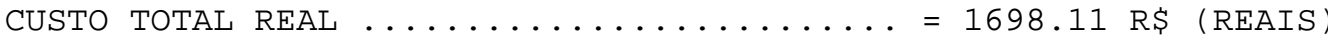

\section{FUNCIONAL - EXPERIMENTO 1 - CUSTOS DA PEÇA 8 (reais)}

CUSTO TOTAL DE MÃO-DE-OBRA ....................... 4430 R\$ (REAIS)

CUSTO DE DEPRECIAÇÃO DE FERRAMENTAL ...... 48.00 R\$ (REAIS)

CUSTO DE TROCA DE FERRAMENTAL ....................... 0.00 RS (REAIS)

CUSTO DE AFIAÇÃO DE FERRAMENTAL .......... 0.00 R\$ (REAIS)

CUSTO TOTAL DE FERRAMENTAL $\ldots \ldots \ldots \ldots \ldots \ldots=48.00$ RS (REAIS)

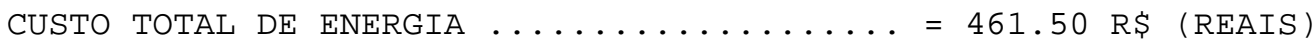

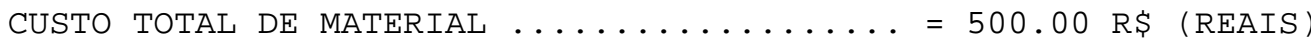

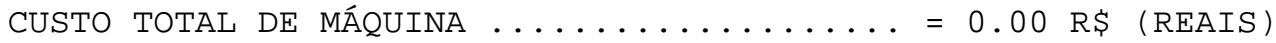

CUSTO TOTAL DE AJUSTAGEM $\ldots \ldots \ldots \ldots \ldots \ldots \ldots=0.00 \mathrm{R}$ (REAIS)

NÚMERO DE PEÇAS PRODUZIDAS (TPP) $\ldots \ldots \ldots \ldots=50$

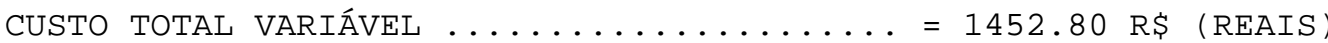

CUSTO TOTAL EFETIVO DE PRODUÇÃO ........ = 1452.80 R\$ (REAIS)

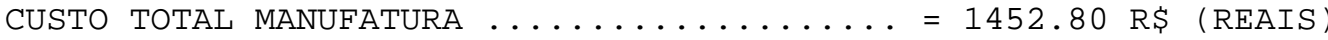

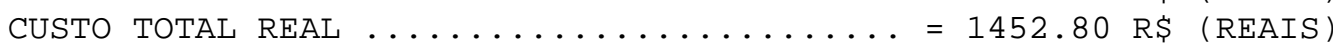

\section{FUNCIONAL - EXPERIMENTO 1 - CUSTOS DA PEÇA 10 (reais)}

\begin{tabular}{|c|c|c|}
\hline USTO & DE DEPRECIAÇÃO DE FERRAMENTAL $\ldots \ldots$ & $=36.00 \mathrm{R} \$$ (REAIS) \\
\hline STO & DE TROCA DE FERRAMENTAL $\ldots \ldots \ldots \ldots$ & $=0.00 \mathrm{R} \$ \quad(\mathrm{REAIS})$ \\
\hline STO & DE AFIAÇÃO DE FERRAMENTAL & $=0.00 \mathrm{R} S \quad(\mathrm{REAIS})$ \\
\hline STO & TOTAL DE FERRAMENTAL & $=36.00 \mathrm{R} \$ \quad(\mathrm{REAIS})$ \\
\hline STO & 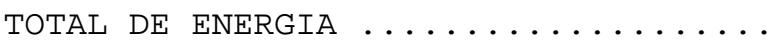 & $=346.12 \mathrm{R} \$$ (REAIS) \\
\hline STO & TOTAL DE MATERIAL $\ldots \ldots \ldots \ldots \ldots \ldots$ & $=500.00 \mathrm{R} \$$ (REAIS) \\
\hline JSTO & TOTAL DE MÁQUINA & $=0.00 \mathrm{R} S \quad(\mathrm{REAIS})$ \\
\hline STO & TOTAL DE AJUSTAGEM $\ldots \ldots \ldots \ldots \ldots \ldots$ & $=0.00 \mathrm{R} S \quad(\mathrm{REAIS})$ \\
\hline ER & DE PEÇAS PRODUZIDAS (TPP) & $=50$ \\
\hline & TOTAL VARIÁVEL & $.27 \mathrm{R} \$$ (REAIS) \\
\hline ISTO & TOTAL EFETIVO DE PRODUÇÃO & $=1266.27 \mathrm{R} \$$ \\
\hline & TOTAL MANUFATURA $\ldots \ldots \ldots \ldots \ldots$ & $5.27 \mathrm{R} \$$ \\
\hline TO & $\ldots \ldots \ldots \ldots$ & $=1266.27 \mathrm{RS}$ (REAIS) \\
\hline
\end{tabular}

\section{FUNCIONAL - EXPERIMENTO 1 - CUSTOS DA PEÇA 11 (reais)}

CUSTO TOTAL DE MÃO-DE-OBRA .......................... 3284 (REAIS)

CUSTO DE DEPRECIAÇÃO DE FERRAMENTAL ...... $=24.00$ R\$ (REAIS)

CUSTO DE TROCA DE FERRAMENTAL ......................... 0.00 (REAIS)

CUSTO DE AFIAÇÃO DE FERRAMENTAL .........

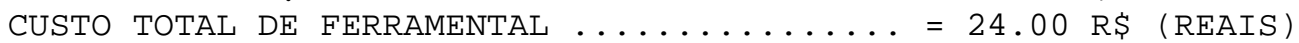

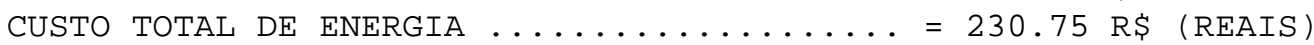

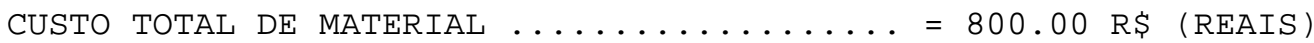

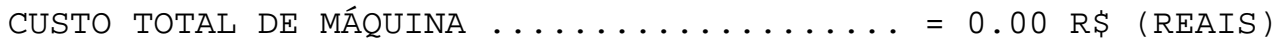

CUSTO TOTAL DE AJUSTAGEM ............. = $0.00 \mathrm{R} \$$ (REAIS)

NÚMERO DE PEÇAS PRODUZIDAS (TPP) $\ldots \ldots \ldots \ldots=80$ 


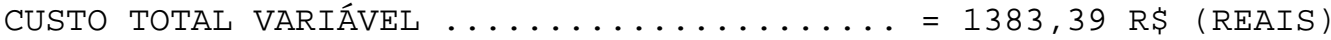

CUSTO TOTAL EFETIVO DE PRODUÇÃO ............................. 39 R\$ (REAIS)

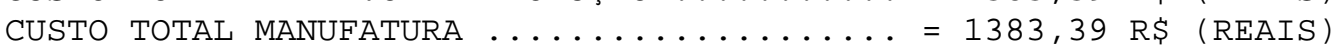

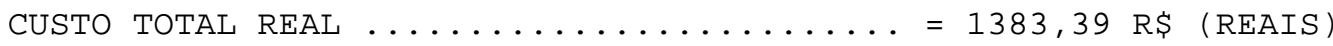

\section{FUNCIONAL - EXPERIMENTO 1 - CUSTOS DA PEÇA 12 (reais)}

\begin{tabular}{|c|c|c|}
\hline STO & DE DEPRECIAÇÃO DE FERRAMENTAL $\ldots \ldots$ & $=16.80 \mathrm{RS} \quad(\mathrm{RE}$ \\
\hline STO & DE TROCA DE FERRAMENTAL $\ldots \ldots \ldots \ldots \ldots$ & $=0.00 \mathrm{R} S$ (REAIS) \\
\hline & DE AFIAÇÃO DE FERRAMENTAL $\ldots \ldots \ldots \ldots$ & $=0.00 \mathrm{R} \$ \quad$ (REAIS) \\
\hline 0 & TOTAL DE FERRAMENTAL .. & $=16.80 \mathrm{R} S \quad$ (REAIS) \\
\hline $\mathrm{O}$ & TOTAL DE ENERGIA $\ldots \ldots \ldots \ldots \ldots$ & $=161.52 \mathrm{R} \$(\mathrm{RE}$ \\
\hline O & TOTAL DE MATERIAL $\ldots \ldots \ldots \ldots \ldots$ & $=600.00 \mathrm{R} \$$ \\
\hline $\mathrm{O}$ & TOTAL DE MÁQUINA & $=0.00 \mathrm{R} S \quad(\mathrm{REAIS})$ \\
\hline ГО & TOTAL DE AJUSTAGEM . . & $=0.00 \mathrm{R} \$ \quad(\mathrm{REA})$ \\
\hline JMER & DE PEÇAS PRODUZIDAS (TPP) & $=60$ \\
\hline & $\mathrm{OTI}$ & $26 \mathrm{R} \$$ \\
\hline & [VO DE PRODUÇÃO & $=991.26 \mathrm{R} \$$ \\
\hline & $\ldots \ldots \ldots \ldots \ldots \ldots$ & $=991.26 \mathrm{R} \$$ \\
\hline & $\ldots \ldots \ldots \ldots \ldots$ & $=991.26 \mathrm{R} \$$ \\
\hline
\end{tabular}

\section{FUNCIONAL - EXPERIMENTO 1 - CUSTOS DA PEÇA 13 (reais)}

CUSTO TOTAL DE MÃO-DE-OBRA ....................... 401.18 RS (REAIS)

CUSTO DE DEPRECIAÇÃO DE FERRAMENTAL ...... $=36.80$ RS (REAIS)

CUSTO DE TROCA DE FERRAMENTAL .......... = $0.00 \mathrm{R} \$$ (REAIS)

CUSTO DE AFIAÇÃO DE FERRAMENTAL .........

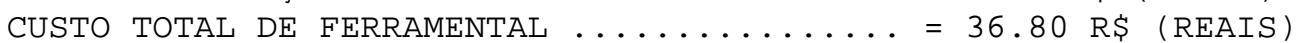

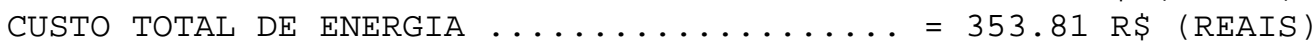

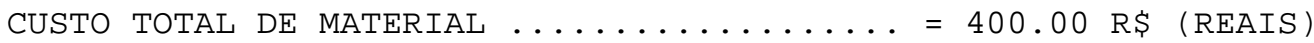

CUSTO TOTAL DE MÁQUINA $\ldots \ldots \ldots \ldots \ldots \ldots \ldots \ldots \ldots \ldots \ldots \ldots$ R

CUSTO TOTAL DE AJUSTAGEM $\ldots \ldots \ldots \ldots \ldots \ldots \ldots=0.00 \mathrm{R}$ (REAIS)

NÚMERO DE PEÇAS PRODUZIDAS (TPP) $\ldots \ldots \ldots=40$

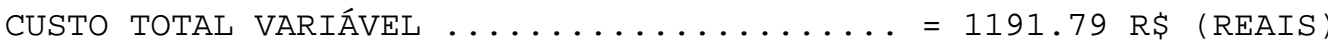

CUSTO TOTAL EFETIVO DE PRODUÇÃO ......... 1191.79 R\$ (REAIS)

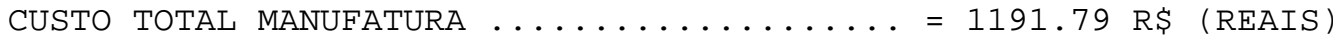

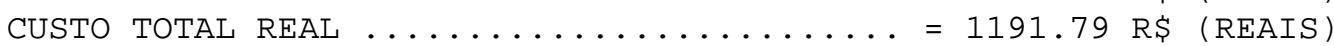

Para o Experimento 2 do modelo funcional tem-se os resultados em tempos:

FUNCIONAL - EXPERIMENTO 2 - TEMPOS DA PEÇA 1 (segundos)

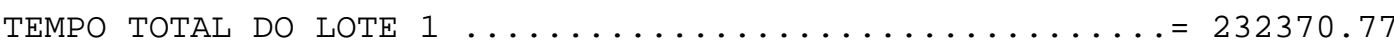

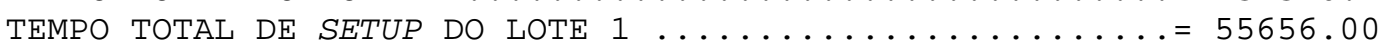

TEMPO TOTAL DE PROCESSAMENTO DO LOTE $1 \ldots \ldots \ldots \ldots \ldots \ldots \ldots=75600.00$

TEMPO TOTAL DE MANUSEIO PARA CARREGAR AS MÁQUINAS .....= 2666.67

TEMPO TOTAL DE MANUSEIO PARA DESCARREGAR AS MÁQUINAS ...=2666.67 
TEMPO DE ESPERA ACUMULADA NO BUfFER DO LOTE $1 \ldots \ldots \ldots \ldots=231752.54$

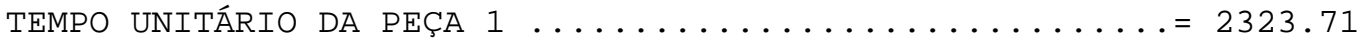

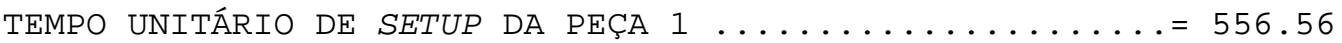

TEMPO UNITÁRIO DE PROCESSAMENTO DA PEÇA $1 \ldots \ldots \ldots \ldots \ldots . \ldots 756.00$

TEMPO UNITÁRIO DE MANUSEIO PARA CARREGAR AS MÁQUINAS $\ldots=26.67$

TEMPO UNITÁRIO DE MANUSEIO PARA DESCARREGAR AS MÁQUINAS $=26.67$

TEMPO DE ESPERA ACUMULADA NO BUFFER DA PEÇA $1 \ldots \ldots \ldots . . . .2317 .53$

Lote de peças $1=100$

Processo de Fabricação (Máquinas) = $2323 \quad 1313 \quad 35 \quad 3545 \quad 575762$

FUNCIONAL - EXPERIMENTO 2 - TEMPOS DA PEÇA 5 (segundos)

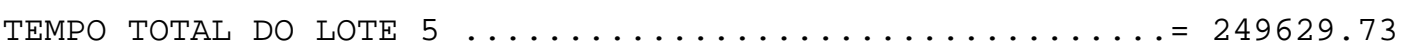

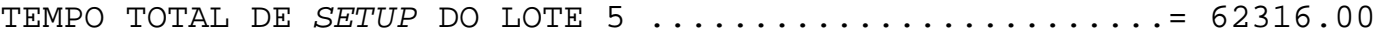

TEMPO TOTAL DE PROCESSAMENTO DO LOTE $5 \ldots \ldots \ldots \ldots \ldots \ldots=165600.00$

TEMPO TOTAL DE MANUSEIO PARA CARREGAR AS MÁQUINAS .....=1333.33

TEMPO TOTAL DE MANUSEIO PARA DESCARREGAR AS MÁQUINAS ...=1333.33

TEMPO DE ESPERA ACUMULADA NO BUFFER DO LOTE $5 \ldots \ldots \ldots \ldots=249004.39$

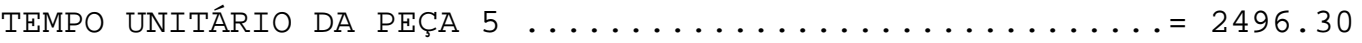

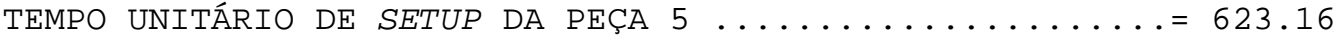

TEMPO UNITÁRIO DE PROCESSAMENTO DA PEÇA $5 \ldots \ldots \ldots \ldots \ldots \ldots=1656.00$

TEMPO UNITÁRIO DE MANUSEIO PARA CARREGAR AS MÁQUINAS $\ldots=13.33$

TEMPO UNITÁRIO DE MANUSEIO PARA DESCARREGAR AS MÁQUINAS. $=13.33$

TEMPO DE ESPERA ACUMULADA NO BUFFER DA PEÇA $5 \ldots \ldots \ldots \ldots=2490.04$

Lote de peças $5=100$

Processo de Fabricação (Máquinas) = $23 \quad 23 \quad 35414545 \quad 5753 \quad 62464$ 13

FUNCIONAL - EXPERIMENTO 2 - TEMPOS DA PEÇA 6 (segundos)

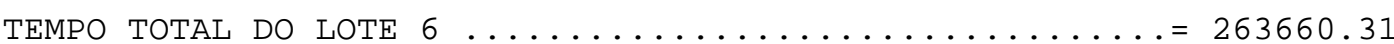

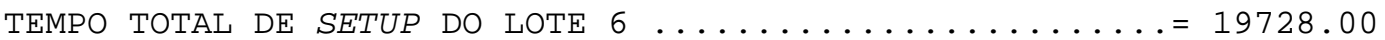

TEMPO TOTAL DE PROCESSAMENTO DO LOTE $6 \ldots \ldots \ldots \ldots \ldots \ldots=180000.00$

TEMPO TOTAL DE MANUSEIO PARA CARREGAR AS MÁQUINAS .....= 1600.00

TEMPO TOTAL DE MANUSEIO PARA DESCARREGAR AS MÁQUINAS . . = 1600.00

TEMPO DE ESPERA ACUMULADA NO BUFFER DO LOTE $6 \ldots \ldots \ldots . \ldots=263318.15$

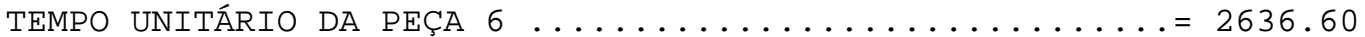

TEMPO UNITÁRIO DE SETUP DA PEÇA $6 \ldots \ldots \ldots \ldots \ldots \ldots \ldots \ldots \ldots . \ldots \ldots$

TEMPO UNITÁRIO DE PROCESSAMENTO DA PEÇA $6 \ldots \ldots \ldots \ldots \ldots \ldots=1800.00$

TEMPO UNITÁRIO DE MANUSEIO PARA CARREGAR AS MÁQUINAS $\ldots=16.00$

TEMPO UNITÁRIO DE MANUSEIO PARA DESCARREGAR AS MÁQUINAS $=16.00$

TEMPO DE ESPERA ACUMULADA NO BUFFER DA PEÇA $6 \ldots \ldots \ldots \ldots=2633.18$

Lote de peças $6=100$

Processo de Fabricação (Máquinas) = $\begin{array}{llllll}23 & 62 & 35 & 53 & 23\end{array}$

FUNCIONAL - EXPERIMENTO 2 - TEMPOS DA PEÇA 8 (segundos)

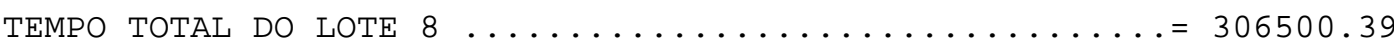

TEMPO TOTAL DE SETUP DO LOTE $8 \ldots \ldots \ldots \ldots \ldots \ldots \ldots \ldots \ldots \ldots \ldots \ldots . \ldots \ldots$ 
TEMPO TOTAL DE PROCESSAMENTO DO LOTE $8 \ldots \ldots \ldots \ldots \ldots \ldots \ldots=172800.00$

TEMPO TOTAL DE MANUSEIO PARA CARREGAR AS MÁQUINAS .....=2933.33

TEMPO TOTAL DE MANUSEIO PARA DESCARREGAR AS MÁQUINAS ...=2933.33

TEMPO DE ESPERA ACUMULADA NO BUFFER DO LOTE $8 \ldots \ldots \ldots \ldots=305891.60$

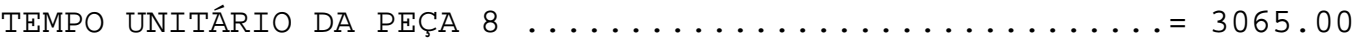

TEMPO UNITÁRIO DE SETUP DA PEÇA $8 \ldots \ldots \ldots \ldots \ldots \ldots \ldots \ldots \ldots \ldots . \ldots \ldots$

TEMPO UNITÁRIO DE PROCESSAMENTO DA PEÇA $8 \ldots \ldots \ldots \ldots \ldots \ldots=1728.00$

TEMPO UNITÁRIO DE MANUSEIO PARA CARREGAR AS MÁQUINAS $\ldots=29.33$

TEMPO UNITÁRIO DE MANUSEIO PARA DESCARREGAR AS MÁQUINAS $=29.33$

TEMPO DE ESPERA ACUMULADA NO BUFFER DA PEÇA $8 \ldots \ldots \ldots \ldots=3058.92$

Lote de peças $8=100$

Processo de Fabricação (Máquinas) = $23 \quad 23 \quad 3541454562 \quad 62464413$

\section{FUNCIONAL - EXPERIMENTO 2 - TEMPOS DA PEÇA 10 (segundos)}

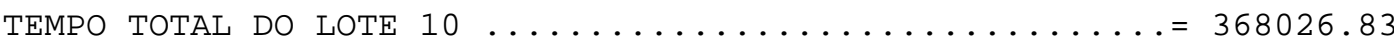

TEMPO TOTAL DE SETUP DO LOTE $10 \ldots \ldots \ldots \ldots \ldots \ldots \ldots \ldots \ldots . \ldots . \ldots . \ldots . \ldots . \ldots 1580.00$

TEMPO TOTAL DE PROCESSAMENTO DO LOTE $10 \ldots \ldots \ldots \ldots \ldots \ldots=129600.00$

TEMPO TOTAL DE MANUSEIO PARA CARREGAR AS MÁQUINAS $\ldots \ldots \ldots=2433.33$

TEMPO TOTAL DE MANUSEIO PARA DESCARREGAR AS MÁQUINAS ...= 2433.33

TEMPO DE ESPERA ACUMULADA NO BUFFER DO LOTE $10 \ldots \ldots \ldots . .367522 .54$

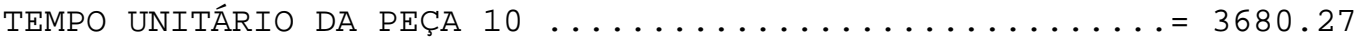

TEMPO UNITÁRIO DE SETUP DA PEÇA $10 \ldots \ldots \ldots \ldots \ldots \ldots \ldots \ldots . \ldots . \ldots 15.80$

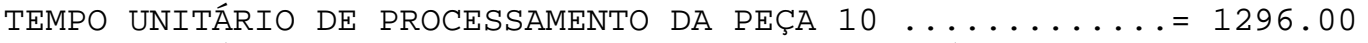

TEMPO UNITÁRIO DE MANUSEIO PARA CARREGAR AS MÁQUINAS $\ldots=24.33$

TEMPO UNITÁRIO DE MANUSEIO PARA DESCARREGAR AS MÁQUINAS $=24.33$

TEMPO DE ESPERA ACUMULADA NO BUFFER DA PEÇA $10 \ldots \ldots \ldots . . .3675 .23$

Lote de peças $10=100$

Processo de Fabricação (Máquinas) = $\begin{array}{llllllllll}23 & 23 & 27 & 35 & 41 & 45 & 45 & 4 & 13\end{array}$

Para o Experimento 2 do modelo funcional tem-se os resultados em custos:

FUNCIONAL - EXPERIMENTO 2 - CUSTOS DA PEÇA 1 (reais)

\begin{tabular}{|c|c|c|}
\hline 0 & $\begin{array}{l}\text { TOTAL DE MAO-DE } \\
\text { DE DEPRECIACÃO }\end{array}$ & 98 RS \\
\hline TO & 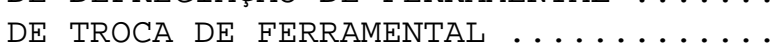 & $=0.00 \mathrm{R} S \quad(\mathrm{REAIS})$ \\
\hline STO & DE AFIAÇÃO DE FERRAMENTAL & $=0.00 \mathrm{R} S \quad(\mathrm{REAIS})$ \\
\hline STO & TOTAL DE FERRAMENTAL $\ldots . . . .$. & $=42.00 \mathrm{R} \$ \quad(\mathrm{REAIS})$ \\
\hline ISTO & 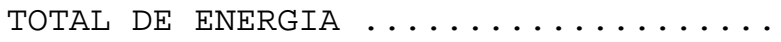 & $=403.81 \mathrm{R} \$ \quad(\mathrm{REAIS})$ \\
\hline JSTO & TOTAL DE MATERIAL .. & $=1000.00 \mathrm{R} \$ \quad(\mathrm{REAIS})$ \\
\hline JSTO & TOTAL DE MÁQUINA & $=0.00 \mathrm{RS} \quad(\mathrm{REAIS})$ \\
\hline JSTO & TOTAL DE AJUSTAGEM $\ldots . . . . . . .$. & $=0.00 \mathrm{R} \$$ \\
\hline ÚMERO & DE PEÇAS PRODUZIDAS (TPP) & $=$ \\
\hline & TAL & $9 \mathrm{R} \$$ \\
\hline & TOTAL EFETIVO DE PRODUÇÃO & $9.79 \mathrm{R} \$$ \\
\hline $\mathrm{O}$ & TOTAL MANUFATURA $\ldots \ldots \ldots \ldots \ldots \ldots$ & $=1919.79 \mathrm{R} S \quad(\mathrm{REAIS})$ \\
\hline TTT & TOTAL REAL & $=1919.79 \mathrm{RS} \quad(\mathrm{REAIS})$ \\
\hline
\end{tabular}


FUNCIONAL - EXPERIMENTO 2 - CUSTOS DA PEÇA 5 (reais)

\begin{tabular}{|c|c|c|}
\hline & OTAL DE MÃO-DE-OBRA .. & $=82$ \\
\hline & DE DEPRECIAÇÃO DE FERRAMENTAL ... & $=92.00 \mathrm{R} \$ \quad(\mathrm{REAIS})$ \\
\hline TO & DE TROCA DE FERRAMENTAL .. & $=0.00 \mathrm{RS} \quad(\mathrm{REAIS})$ \\
\hline STO & 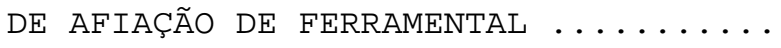 & $=0.00 \mathrm{RS} \quad(\mathrm{REAIS})$ \\
\hline $\mathrm{O}$ & TOTAL DE FERRAMENTAL $\ldots \ldots \ldots \ldots \ldots$ & $=92.00 \mathrm{R} \$ \quad(\mathrm{REAIS})$ \\
\hline ISTO & TOTAL DE ENERGIA ..... & $=884.53 \mathrm{R} \$ \quad(\mathrm{REAIS})$ \\
\hline TO & 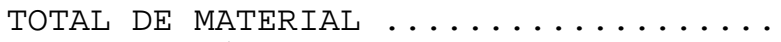 & $=1000.00 \mathrm{R} \$(\mathrm{REAIS})$ \\
\hline STO & TOTAL DE MÁQUINA ... & $=0.00 \mathrm{R} S \quad(\mathrm{REAIS})$ \\
\hline STO & TOTAL DE AJUSTAGEM . & $=0.00 \mathrm{RS} \quad(\mathrm{REAIS})$ \\
\hline UER & DE PEÇAS PRODUZIDAS (TPP) & 100 \\
\hline & OTAL & $56 \mathrm{R} \$$ \\
\hline & TOTAL EFETIVO DE PRODUÇÃO .. & $=2799.56 \mathrm{RS} \quad(\mathrm{REAIS})$ \\
\hline & TOTAL MANUFATURA & $=2799.56 \mathrm{R} \$ \quad(\mathrm{RE}$ \\
\hline & OTAL REAL & $=2799.56 \mathrm{R} \$$ \\
\hline
\end{tabular}

FUNCIONAL - EXPERIMENTO 2 - CUSTOS DA PEÇA 6 (reais)

CUSTO TOTAL DE MÃO-DE-OBRA .......................... 721.24 R\$ (REAIS)

CUSTO DE DEPRECIAÇÃO DE FERRAMENTAL ...... $=100.00$ R\$ (REAIS)

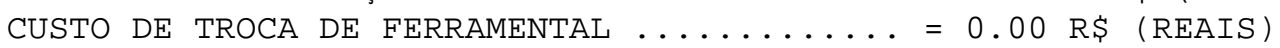

CUSTO DE AFIAÇÃO DE FERRAMENTAL .......................... 0.00 (REAIS)

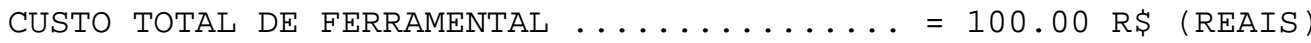

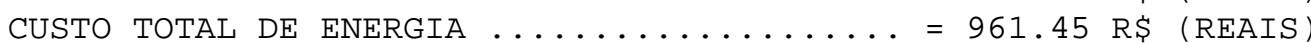

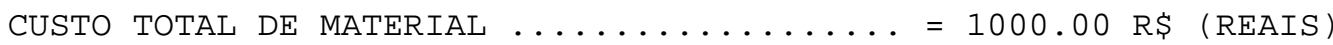

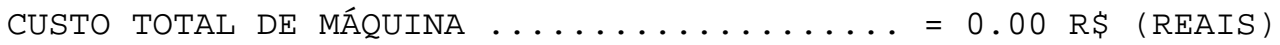

CUSTO TOTAL DE AJUSTAGEM ....................... 0.00 RS (REAIS

NÚMERO DE PEÇAS PRODUZIDAS $(\mathrm{TPP}) \ldots \ldots \ldots \ldots=100$

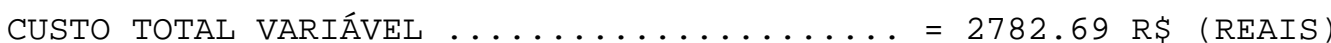

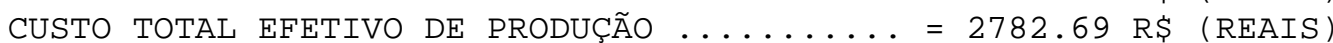

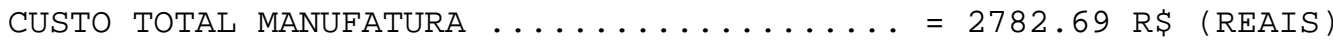

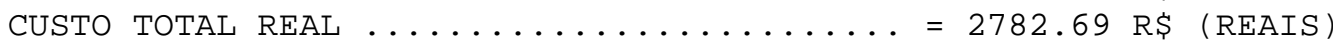

\section{FUNCIONAL - EXPERIMENTO 2 - CUSTOS DA PEÇA 8 (reais)}

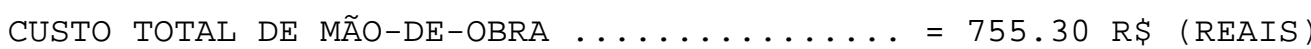

CUSTO DE DEPRECIAÇÃO DE FERRAMENTAL ...... 96.00 R\$ (REAIS)

CUSTO DE TROCA DE FERRAMENTAL ....................... 0.00 RS (REAIS)

CUSTO DE AFIAÇÃO DE FERRAMENTAL ........................... 0.00 (REAIS)

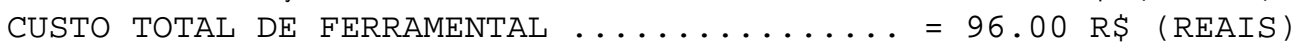

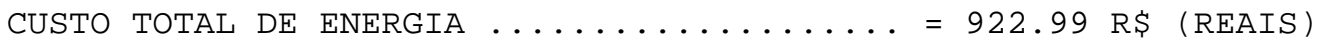

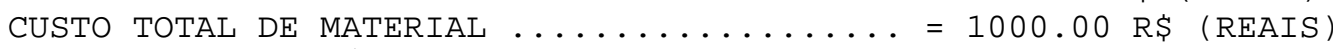

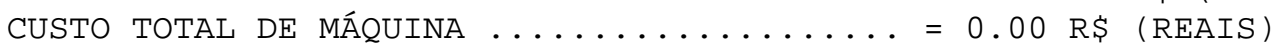

CUSTO TOTAL DE AJUSTAGEM $\ldots \ldots \ldots \ldots \ldots \ldots \ldots=0.00 \mathrm{R} \$$ (REAIS)

NÚMERO DE PEÇAS PRODUZIDAS $(\mathrm{TPP}) \ldots \ldots \ldots=100$

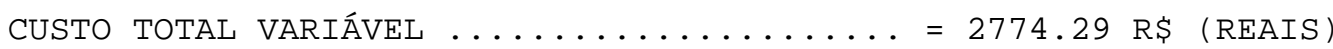

CUSTO TOTAL EFETIVO DE PRODUÇÃO ........ 


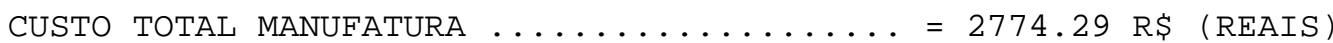

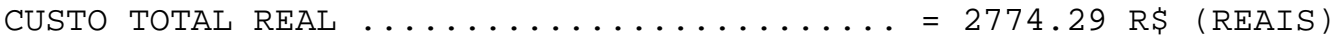

FUNCIONAL - EXPERIMENTO 2 - CUSTOS DA PEÇA 10 (reais)

\begin{tabular}{|c|c|c|}
\hline JSTO & DE DEPRECIAÇÃO DE FERRAMENTAL $\ldots \ldots \ldots$ & $=72.00 \mathrm{RS}$ (REAIS) \\
\hline $\mathrm{TO}$ & DE TROCA DE FERRAMENTAL $\ldots \ldots \ldots \ldots \ldots$ & $=0.00 \mathrm{R} S \quad(\mathrm{REAIS})$ \\
\hline STO & DE AFIAÇÃO DE FERRAMENTAL & $=0.00 \mathrm{R} S \quad$ (REAIS) \\
\hline STO & TOTAL DE FERRAMENTAL $\ldots \ldots \ldots \ldots$ & $=72.00 \mathrm{R} \$ \quad$ (REAIS) \\
\hline STO & TOTAL DE ENERGIA $\ldots \ldots \ldots \ldots \ldots$ & $=692.24 \mathrm{R} \$$ (REAIS) \\
\hline $\mathrm{JTO}$ & TOTAL DE MATERIAL & $=1000.00 \mathrm{R} \$$ (REAIS) \\
\hline STO & TOTAL DE MÁQUINA ....... & $=0.00 \mathrm{R} S \quad(\mathrm{REAIS})$ \\
\hline JSTO & TOTAL DE AJUSTAGEM ... & $=0.00 \mathrm{R} S \quad(\mathrm{REAIS})$ \\
\hline P & DE PEÇAS E & $=100$ \\
\hline & OTAL & $39 \mathrm{R} \$$ \\
\hline & VO DE $\quad$ PRODUÇÃO & ( REAIS) \\
\hline I & TOTAL MANUFATURA $\ldots \ldots \ldots \ldots \ldots$ & $=2382.39 \mathrm{R} \$$ (REAIS) \\
\hline & TOTAL REAL & $=2382.39 \mathrm{R} \$$ (REAIS) \\
\hline
\end{tabular}

Para o Experimento 1 do modelo celular tem-se os resultados em tempos:

\section{CELULAR - EXPERIMENTO 1 - TEMPOS DA PEÇA 1 (segundos)}

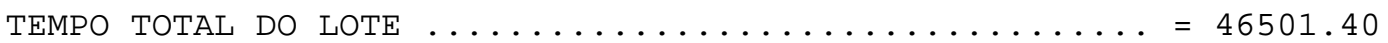

TEMPO TOTAL DE PROCESSAMENTO DO LOTE $1 \ldots \ldots \ldots \ldots \ldots \ldots \ldots=50400.00$

TEMPO TOTAL DE MANUSEIO PARA CARREGAR AS MÁQUINAS .....= 2392.33

TEMPO TOTAL DE MANUSEIO PARA DESCARREGAR AS MÁQUINAS $\ldots=2392.33$

TEMPO DE ESPERA ACUMULADA NO BUFFER DO LOTE $1 \ldots \ldots \ldots \ldots=522368.16$

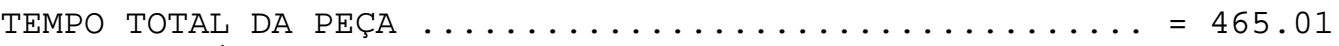

TEMPO UNITÁRIO DE PROCESSAMENTO DA PEÇA $1 \ldots \ldots \ldots \ldots \ldots . . \ldots 504.00$

TEMPO UNITÁRIO DE MANUSEIO PARA CARREGAR AS MÁQUINAS . . = 23.92

TEMPO UNITÁRIO DE MANUSEIO PARA DESCARREGAR AS MÁQUINAS $=23.92$

TEMPO DE ESPERA ACUMULADA NO BUFFER DA PEÇA $1 \ldots \ldots \ldots \ldots=5223.68$

TEMPO TOTAL DE SETUP DA FAMÍLIA $=6000$

Processo de Fabricação (Máquinas) = $\begin{array}{lllllllllll}23 & 23 & 13 & 13 & 35 & 0 & 0 & 0 & 0 & 0\end{array}$

Lote de pecas $1=100$

Processo da família $=2$

TEMPO UNITÁRIO DE SETUP, USINAGEM, CARREGAMENTO E DESCARREGAMENTO DE MÁQUINA

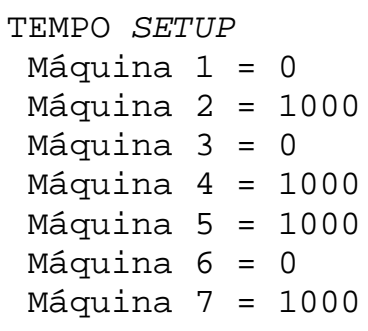




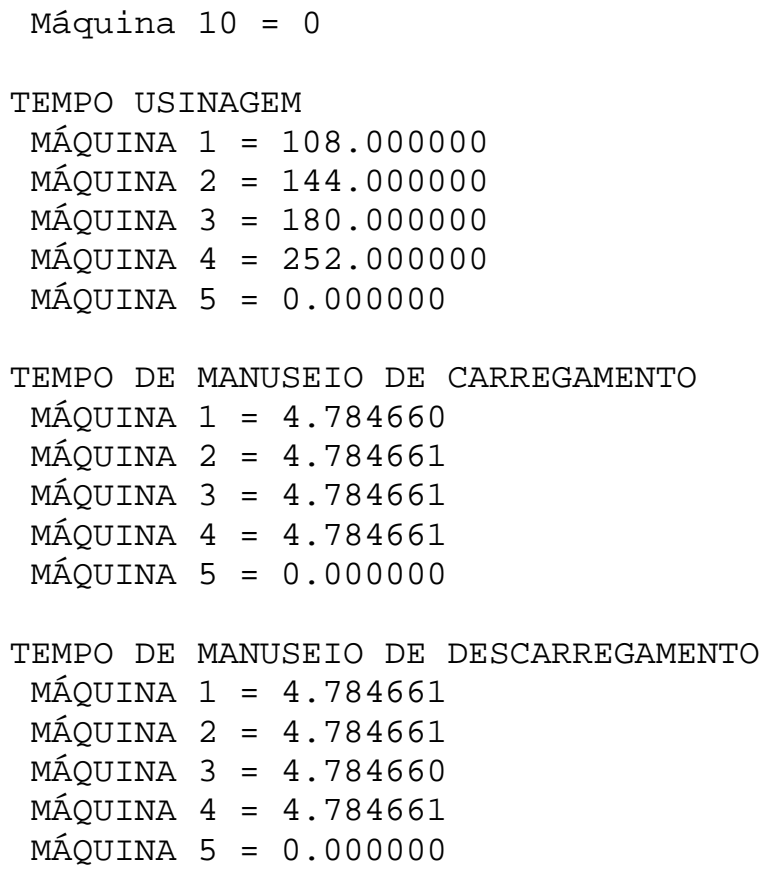

\section{CELULAR - EXPERIMENTO 1 - TEMPOS DA PEÇA 6 (segundos)}

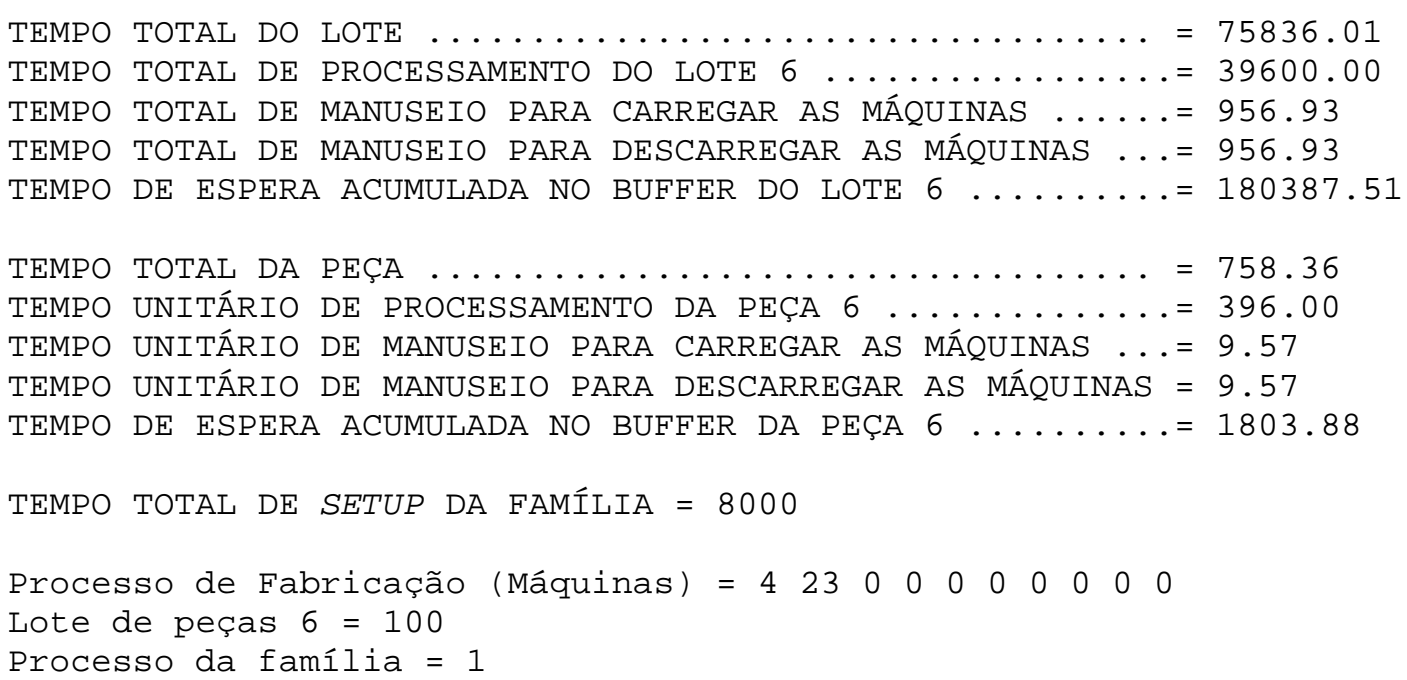

TEMPO UNITÁRIO DE SETUP, USINAGEM, CARREGAMENTO E DESCARREGAMENTO DE MÁQUINA

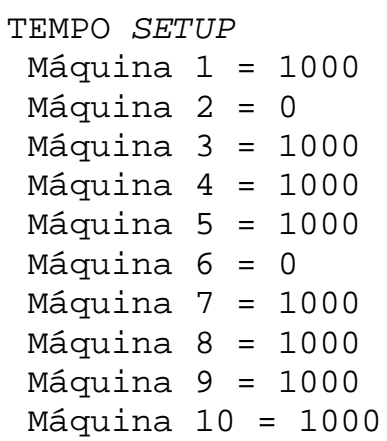




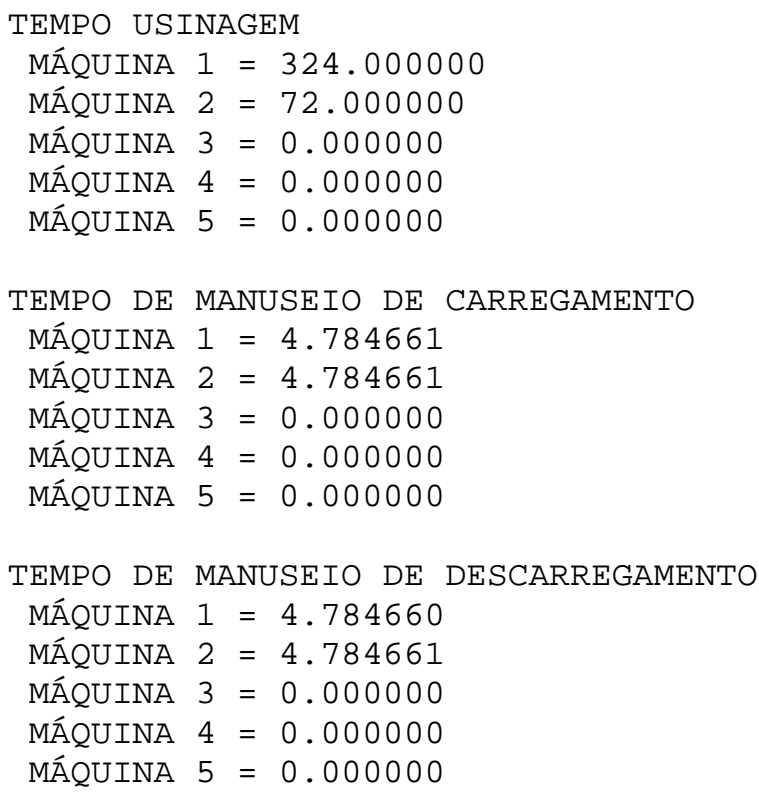

\section{CELULAR - EXPERIMENTO 1 - TEMPOS DA PEÇA 8 (segundos)}

TEMPO TOTAL DO LOTE .................... $=111606.01$

TEMPO TOTAL DE PROCESSAMENTO DO LOTE $8 \ldots \ldots \ldots \ldots \ldots \ldots \ldots=90000.00$

TEMPO TOTAL DE MANUSEIO PARA CARREGAR AS MÁQUINAS $\ldots \ldots \ldots=1913.86$

TEMPO TOTAL DE MANUSEIO PARA DESCARREGAR AS MÁQUINAS $\ldots=1913.86$

TEMPO DE ESPERA ACUMULADA NO BUFFER DO LOTE $8 \ldots \ldots \ldots \ldots=848425.37$

TEMPO TOTAL DA PEÇA .....................

TEMPO UNITÁRIO DE PROCESSAMENTO DA PEÇA $8 \ldots \ldots \ldots \ldots \ldots \ldots=900.00$

TEMPO UNITÁRIO DE MANUSEIO PARA CARREGAR AS MÁQUINAS $\ldots=19.14$

TEMPO UNITÁRIO DE MANUSEIO PARA DESCARREGAR AS MÁQUINAS $=19.14$

TEMPO DE ESPERA ACUMULADA NO BUFFER DA PEÇA $8 \ldots \ldots \ldots \ldots=8484.25$

TEMPO TOTAL DE SETUP DA FAMÍLIA $=6000$

Processo de Fabricação (Máquinas) = $\begin{array}{lllllllllll}23 & 23 & 35 & 41 & 0 & 0 & 0 & 0 & 0 & 0\end{array}$

Lote de peças $8=100$

Processo da família $=2$

TEMPO UNITÁRIO DE SETUP, USINAGEM, CARREGAMENTO E DESCARREGAMENTO DE MÁQUINA

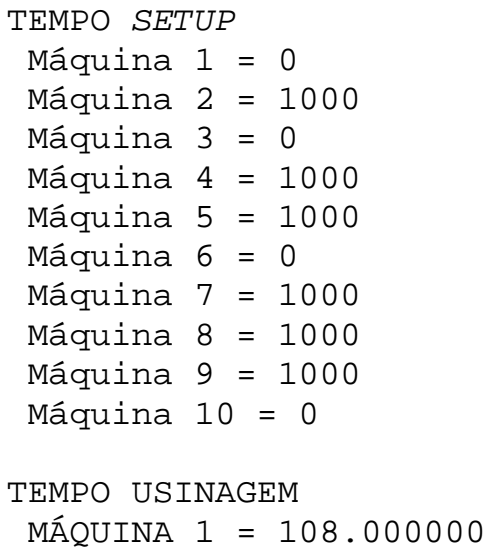


MÁQUINA $2=108.000000$

MÁQUINA $3=216.000000$

MÁQUINA $4=468.000000$

TEMPO DE MANUSEIO DE CARREGAMENTO

MÁQUINA $1=4.784660$

MÁQUINA $2=4.784661$

MÁQUINA $3=4.784661$

MÁQUINA $4=4.784661$

TEMPO DE MANUSEIO DE DESCARREGAMENTO

MÁQUINA $1=4.784661$

MÁQUINA $2=4.784661$

MÁQUINA $3=4.784660$

MÁQUINA $4=4.784661$

\section{CELULAR - EXPERIMENTO 1 - TEMPOS DA PEÇA 10 (segundos)}

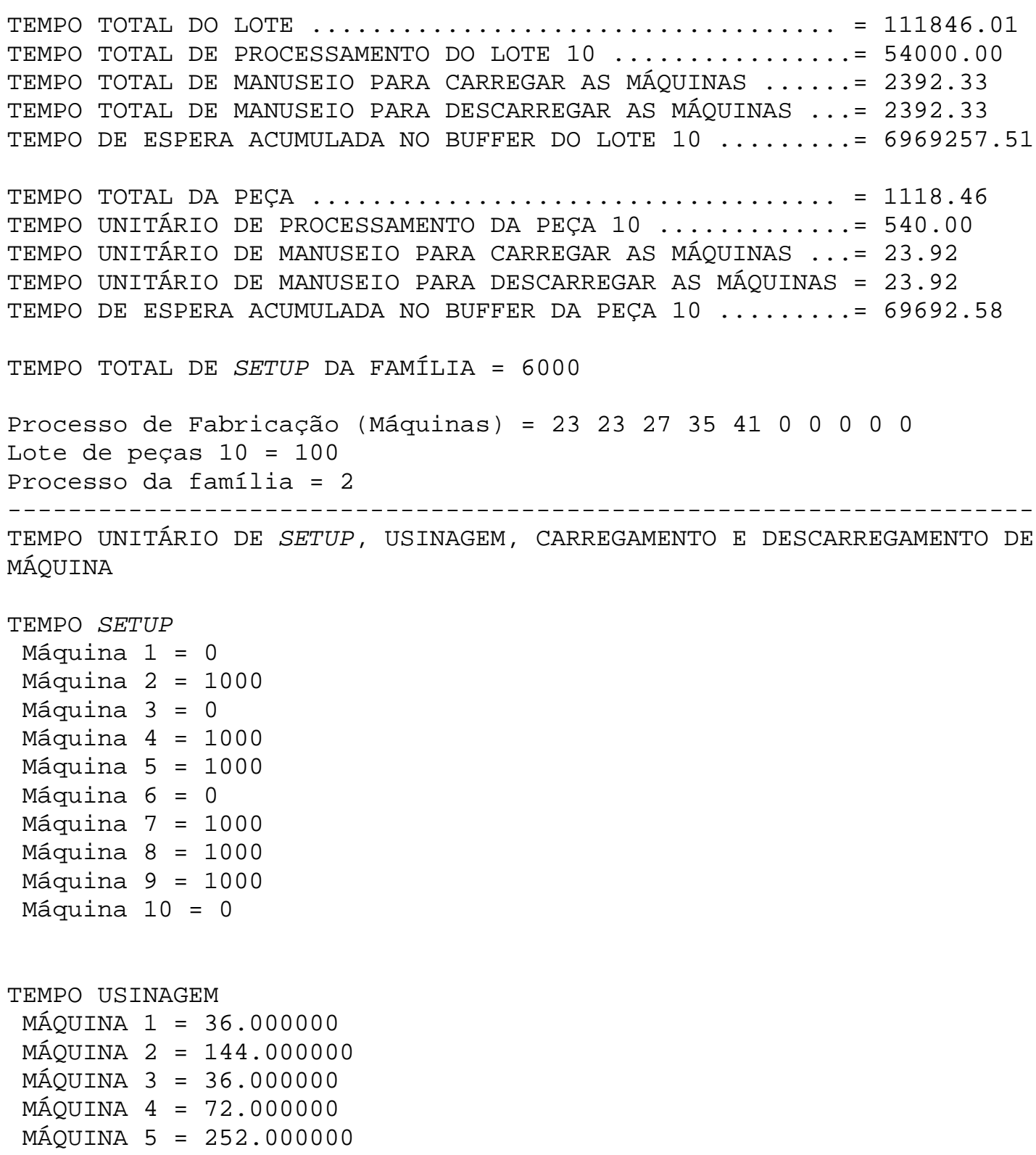


TEMPO DE MANUSEIO DE CARREGAMENTO

MÁQUINA $1=4.784660$

MÁQUINA $2=4.784661$

MÁQUINA $3=4.784661$

MÁQUINA $4=4.784661$

MÁQUINA $5=4.784661$

TEMPO DE MANUSEIO DE DESCARREGAMENTO

MÁQUINA $1=4.784661$

MÁQUINA $2=4.784661$

MÁQUINA $3=4.784661$

MÁQUINA $4=4.784660$

MÁQUINA $5=4.784661$

\section{CELULAR - EXPERIMENTO 1 - TEMPOS DA PEÇA 11 (segundos)}

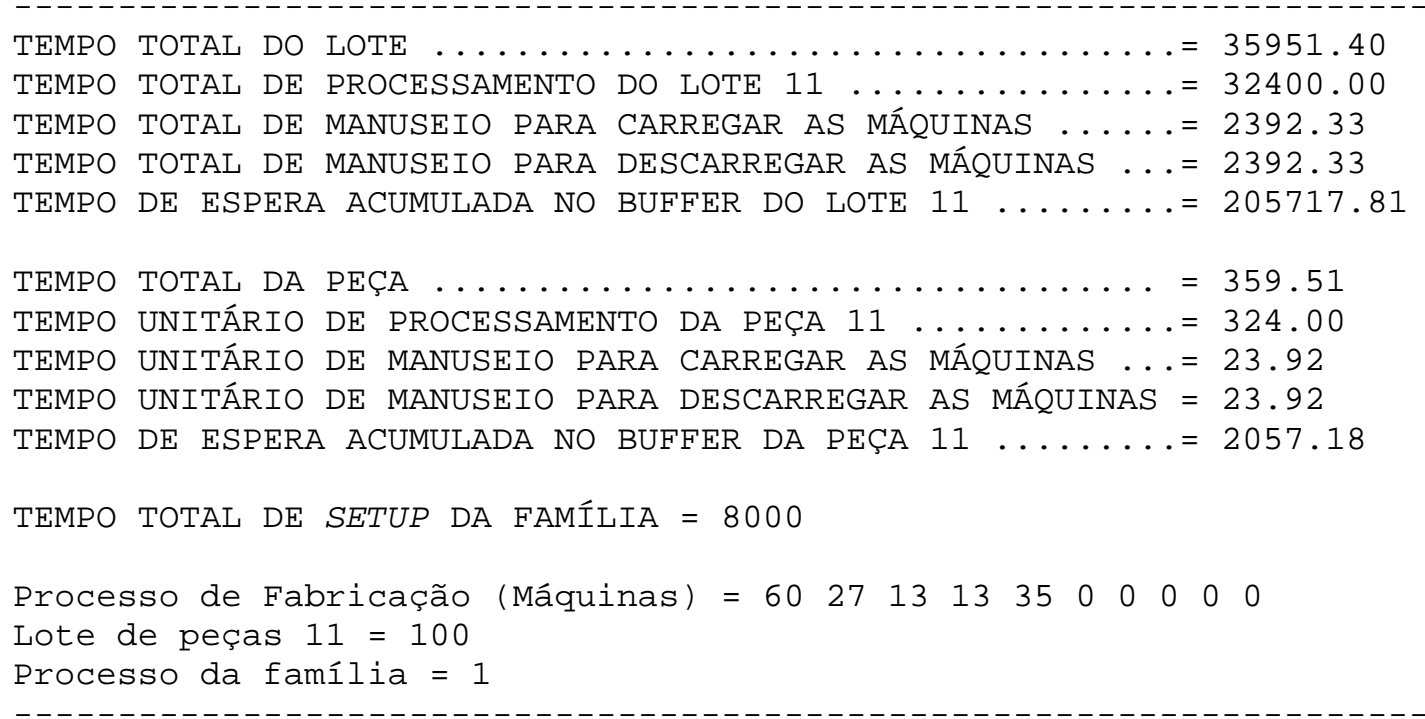

TEMPO UNITÁRIO DE SETUP, USINAGEM, CARREGAMENTO E DESCARREGAMENTO DE MÁQUINA

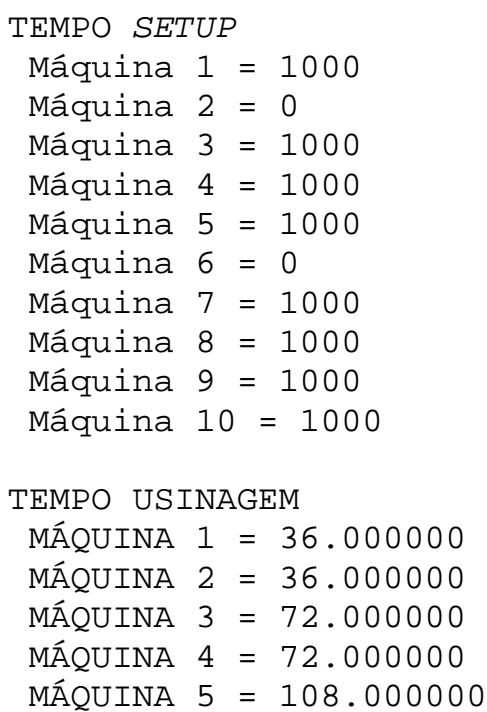

TEMPO DE MANUSEIO DE CARREGAMENTO 


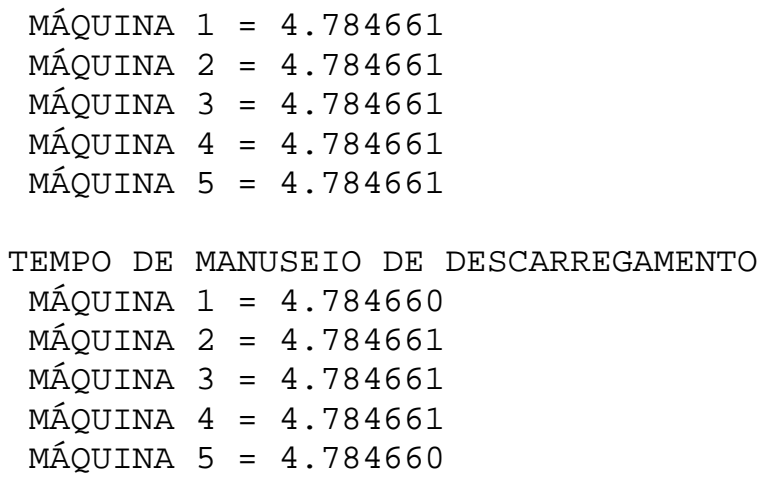

\section{CELULAR - EXPERIMENTO 1 - TEMPOS DA PEÇA 12 (segundos)}

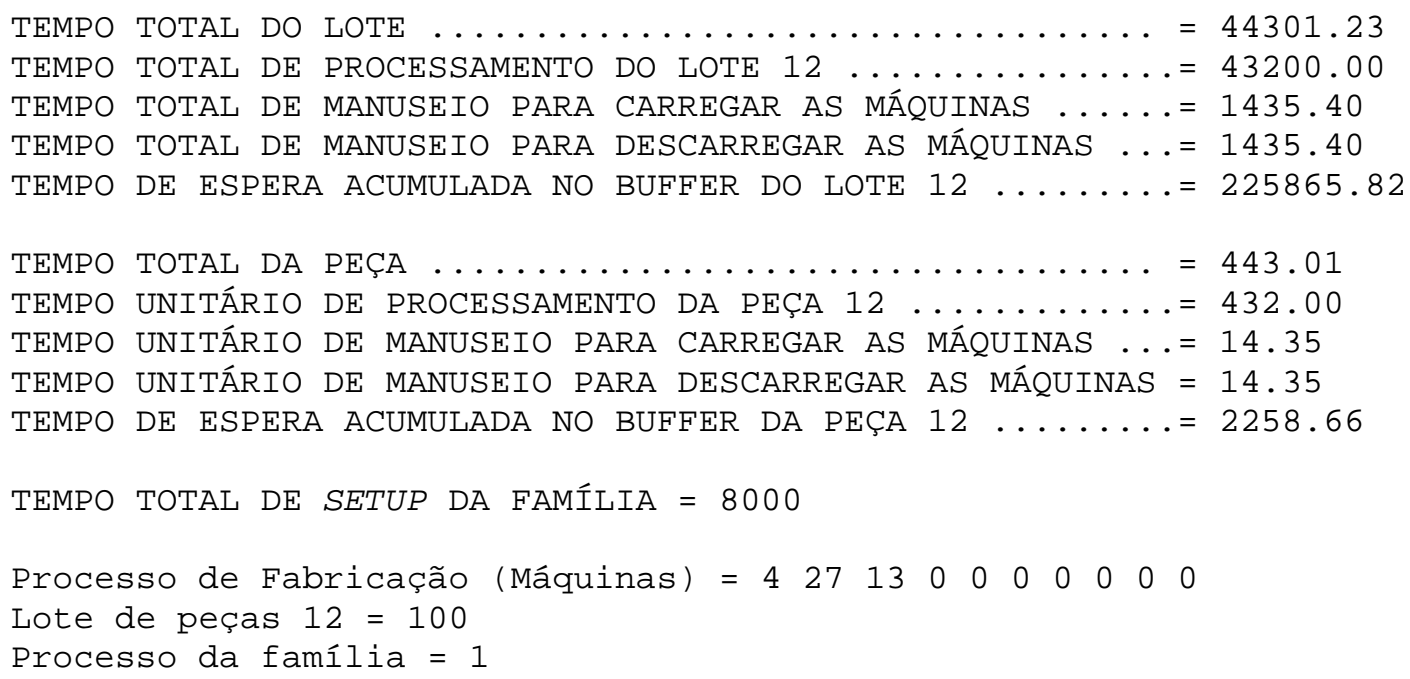

TEMPO UNITÁRIO DE SETUP, USINAGEM, CARREGAMENTO E DESCARREGAMENTO DE MÁQUINA

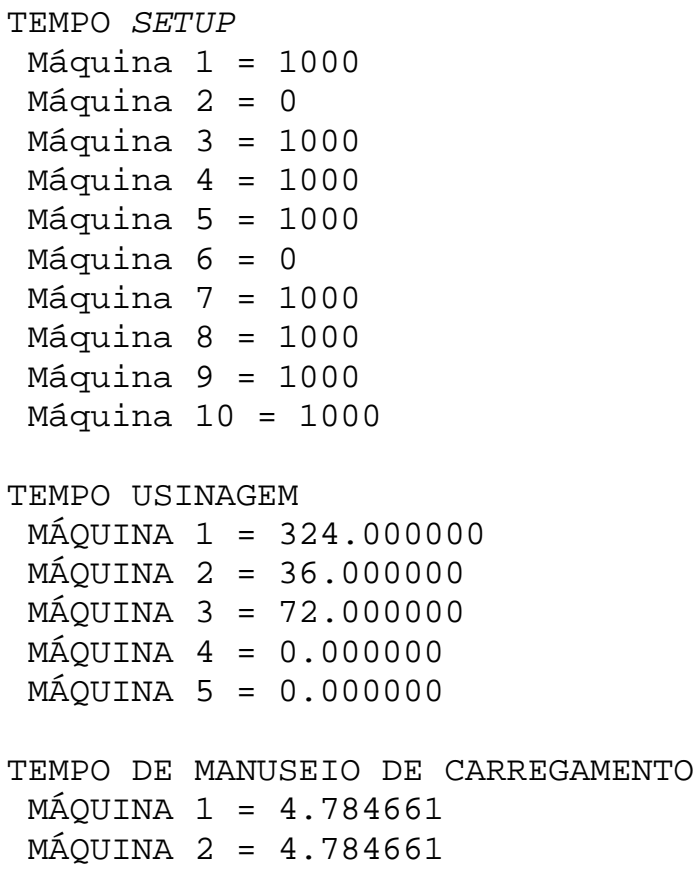


MÁQUINA $5=0.000000$

TEMPO DE MANUSEIO DE DESCARREGAMENTO

MÁQUINA $1=4.784661$

MÁQUINA $2=4.784661$

MÁQUINA $3=4.784660$

MÁQUINA $4=4.784661$

MÁQUINA $5=0.000000$

Para o Experimento 1 do modelo celular tem-se os resultados em custos:

\begin{tabular}{|c|c|}
\hline & CELULAR - EXPERIMENTO 1 - CUSTOS DA PEÇA 1 (reais) \\
\hline CUSTO & TOTAL DE MÃO-DE-OBRA \\
\hline CUSTO & DE DEPRECIAÇÃO DE FERRAMENTAL $\ldots . . .=28.00$ R\$ (REAIS) \\
\hline CUSTO & DE TROCA DE FERRAMENTAL $\ldots \ldots \ldots \ldots=0.00$ R\$ (REAIS) \\
\hline CUSTO & DE AFIAÇÃO DE FERRAMENTAL $\ldots \ldots \ldots \ldots=0.00$ R\$ (REAIS) \\
\hline CUSTO & TOTAL DE FERRAMENTAL $\ldots \ldots \ldots \ldots \ldots \ldots=28.00$ R\$ (REAIS) \\
\hline CUSTO & TOTAL DE ENERGIA $\ldots \ldots \ldots \ldots \ldots \ldots \ldots \ldots \ldots .21$ R\$ (REAIS) \\
\hline CUSTO & 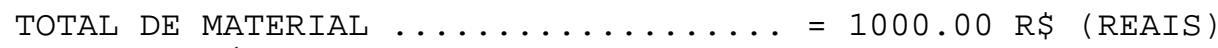 \\
\hline CUSTO & TOTAL DE MÁQUINA .............. = 0.00 RS (REAIS) \\
\hline CUSTO & TOTAL DE AJUSTAGEM $\ldots \ldots \ldots \ldots \ldots \ldots=0.00$ RS (REAIS) \\
\hline NÚMERO & O DE PEÇAS PRODUZIDAS (TPP) \\
\hline CUSTO & 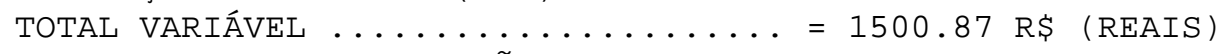 \\
\hline CUSTO & TOTAL EFETIVO DE PRODUÇÃO $\ldots \ldots \ldots \ldots=1500.87$ R\$ (REAIS) \\
\hline CUSTO & 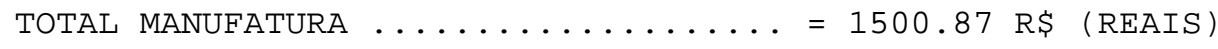 \\
\hline CUSTO & 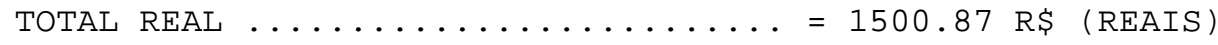 \\
\hline
\end{tabular}

\section{CELULAR - EXPERIMENTO 1 - CUSTOS DA PEÇA 5 (reais)}

CUSTO TOTAL DE MÃO-DE-OBRA .......... 268.67 RS (REAIS)

CUSTO DE DEPRECIAÇÃO DE FERRAMENTAL ...... 38.00 R\$ (REAIS)

CUSTO DE TROCA DE FERRAMENTAL .......... = 0.00 R\$ (REAIS)

CUSTO DE AFIAÇÃO DE FERRAMENTAL ......... = 0.00 R\$ (REAIS)

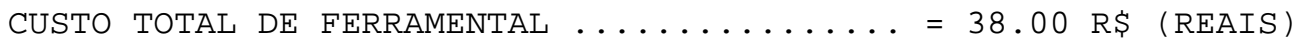

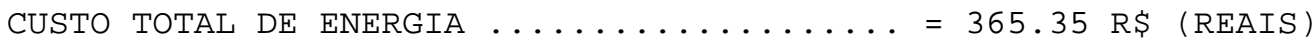

CUSTO TOTAL DE MATERIAL .........................................

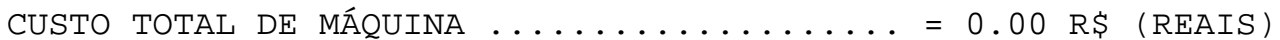

CUSTO TOTAL DE AJUSTAGEM $\ldots \ldots \ldots \ldots \ldots \ldots \ldots=0.00 \mathrm{R} S$ (REAIS)

NÚMERO DE PEÇAS PRODUZIDAS (TPP) $\ldots \ldots \ldots \ldots=100$

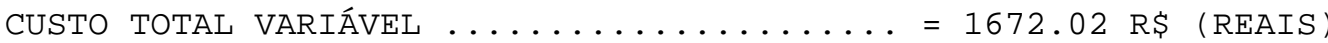

CUSTO TOTAL EFETIVO DE PRODUÇÃO ............................ 1672.02 (REAIS)

CUSTO TOTAL MANUFATURA $\ldots \ldots \ldots \ldots \ldots \ldots \ldots \ldots=1672.02$ R\$ (REAIS)

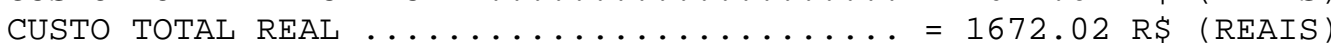

\section{CELULAR - EXPERIMENTO 1 - CUSTOS DA PEÇA 6 (reais)}

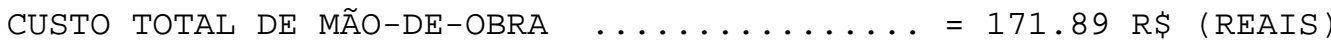

CUSTO DE DEPRECIAÇÃO DE FERRAMENTAL ...... $=22.00 \mathrm{R} \$$ (REAIS)

CUSTO DE TROCA DE FERRAMENTAL $\ldots \ldots \ldots \ldots \ldots=0.00$ RS (REAIS)

CUSTO DE AFIAÇÃO DE FERRAMENTAL ..............................

CUSTO TOTAL DE FERRAMENTAL ...................... 22.00 RS (REAIS) 


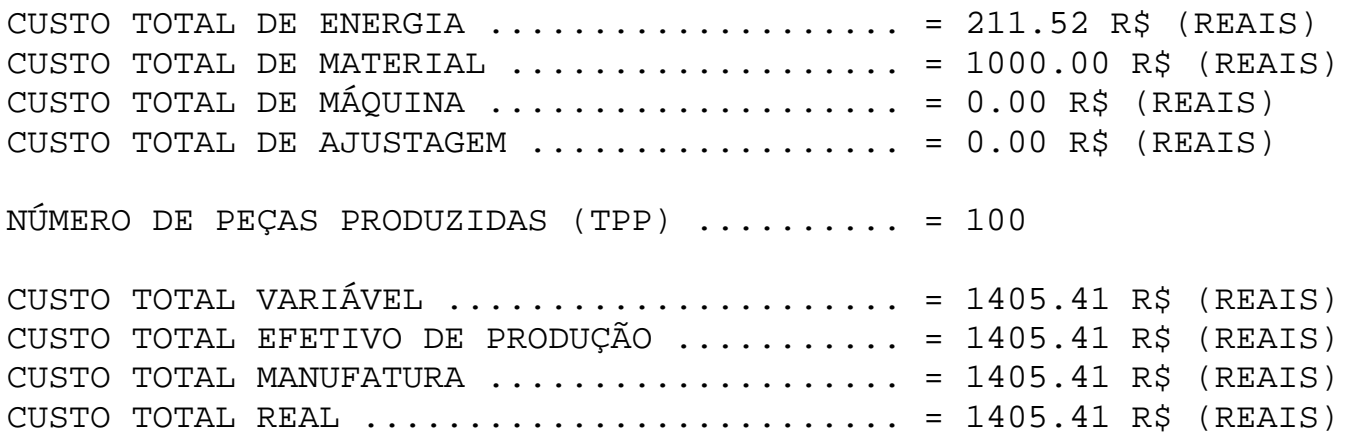

\section{CELULAR - EXPERIMENTO 1 - CUSTOS DA PEÇA 8(reais)}

CUSTO TOTAL DE MÃO-DE-OBRA $\ldots \ldots \ldots \ldots \ldots \ldots=346.67$ RS (REAIS)

CUSTO DE DEPRECIAÇÃO DE FERRAMENTAL ...... $=50.00$ R\$ (REAIS)

CUSTO DE TROCA DE FERRAMENTAL ........................ 0.00 RS (REAIS)

CUSTO DE AFIAÇÃO DE FERRAMENTAL ............................. 0.00 (REAIS)

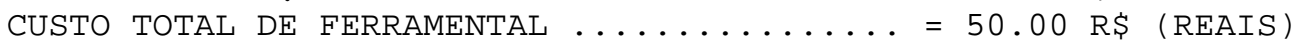

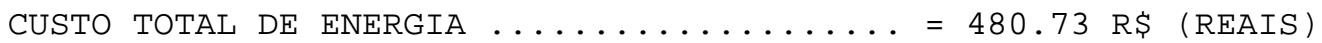

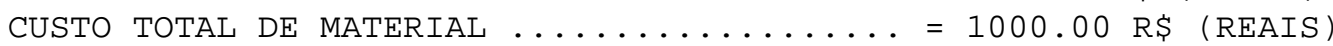

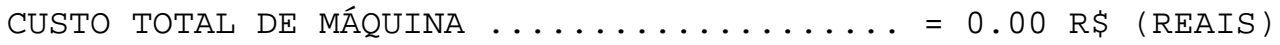

CUSTO TOTAL DE AJUSTAGEM .................... 0.00 RS (REAIS)

NÚMERO DE PEÇAS PRODUZIDAS $(\mathrm{TPP}) \ldots \ldots \ldots=100$

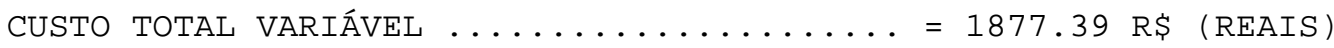

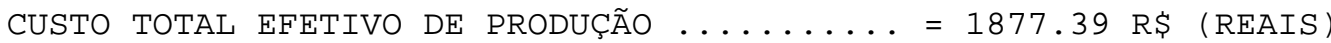

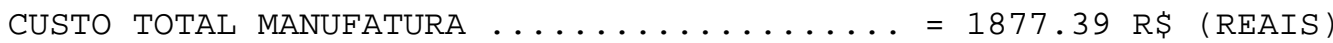

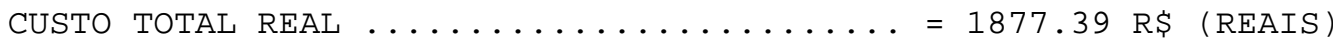

\section{CELULAR - EXPERIMENTO 1 - CUSTOS DA PEÇA 10 (reais)}

CUSTO TOTAL DE MÃO-DE-OBRA $\ldots \ldots \ldots \ldots \ldots \ldots=216.67$ R\$ (REAIS)

CUSTO DE DEPRECIAÇÃO DE FERRAMENTAL ...... 30.00 R\$ (REAIS)

CUSTO DE TROCA DE FERRAMENTAL ........................ 0.00 RS (REAIS)

CUSTO DE AFIAÇÃO DE FERRAMENTAL ........................ 0.00 (REAIS)

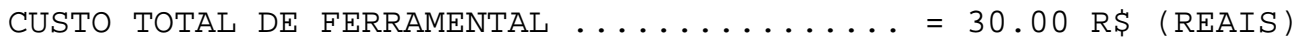

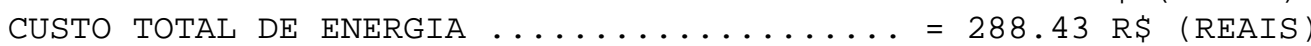

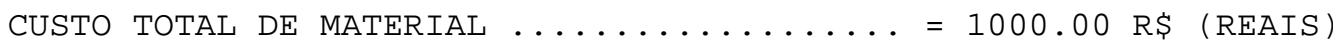

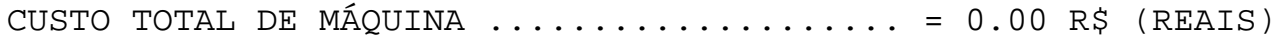

CUSTO TOTAL DE AJUSTAGEM $\ldots \ldots \ldots \ldots \ldots \ldots \ldots . . \ldots=0.00 \mathrm{R} \$$ (REAIS)

NÚMERO DE PEÇAS PRODUZIDAS $(\mathrm{TPP}) \ldots \ldots \ldots \ldots=100$

CUSTO TOTAL VARIÁVEL ............... 1535.10 R\$ (REAIS)

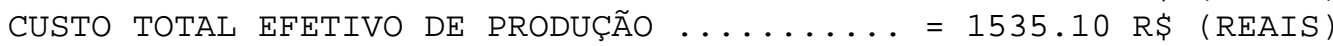

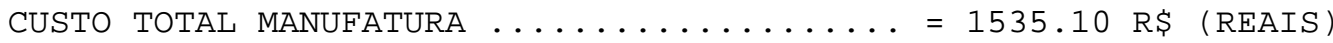

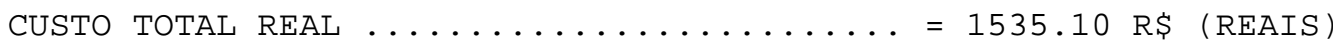

\section{CELULAR - EXPERIMENTO 1 - CUSTOS DA PEÇA 11 (reais)}

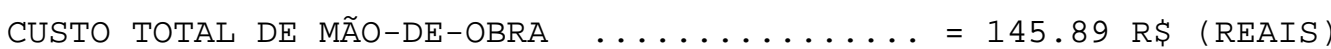

CUSTO DE DEPRECIAÇÃO DE FERRAMENTAL ...... = $18.00 \mathrm{R} \$$ (REAIS)

CUSTO DE TROCA DE FERRAMENTAL .......... = 0.00 R\$ (REAIS) 


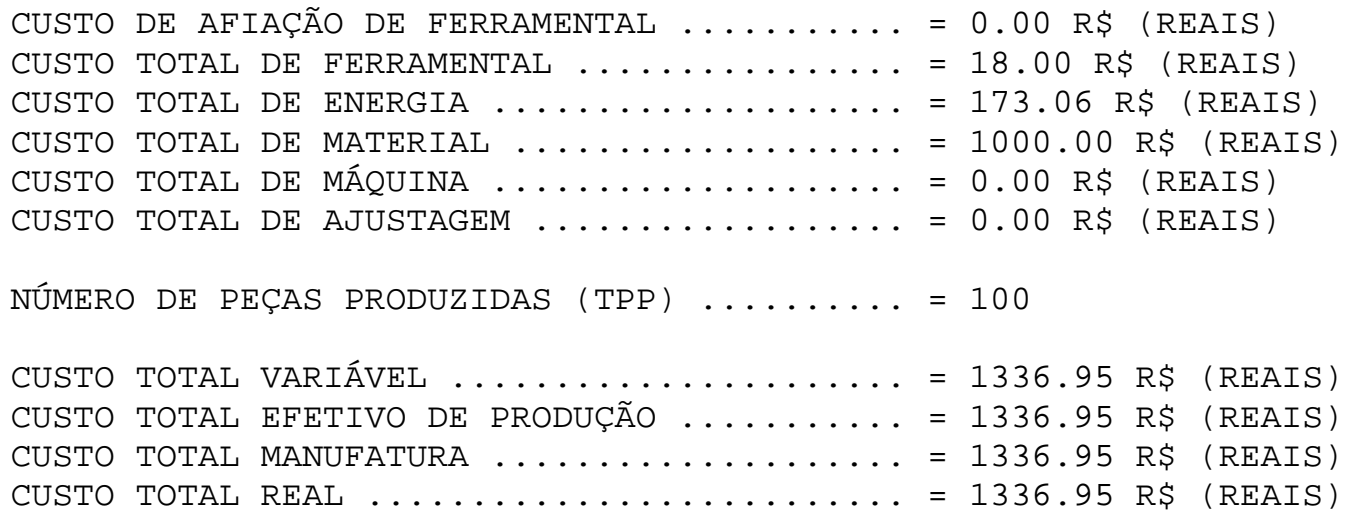

\section{CELULAR - EXPERIMENTO 1 - CUSTOS DA PEÇA 12 (reais)}

CUSTO TOTAL DE MÃO-DE-OBRA ..........................

CUSTO DE DEPRECIAÇÃO DE FERRAMENTAL ...... $=24.00 \mathrm{R} \$$ (REAIS)

CUSTO DE TROCA DE FERRAMENTAL ........................ 0.00 RS (REAIS)

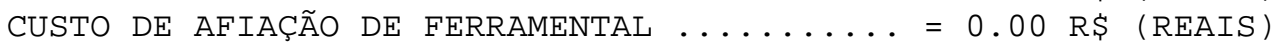

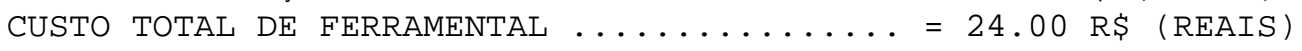

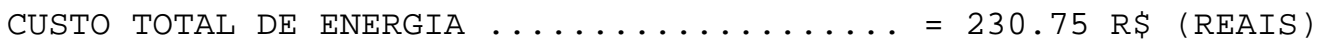

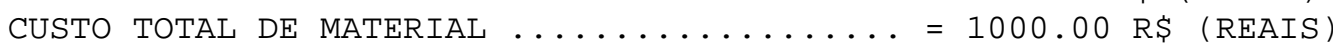

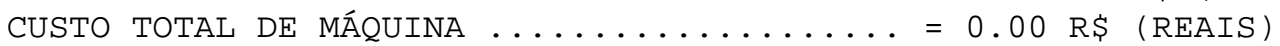

CUSTO TOTAL DE AJUSTAGEM $\ldots \ldots \ldots \ldots \ldots \ldots \ldots=0.00 \mathrm{R} \$$ (REAIS)

NÚMERO DE PEÇAS PRODUZIDAS $(\mathrm{TPP}) \ldots \ldots \ldots \ldots=100$

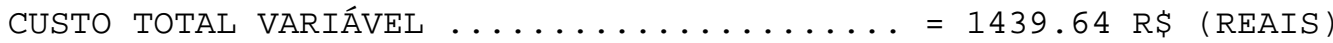

CUSTO TOTAL EFETIVO DE PRODUÇÃO ........ = 1439.64 R\$ (REAIS)

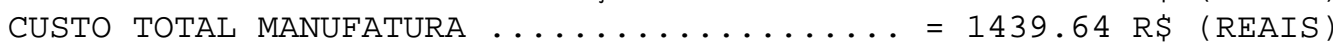

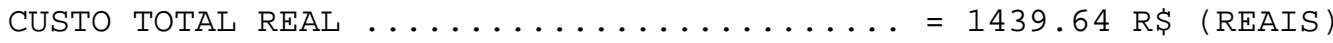

\section{CELULAR - EXPERIMENTO 1 - CUSTOS DA PEÇA 13 (reais)}

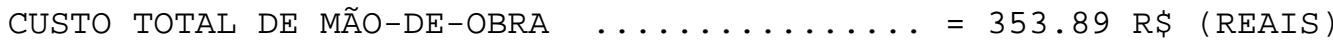

CUSTO DE DEPRECIAÇÃO DE FERRAMENTAL ......

CUSTO DE TROCA DE FERRAMENTAL ........................... 0.00 (REAIS)

CUSTO DE AFIAÇÃO DE FERRAMENTAL ......................... 0.00 (REAIS)

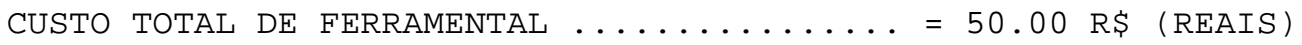

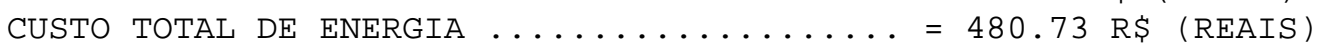

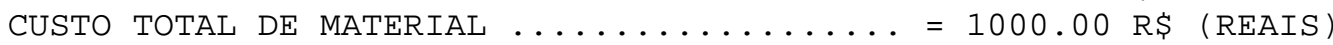

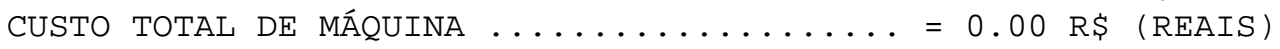

CUSTO TOTAL DE AJUSTAGEM .................... 0.00 RS (REAIS)

NÚMERO DE PEÇAS PRODUZIDAS (TPP) $\ldots \ldots \ldots \ldots=100$

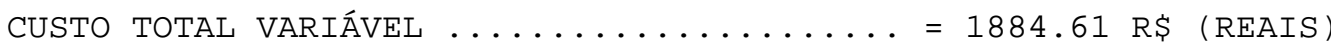

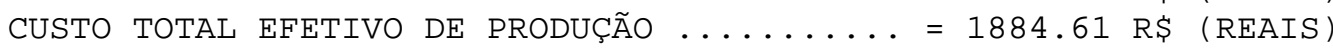

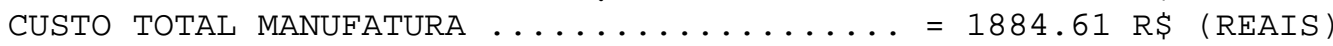

CUSTO TOTAL REAL ............................... 1884.61 (REAIS)

Para o Experimento 2 do modelo celular tem-se os resultados em tempos: 


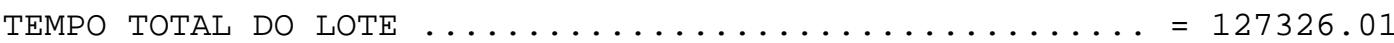

TEMPO TOTAL DE PROCESSAMENTO DO LOTE $8 \ldots \ldots \ldots \ldots \ldots \ldots \ldots=117000.00$

TEMPO TOTAL DE MANUSEIO PARA CARREGAR AS MÁQUINAS .....= 2488.02

TEMPO TOTAL DE MANUSEIO PARA DESCARREGAR AS MÁQUINAS $\ldots=2488.02$

TEMPO DE ESPERA ACUMULADA NO BUFFER DO LOTE $8 \ldots \ldots \ldots \ldots=853514.74$

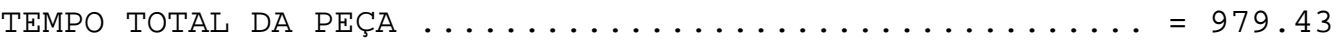

TEMPO UNITÁRIO DE PROCESSAMENTO DA PEÇA $8 \ldots \ldots \ldots \ldots \ldots . \ldots=900.00$

TEMPO UNITÁRIO DE MANUSEIO PARA CARREGAR AS MÁQUINAS $\ldots=19.14$

TEMPO UNITÁRIO DE MANUSEIO PARA DESCARREGAR AS MÁQUINAS $=19.14$

TEMPO DE ESPERA ACUMULADA NO BUFFER DA PEÇA $8 \ldots \ldots \ldots \ldots=6565.50$

TEMPO TOTAL DE SETUP DA FAMÍLIA $=5000$

Processo de Fabricação (Máquinas) = $\begin{array}{lllllllllll}23 & 23 & 35 & 41 & 0 & 0 & 0 & 0 & 0 & 0\end{array}$

Lote de peças $8=130$

Processo da família $=2$

TEMPO UNITÁRIO DE SETUP, USINAGEM, CARREGAMENTO E DESCARREGAMENTO DE MÁQUINA

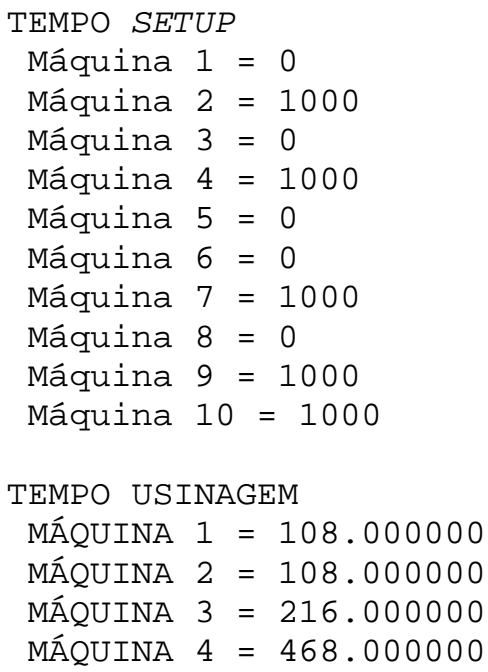

\section{CELULAR - EXPERIMENTO 2 - TEMPOS DA PEÇA 10 (segundos)}

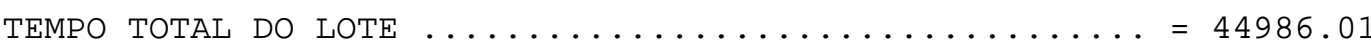

TEMPO TOTAL DE PROCESSAMENTO DO LOTE $10 \ldots \ldots \ldots \ldots \ldots \ldots=81000.00$

TEMPO TOTAL DE MANUSEIO PARA CARREGAR AS MÁQUINAS $\ldots . . .=3588.50$

TEMPO TOTAL DE MANUSEIO PARA DESCARREGAR AS MÁQUINAS $\ldots=3588.50$ 


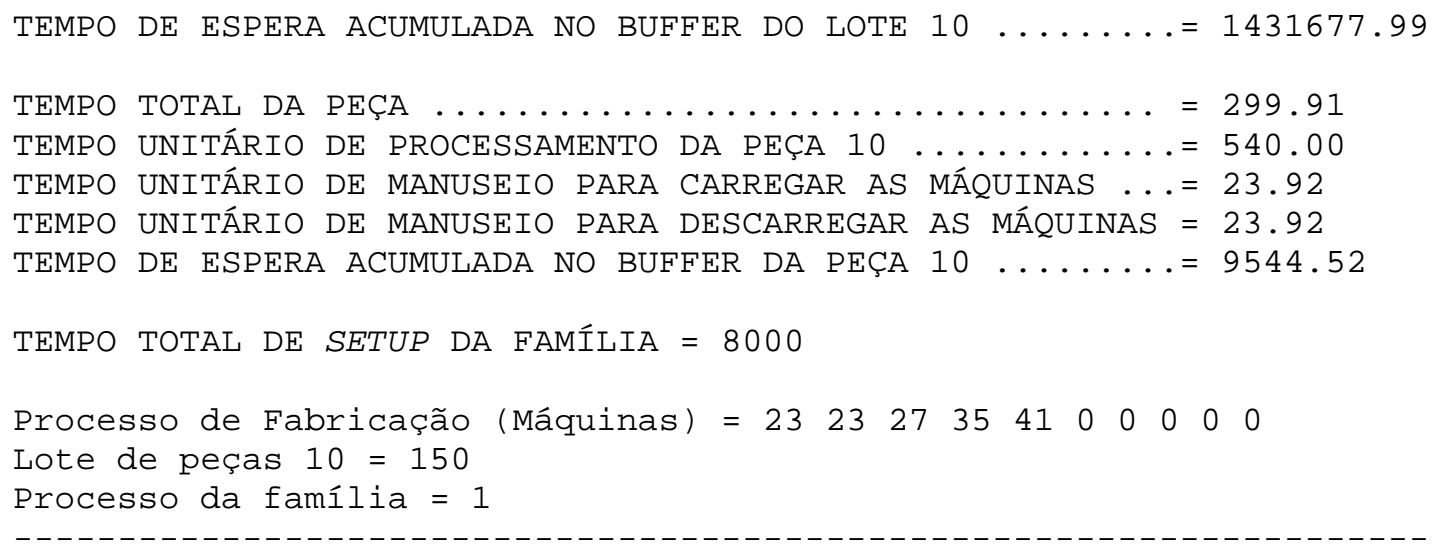
TEMPO UNITÁRIO DE SETUP, USINAGEM, CARREGAMENTO E DESCARREGAMENTO DE MÁQUINA

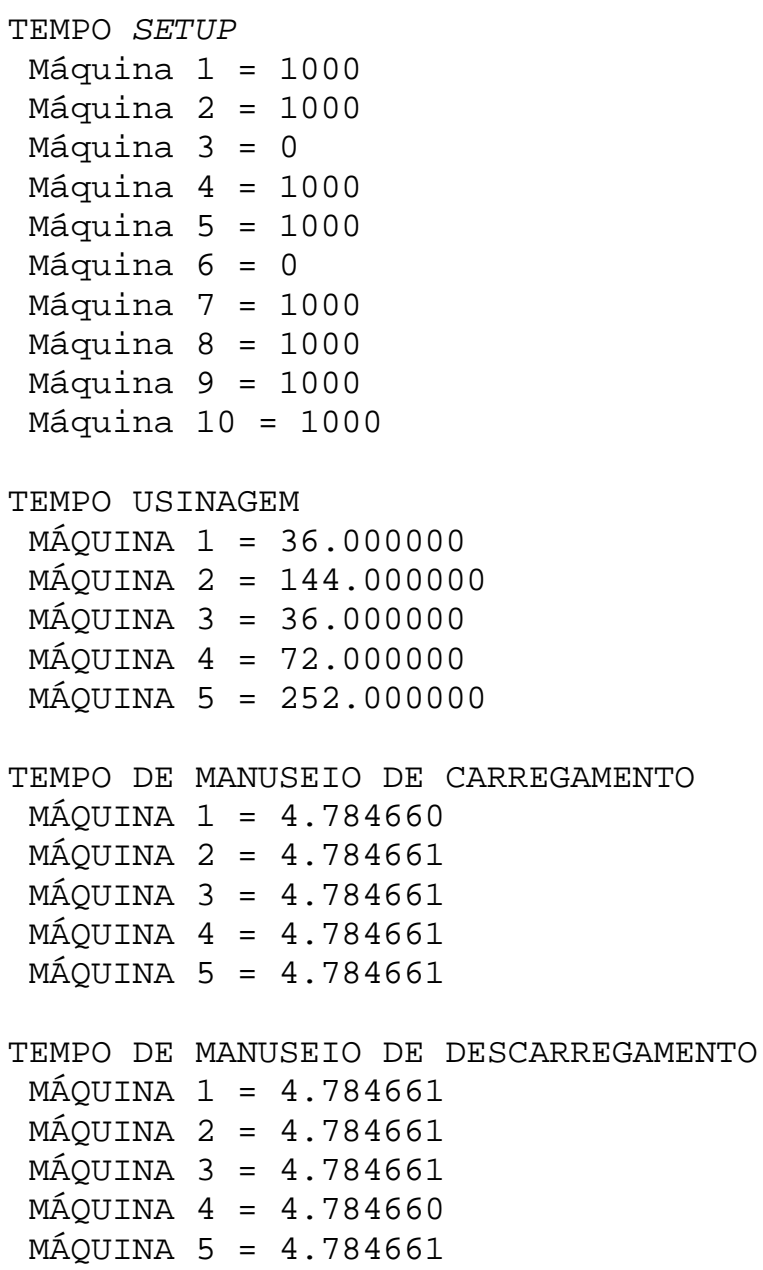

\section{CELULAR - EXPERIMENTO 2 - TEMPOS DA PEÇA 11 (segundos)}

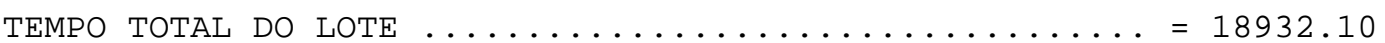

TEMPO TOTAL DE PROCESSAMENTO DO LOTE $11 \ldots \ldots \ldots \ldots \ldots \ldots \ldots=48600.00$

TEMPO TOTAL DE MANUSEIO PARA CARREGAR AS MÁQUINAS $\ldots \ldots=3588.50$

TEMPO TOTAL DE MANUSEIO PARA DESCARREGAR AS MÁQUINAS $\ldots=3588.50$

TEMPO DE ESPERA ACUMULADA NO BUFFER DO LOTE $11 \ldots \ldots . \ldots=185037.30$ 


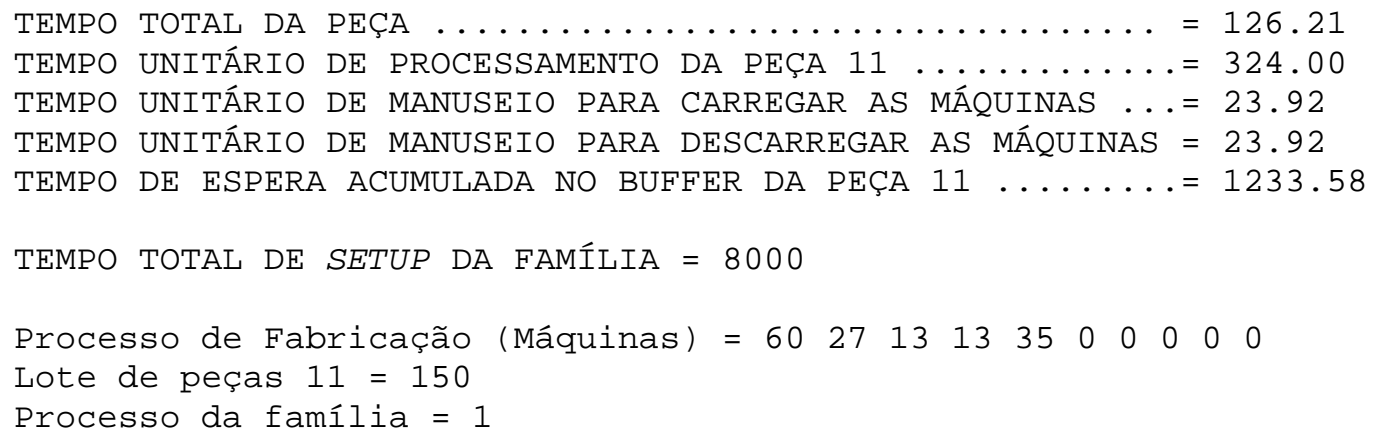

TEMPO UNITÁRIO DE SETUP, USINAGEM, CARREGAMENTO E DESCARREGAMENTO DE MÁQUINA

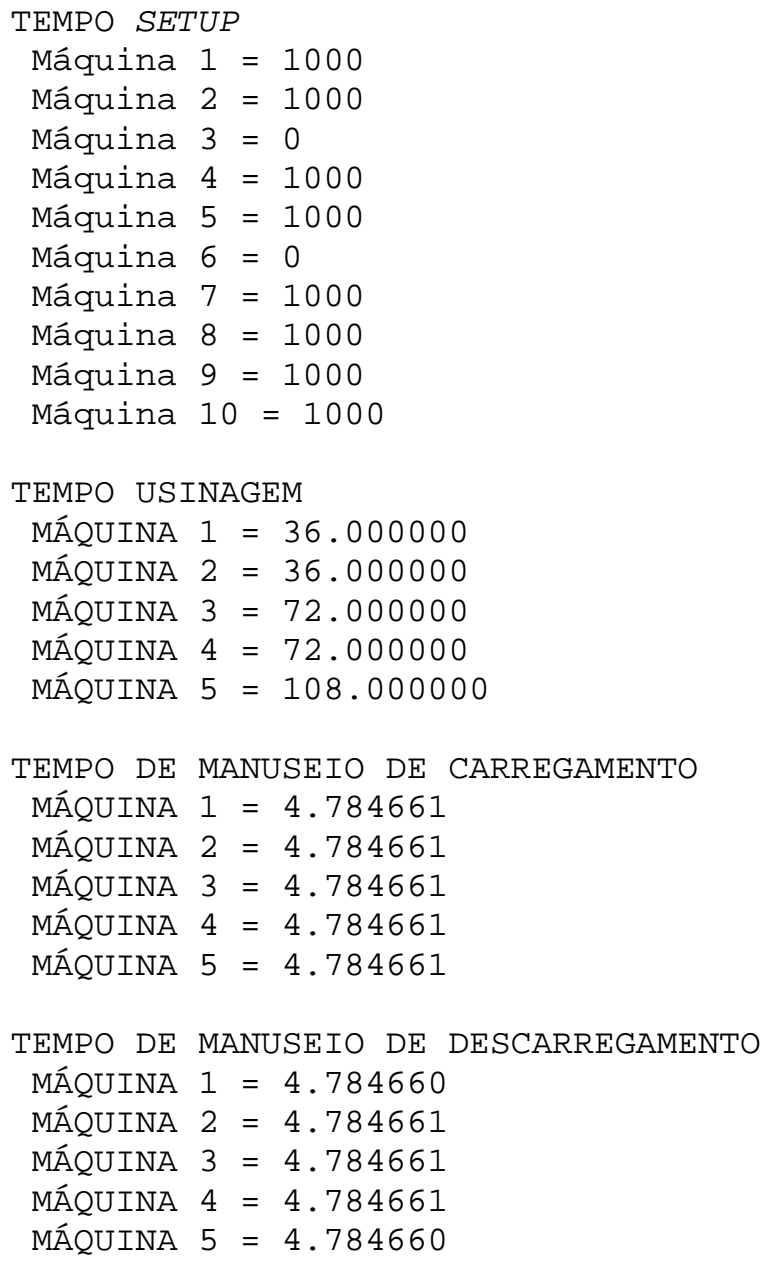

\section{CELULAR - EXPERIMENTO 2 - TEMPOS DA PEÇA 12 (segundos)}

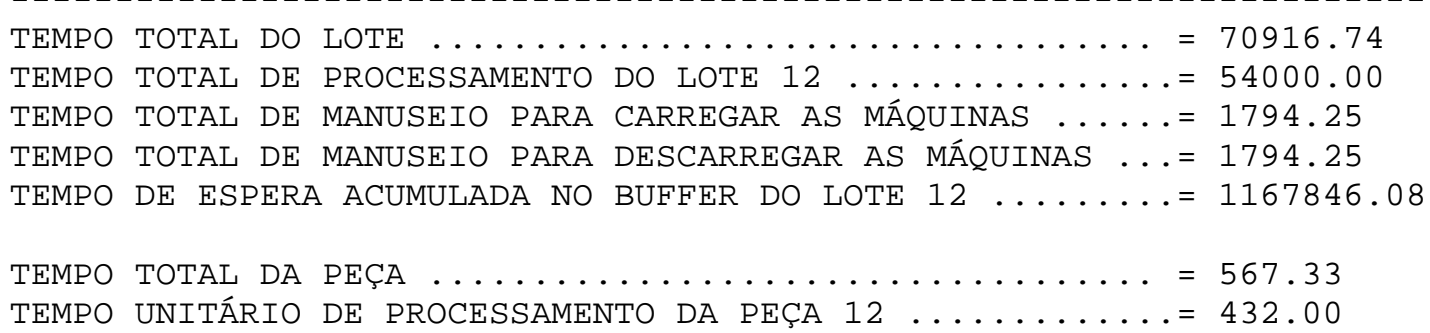




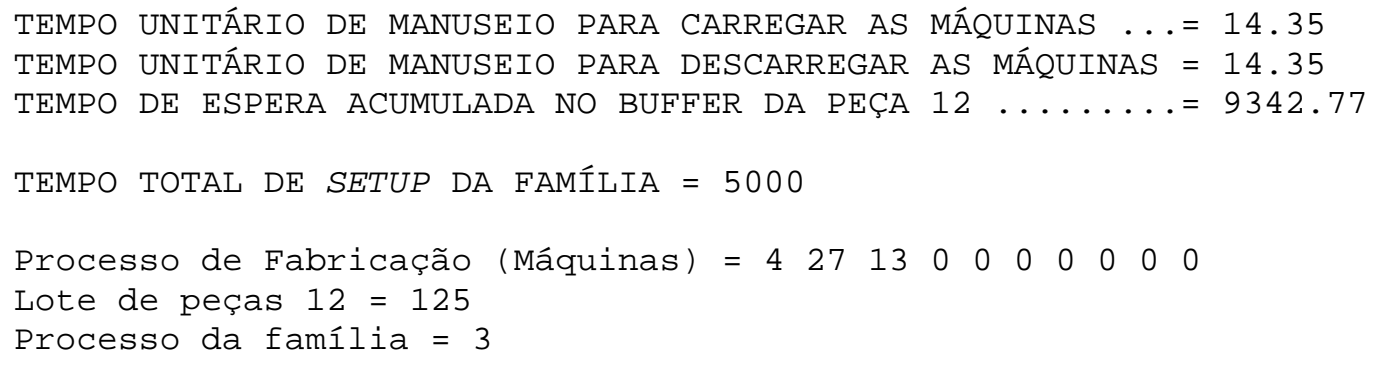

\section{CELULAR - EXPERIMENTO 2 - TEMPOS DA PEÇA 13 (segundos)}

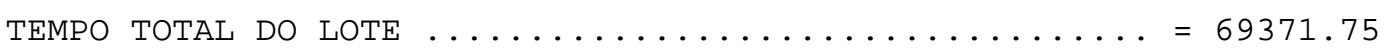

TEMPO TOTAL DE PROCESSAMENTO DO LOTE $13 \ldots \ldots \ldots \ldots \ldots \ldots=112500.00$

TEMPO TOTAL DE MANUSEIO PARA CARREGAR AS MÁQUINAS $\ldots \ldots=2392.33$

TEMPO TOTAL DE MANUSEIO PARA DESCARREGAR AS MÁQUINAS ...=2392.33

TEMPO DE ESPERA ACUMULADA NO BUFFER DO LOTE $13 \ldots \ldots . \ldots=870138.44$

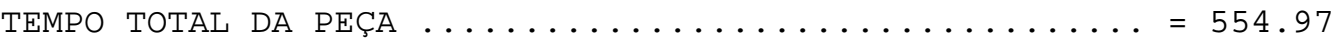

TEMPO UNITÁRIO DE PROCESSAMENTO DA PEÇA $13 \ldots \ldots \ldots \ldots \ldots \ldots=900.00$

TEMPO UNITÁRIO DE MANUSEIO PARA CARREGAR AS MÁQUINAS . .= 19.14 
TEMPO UNITÁRIO DE MANUSEIO PARA DESCARREGAR AS MÁQUINAS $=19.14$ TEMPO DE ESPERA ACUMULADA NO BUFFER DA PEÇA $13 \ldots \ldots \ldots . . .6961 .11$

TEMPO TOTAL ACUMULADO DE ESPERA $=870138.443322$

TEMPO TOTAL DE SETUP DA FAMÍLIA $=5000$

Processo de Fabricação (Máquinas) = $\begin{array}{lllllllllll}23 & 23 & 35 & 41 & 0 & 0 & 0 & 0 & 0 & 0\end{array}$

Lote de peças $13=125$

Processo da família $=2$

TEMPO UNITÁRIO DE SETUP, USINAGEM, CARREGAMENTO E DESCARREGAMENTO DE MÁQUINA

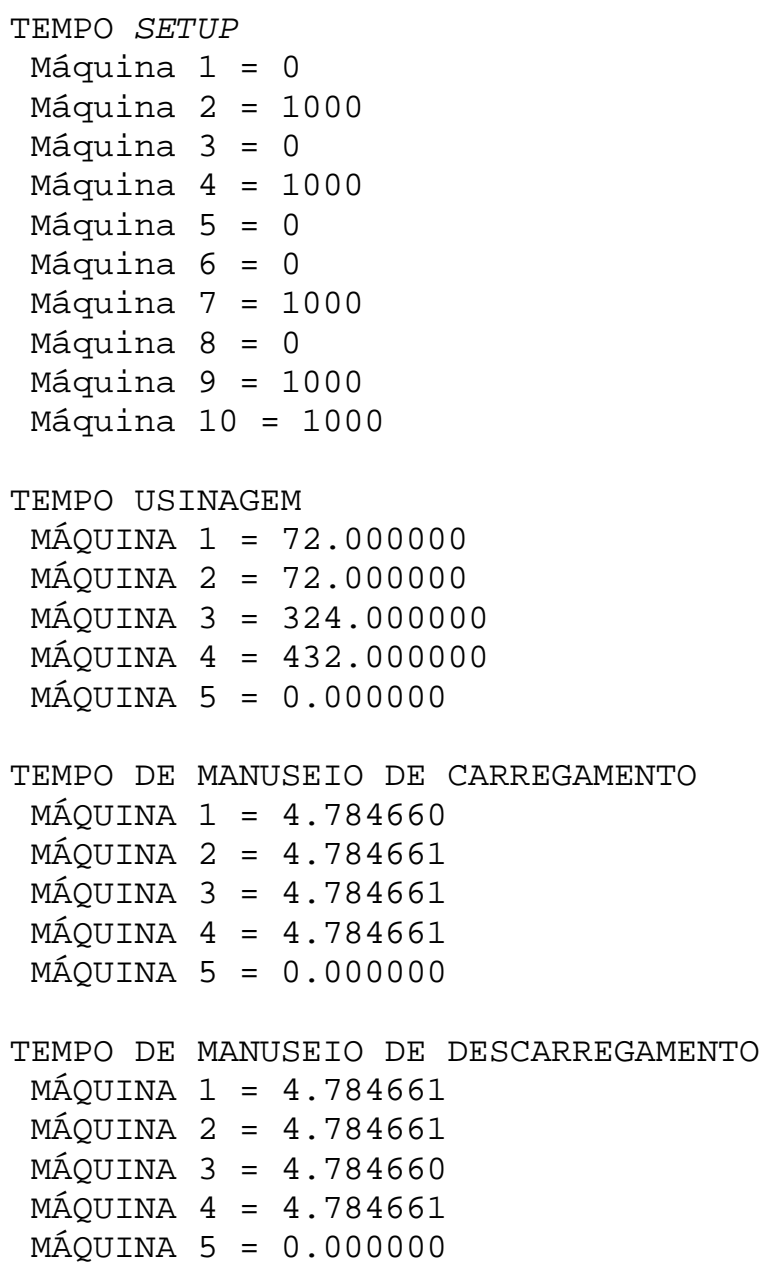

Para o Experimento 2 do modelo celular tem-se os resultados em custos:

\section{CELULAR - EXPERIMENTO 2 - CUSTOS DA PEÇA 6 (reais)}

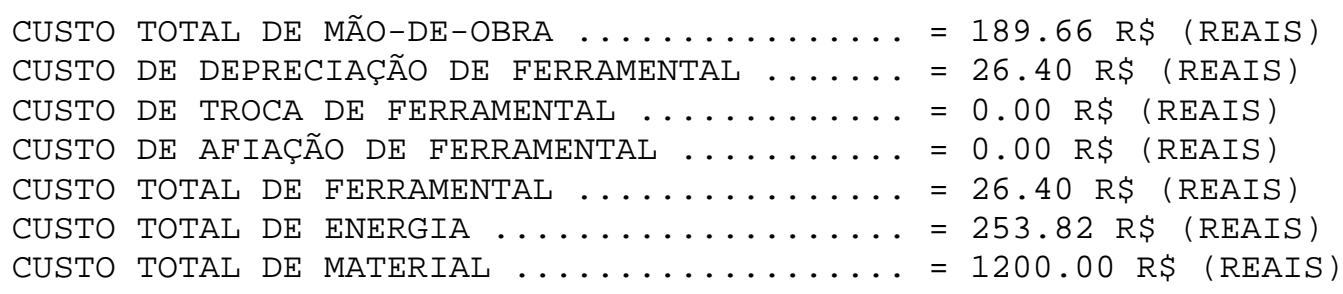




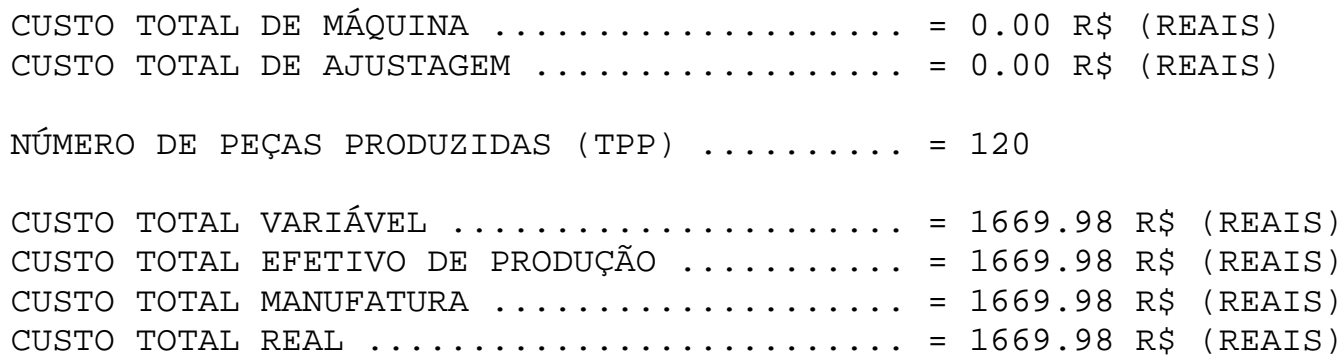

\section{CELULAR - EXPERIMENTO 2 - CUSTOS DA PEÇA 8 (reais)}

CUSTO TOTAL DE MÃO-DE-OBRA ......................... 440.56 (REAIS)

CUSTO DE DEPRECIAÇÃO DE FERRAMENTAL ...... $=65.00$ RS (REAIS)

CUSTO DE TROCA DE FERRAMENTAL ....................... 0.00 (REAIS)

CUSTO DE AFIAÇÃO DE FERRAMENTAL .........

CUSTO TOTAL DE FERRAMENTAL $\ldots \ldots \ldots \ldots \ldots \ldots=65.00$ RS (REAIS)

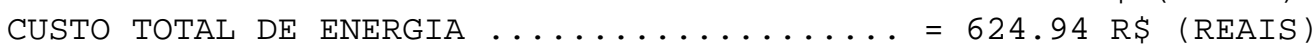

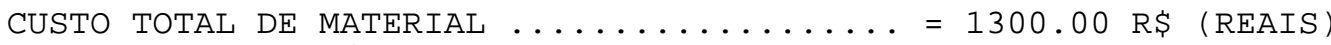

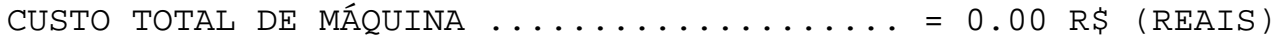

CUSTO TOTAL DE AJUSTAGEM $\ldots \ldots \ldots \ldots \ldots \ldots \ldots . . \ldots=0.00 \mathrm{R} \$$ (REAIS)

NÚMERO DE PEÇAS PRODUZIDAS $(\mathrm{TPP}) \ldots \ldots \ldots=130$

CUSTO TOTAL VARIÁVEL .............. $=2430.50$ R\$ (REAIS)

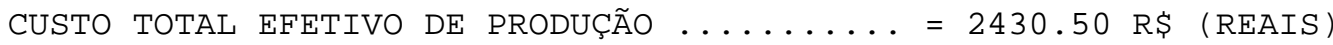

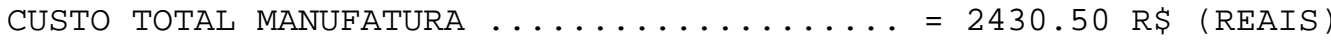

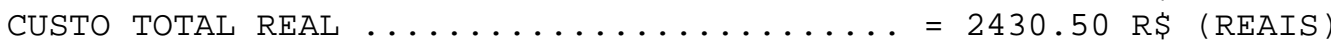

\section{CELULAR - EXPERIMENTO 2 - CUSTOS DA PEÇA 10 (reais)}

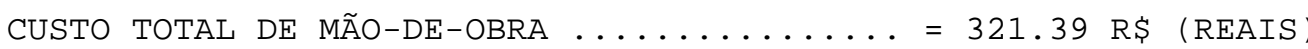

CUSTO DE DEPRECIAÇÃO DE FERRAMENTAL ..... $=45.00 \mathrm{R} \$$ (REAIS)

CUSTO DE TROCA DE FERRAMENTAL ........................ 0.00 (REAIS)

CUSTO DE AFIAÇÃO DE FERRAMENTAL ................................ (REAIS)

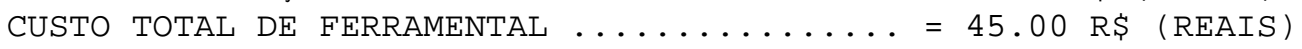

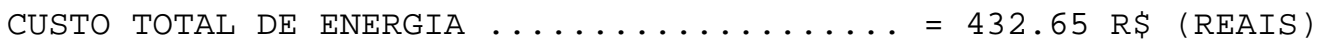

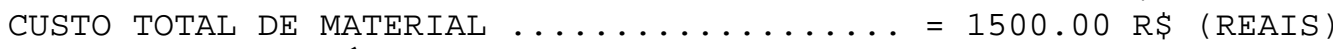

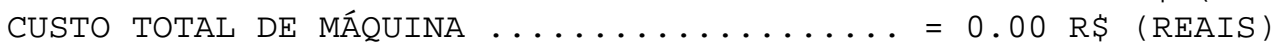

CUSTO TOTAL DE AJUSTAGEM $\ldots \ldots \ldots \ldots \ldots \ldots \ldots=0.00 \mathrm{R}$ (REAIS)

NÚMERO DE PEÇAS PRODUZIDAS $(\mathrm{TPP}) \ldots \ldots \ldots=150$

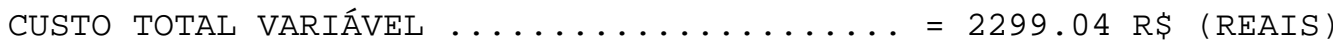

CUSTO TOTAL EFETIVO DE PRODUÇÃO ........

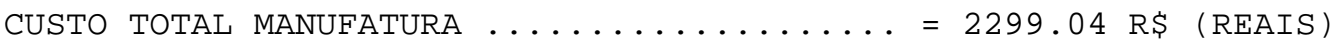

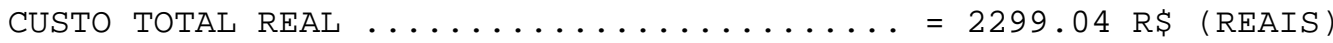

\section{CELULAR - EXPERIMENTO 2 - CUSTOS DA PEÇA 11 (reais)}

CUSTO TOTAL DE MÃO-DE-OBRA ........................ 2049 R\$ (REAIS)

CUSTO DE DEPRECIAÇÃO DE FERRAMENTAL ...... 27.00 R\$ (REAIS)

CUSTO DE TROCA DE FERRAMENTAL ......................... 0.00 (REAIS)

CUSTO DE AFIAÇÃO DE FERRAMENTAL ......... = 0.00 R\$ (REAIS)

CUSTO TOTAL DE FERRAMENTAL $\ldots \ldots \ldots \ldots \ldots \ldots=27.00 \mathrm{R} \$$ (REAIS) 


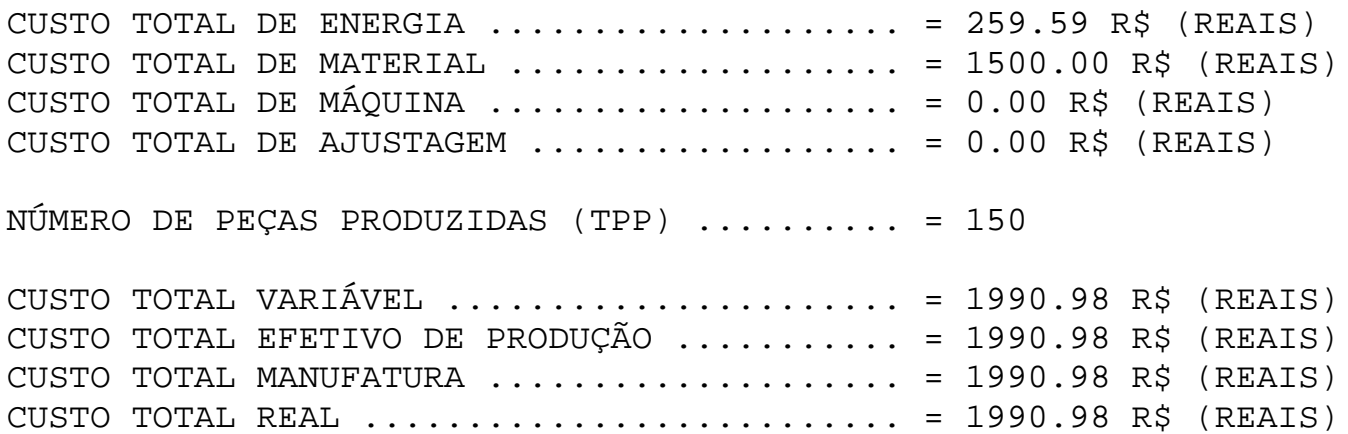

\section{CELULAR - EXPERIMENTO 2 - CUSTOS DA PEÇA 12 (reais)}

\begin{tabular}{|c|c|c|}
\hline JSTO & DE DEPRECIAÇÃO DE FERRAMENTAL $\ldots \ldots$ & $=30.00 \mathrm{RS} \quad(\mathrm{REAIS})$ \\
\hline TO & DE TROCA DE FERRAMENTAL .. & $=0.00 \mathrm{R} S \quad(\mathrm{REAIS})$ \\
\hline STO & DE AFIAÇÃO DE FERRAMENTAL & $=0.00 \mathrm{R} S \quad(\mathrm{REAIS})$ \\
\hline STO & TOTAL DE FERRAMENTAL .... & $=30.00 \mathrm{R} \$ \quad(\mathrm{REAIS})$ \\
\hline STO & TOTAL DE ENERGIA & $=288.43 \mathrm{R} \$$ (REAIS) \\
\hline JSTO & TOTAL DE MATERIAL ... & $=1250.00 \mathrm{R} \$$ (REAIS) \\
\hline STO & TOTAL DE MÁQUINA .... & $=0.00 \mathrm{R} \$ \quad(\mathrm{REAIS})$ \\
\hline JSTO & TOTAL DE AJUSTAGEM .... & $=0.00 \mathrm{R} \$$ \\
\hline ÍMER & DE PEÇAS PRODUZIDAS (TPP) & $=$ \\
\hline & ARIÁVEL & $49 \mathrm{R} \$$ \\
\hline JSTO & TOTAL EFETIVO DE PRODUÇÃO & 781.49 R\$ (REAIS) \\
\hline & TOTAL MANUFATURA $\ldots . . .$. & 781.49 R\$ (REAIS) \\
\hline & DTAL REAL & $781.49 \mathrm{R} \$$ \\
\hline
\end{tabular}

\section{CELULAR - EXPERIMENTO 2 - CUSTOS DA PEÇA 13 (reais)}

CUSTO TOTAL DE MÃO-DE-OBRA ...................... 4241 R\$ (REAIS)

CUSTO DE DEPRECIAÇÃO DE FERRAMENTAL ...... $62.50 \mathrm{R} \$$ (REAIS)

CUSTO DE TROCA DE FERRAMENTAL ........................ 0.00 (REAIS)

CUSTO DE AFIAÇÃO DE FERRAMENTAL ......................... 0.00 (REAIS)

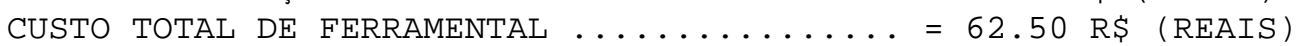

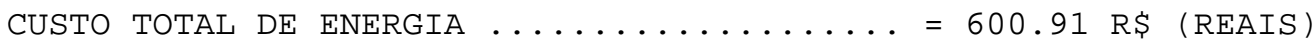

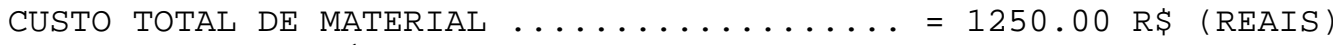

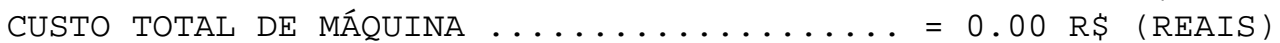

CUSTO TOTAL DE AJUSTAGEM $\ldots \ldots \ldots \ldots \ldots \ldots \ldots . . \ldots 0$ R\$ (REAIS)

NÚMERO DE PEÇAS PRODUZIDAS $(\mathrm{TPP}) \ldots \ldots \ldots=125$

CUSTO TOTAL VARIÁVEL ................................. 2337.31 R\$ (REAIS)

CUSTO TOTAL EFETIVO DE PRODUÇÃO ........ $=2337.31$ R\$ (REAIS)

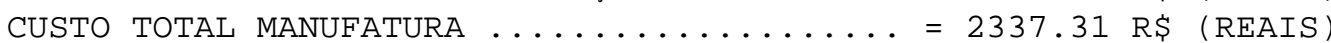

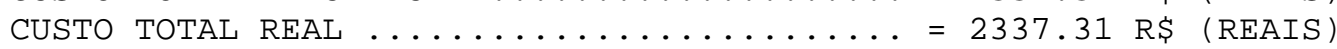

